Aus der Klinik für Unfallchirurgie, Orthopädie und Plastische Chirurgie

(Prof. Dr. med. W. Lehmann)

der Medizinischen Fakultät der Universität Göttingen

\title{
Einfluss von Urocortin auf die Skelettmuskulatur der osteoporotischen Ratte
}

\author{
INAUGURAL-DISSERTATION \\ zur Erlangung des Doktorgrades \\ der Medizinischen Fakultät der \\ Georg-August-Universität zu Göttingen
}

vorgelegt von

Laura Katharina Geisberg

aus

Leverkusen

Göttingen 2017 
Dekan:

Referent:

Korreferentin:

Drittreferent/in:
Prof. Dr. rer. nat. H. K. Kroemer

Prof. Dr. S. Sehmisch

PD Dr. Dana Seidlova-Wuttke

Prof. Dr. Martin Oppermann

Datum der mündlichen Prüfung: 26. Juni 2018 
Hiermit erkläre ich, die Dissertation mit dem Titel "Einfluss von Urocortin auf die Skelettmuskulatur der osteoporotischen Ratte" eigenständig angefertigt und keine anderen als die von mir angegebenen Quellen und Hilfsmittel verwendet zu haben.

Göttingen, den 


\section{Inhaltsverzeichnis}

$\underline{\text { Seite }}$

Abkürzungsverzeichnis ..................................................................

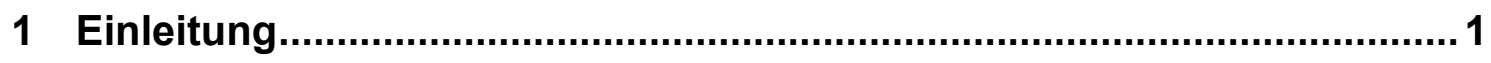

1.1 Zielsetzung und Fragestellung ………………............................ 1

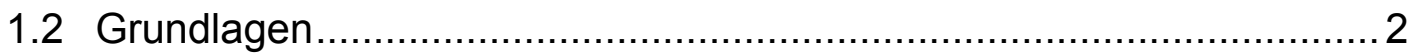

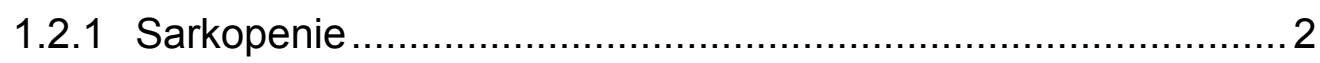

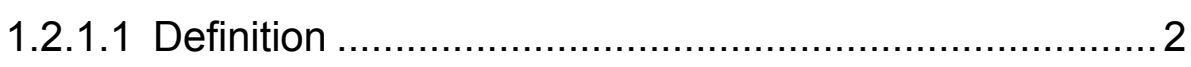

1.2.1.2 Epidemiologie .................................................... 3

1.2.1.3 Pathogenese ..................................................... 4

1.2.1.4 Diagnostik ....................................................... 5

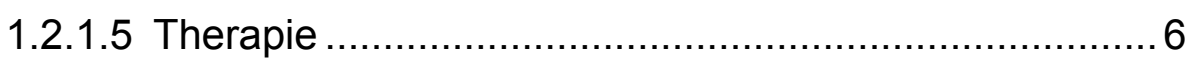

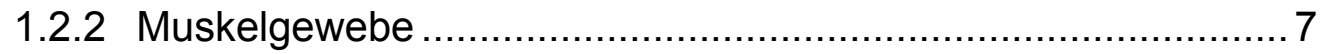

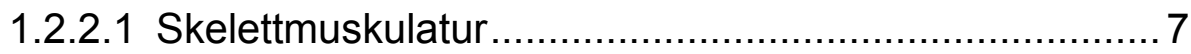

1.2.2.1.1 Typ-I-Muskelfaser.................................... 8

1.2.2.1.2 Typ-Ila-Muskelfaser (Intermediärtyp) ............ 8

1.2.2.1.3 Typ-Ilb-Muskelfaser..................................... 9

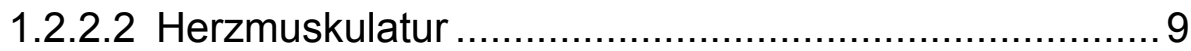

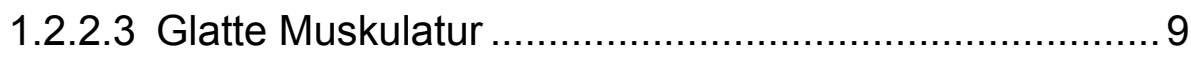

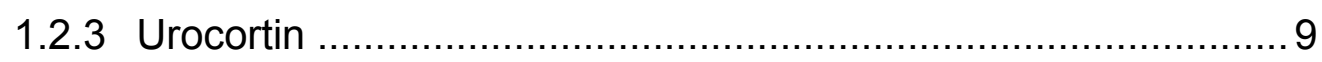

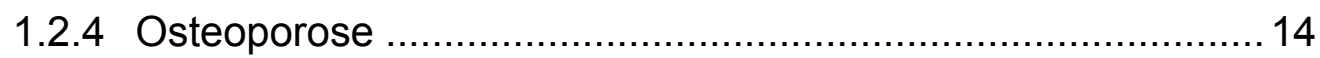

1.2.4.1 Definition ............................................................ 14

1.2.4.2 Epidemiologie ................................................... 15

1.2.4.3 Pathogenese und Risikofaktoren ............................. 15

1.2.4.4 Diagnostik ....................................................... 15

1.2.4.4.1 Anamnese und körperliche Untersuchung ... 16

1.2.4.4.2 Labor ...................................................... 16

1.2.4.4.3 DXA-Osteodensitometrie............................ 16

1.2.4.4.4 Röntgen .................................................... 17

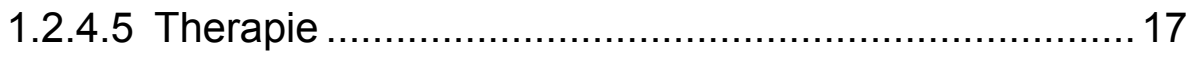

1.2.5 Sarkopenie und Osteoporose …....................................... 18 


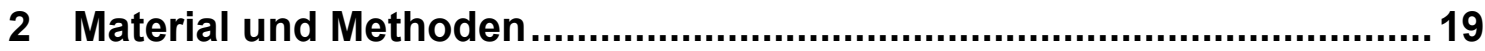

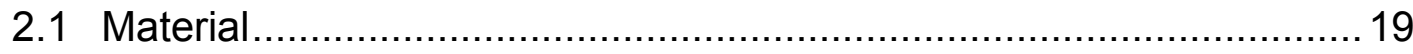

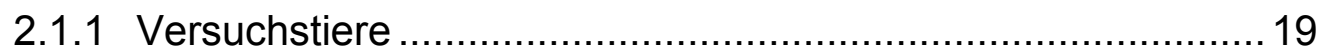

2.1.2 Proben für die histologischen Untersuchungen ...................... 19

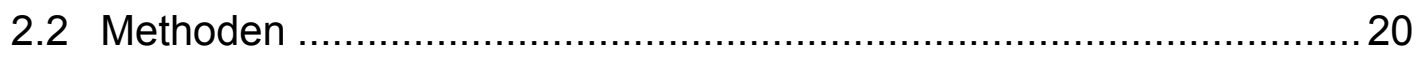

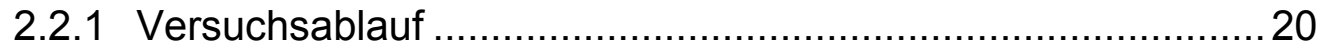

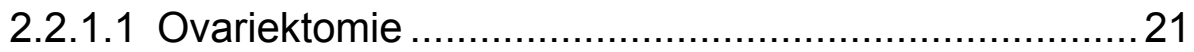

2.2.1.2 Behandlung mit Urocortin....................................... 22

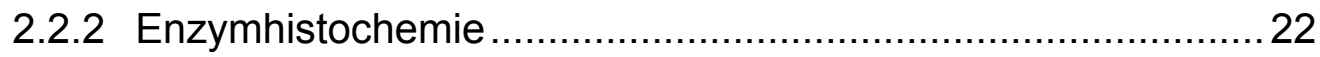

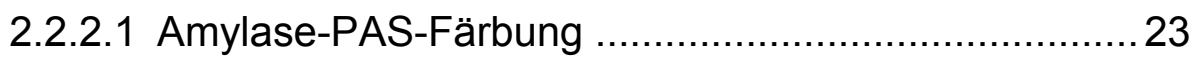

2.2.2.1.1 Rezeptur ............................................... 23

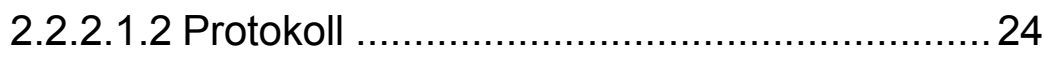

2.2.2.2 ATPase-/Diaphorase-Färbung ................................... 25

2.2.2.2.1 Rezeptur ............................................... 25

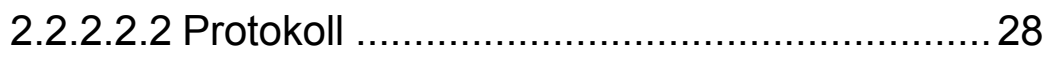

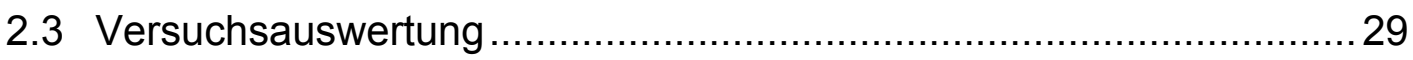

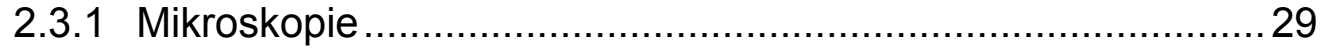

2.3.2 Auswertung Amylase-PAS-Färbung …………………….......29

2.3.3 Auswertung ATPase-/Diaphorase-Färbung …….....................30

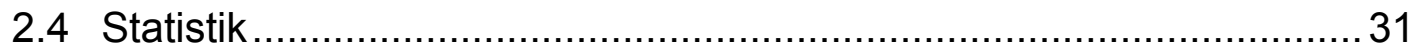

3 Ergebnisse

3.1 Futteraufnahme der Ratten im Verlauf .............................................. 32

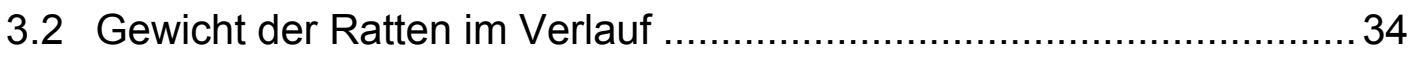

3.3 Uterusgewicht der Ratten im Verlauf................................................ 34

3.4 Ergebnisse der histologischen Untersuchungen ............................... 35

3.4.1 Ergebnisse der Amylase-PAS-Färbung …………................. 35

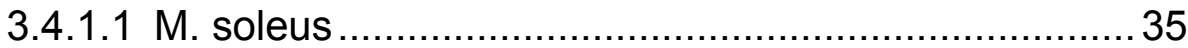

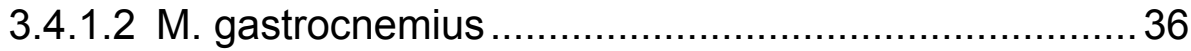

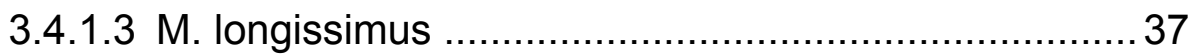

3.4.2 Ergebnisse der ATPase-/Diaphorase-Färbung ....................... 38

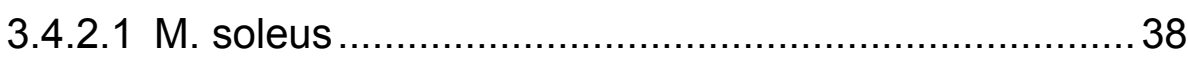


3.4.2.1.1 SO- und FOG-Fasertyp ............................... 38

3.4.2.2 M. gastrocnemius .................................................... 40

3.4.2.2.1 SO- und FOG-Fasertyp ............................. 40

3.4.2.2.2 FG-Fasertyp .......................................... 42

3.4.2.3 M. longissimus …................................................. 44

3.4.2.3.1 SO- und FOG-Fasertyp ............................. 44

3.4.2.3.2 FG-Fasertyp ........................................ 46

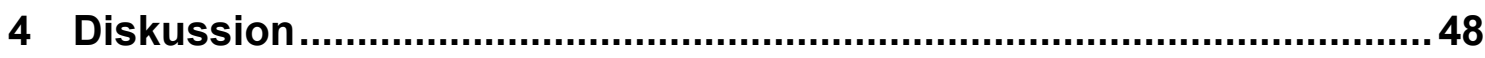

4.1 Die ovariektomierte Ratte als Osteoporosemodell .............................49

4.2 Analyse der Ergebnisse der Futteraufnahme, der Tiergewichte und des Uterusgewichtes ...................................................................5

4.3 Analyse der histologischen Untersuchungen ..................................51

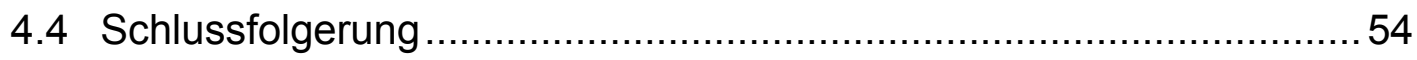

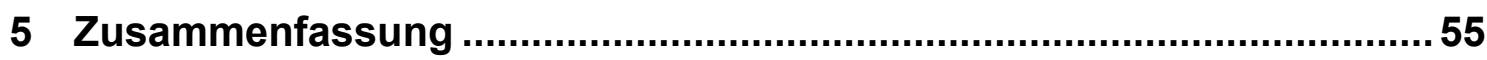

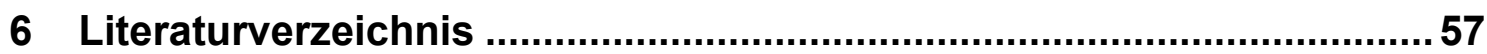

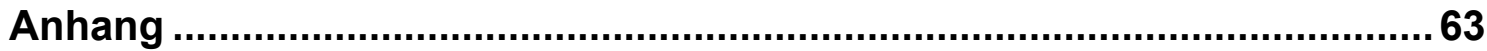

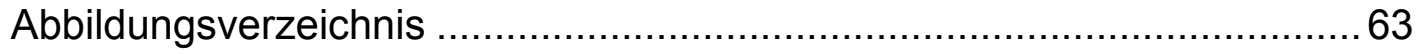

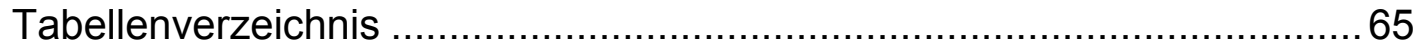

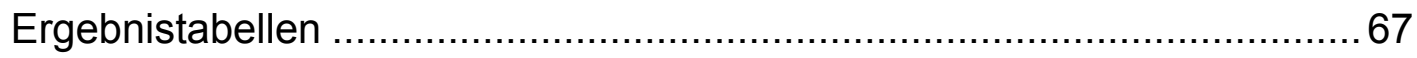




\section{Abkürzungsverzeichnis}

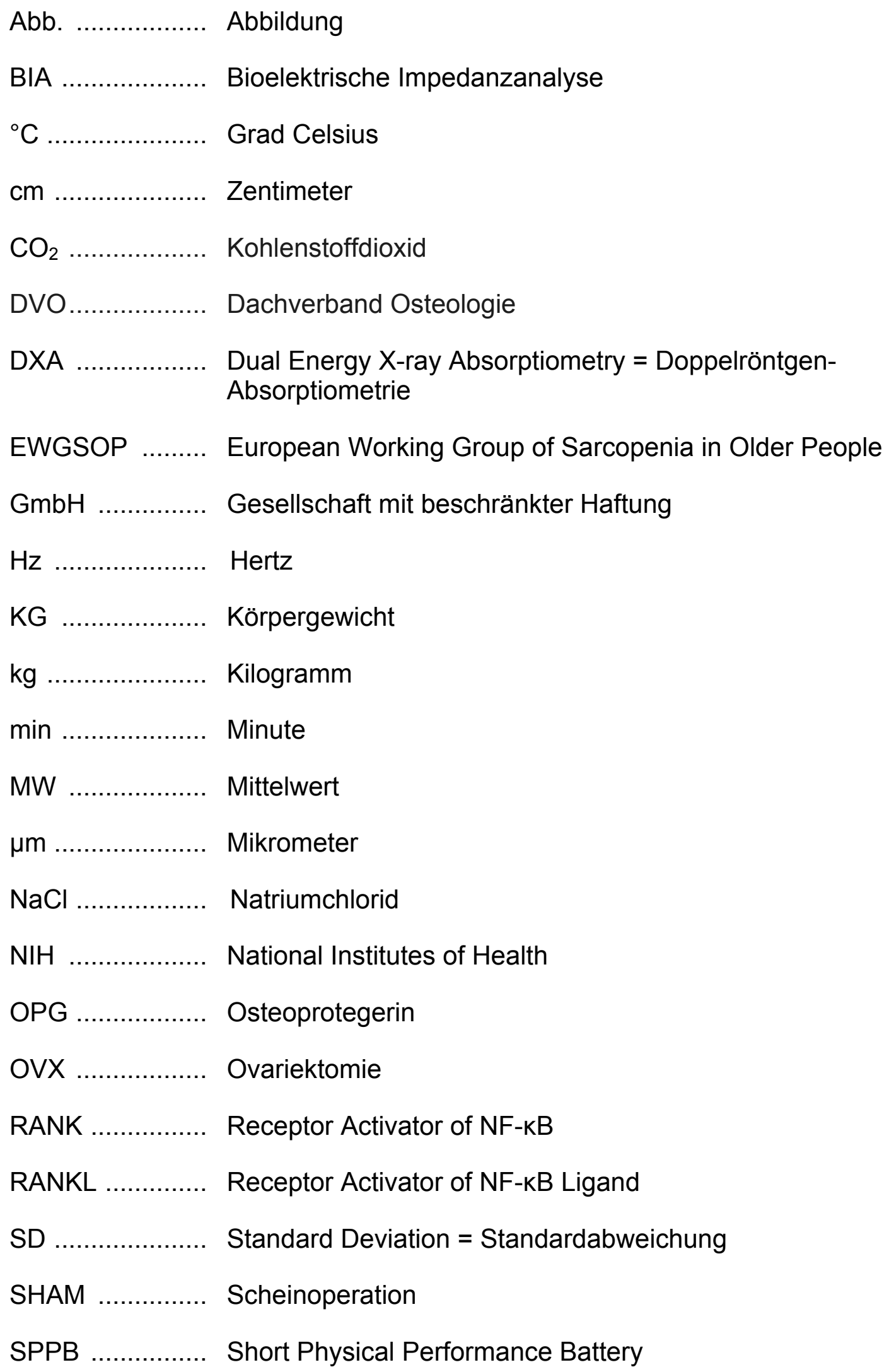

$\mathrm{NIH}$

National Institutes of Health

OPG

Osteoprotegerin

OVX Ovariektomie

RANK Receptor Activator of NF-KB

RANKL Receptor Activator of NF-KB Ligand

SD Standard Deviation $=$ Standardabweichung

SHAM Scheinoperation

SPPB Short Physical Performance Battery 
Tab.

Tabelle

WHO

World Health Organization $=$ Weltgesundheitsorganisation

ZTE Zentrale Tierexperimentelle Einrichtung (der Universitätsmedizin Göttingen) 


\section{Einleitung}

\subsection{Zielsetzung und Fragestellung}

Die Erforschung der Osteoporose entwickelt sich stetig weiter. Vor dem Hintergrund des demografischen Wandels ist dies unerlässlich. Im Alter kommt es zu einem ständigen Verlust von Knochensubstanz, zusätzlich verringern sich Muskelmasse und Muskelkraft, was als Sarkopenie bezeichnet wird (Walston 2012). Der Muskel hat unter anderem die Aufgabe, den Knochen zu schützen. Wenn dies aber aufgrund stetiger Abnahme von Masse und auch Kraft nicht mehr möglich ist, entstehen (pathologische) Frakturen. So wird in dieser Arbeit besonders die Muskelanalyse hervorgehoben.

Es sind diverse Medikamente für die antiosteoporotische Therapie zugelassen, die auf unterschiedlichen Wegen angreifen und eine Progredienz der Erkrankung verhindern. Bedauerlicherweise besitzen diese zahlreiche unerwünschte Arzneimittelwirkungen, sodass die Bereitschaft der Patienten, sie langfristig einzunehmen, sinkt. Das Bestreben gegenwärtiger Forschung ist es, möglichst gut wirksame Medikamente mit einem geringen Nebenwirkungsspektrum zu entwickeln. Der Einsatz von Urocortin als osteoprotektive Substanz stellt möglicherweise eine neue, noch nicht diskutierte medikamentöse Therapie der Osteoporose dar.

Es ist beschrieben, dass Urocortin einen Verlust an Muskelmasse verhindern und außerdem die Muskelmasse und Muskelkraft atrophierter und auch gesunder Skelettmuskulatur in Mäusen verbessern kann (Hinkle et al. 2003). Somit ist denkbar, dass das Neuropeptid Urocortin positive Resultate in Bezug auf das Verhältnis von Kapillaren zu Muskelfasern, den Faserdurchmesser und die Faserquerschnittsfläche erbringt und zur Therapie der Sarkopenie und Prävention der Osteoporose eingesetzt werden kann. Um diese Fragestellung experimentell beantworten zu können, verabreichte man den Tieren, die zuvor eine Osteoporose entwickelt hatten, über einen bestimmten Zeitraum niedrig ( $3 \mu \mathrm{g}$ pro $\mathrm{kg} \mathrm{KG}$ ) und hoch ( $30 \mu \mathrm{g}$ pro $\mathrm{kg} \mathrm{KG}$ ) dosiertes Urocortin und verglich die Ergebnisse miteinander. 
Ziel der vorliegenden Arbeit war es, den Einfluss unterschiedlicher Dosierungen des Neuropeptids Urocortin (UCN) auf die Skelettmuskulatur der osteoporotischen Ratte zu untersuchen. Die Ergebnisse dieser Studie werden im Folgenden zum ersten Mal vorgestellt.

\subsection{Grundlagen}

\subsubsection{Sarkopenie}

\subsubsection{Definition}

Das Wort Sarkopenie stammt aus dem Griechischen und bedeutet wortwörtlich übersetzt Fleischmangel. Der Begriff „sarx“ steht für Fleisch und das Wort „penia" für Mangel (Bauer et al. 2008). Irwin Rosenberg erörterte den Begriff der Sarkopenie erstmals im Jahr 1988 auf einer Konferenz in Albuquerque, New Mexico und beschreibt inn durch den altersabhängigen Verlust von Muskelmasse. Mit steigendem Lebensalter eines Menschen wird eine Abnahme von Muskelmasse und vor allem Muskelkraft beobachtet (Abb. 1 und Abb. 2). Ab einem Alter von 30 Jahren verliert der menschliche Skelettmuskel pro Jahr ungefähr $1 \%$ seiner Masse (Morley et al. 2014). Das Alter ist zwar ein nicht unerheblicher Faktor, der bei der Entwicklung einer Sarkopenie eine Rolle spielt, jedoch ist es keine Voraussetzung für die Diagnosestellung. Mittlerweile ist man sich international einig, dass in die Definition der Sarkopenie nicht nur die Muskelmasse, sondern auch die Muskelfunktion mit einfließen sollte (Cederholm und Morley 2015). Die Muskelfunktion, beschrieben durch die Parameter Kraft und Ausdauer, hat größeren Einfluss auf das Outcome als die Muskelmasse (Cederholm und Morley 2015). Die Sarkopenie geht mit einer erheblichen Einschränkung in Alltagsaktivitäten und einer erhöhten Mortalität einher (Bianchi et al. 2016). 


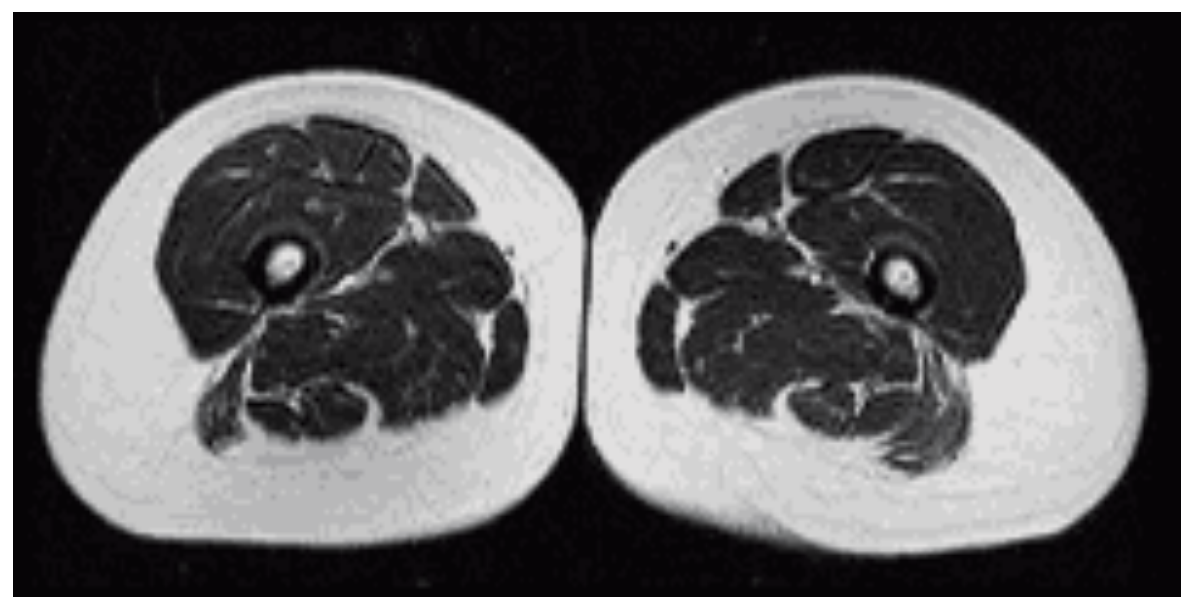

Abb. 1: Oberschenkelmuskulatur einer 26-jährigen Frau (mit freundlicher Genehmigung von Prof. Chris Boesch, Bern)

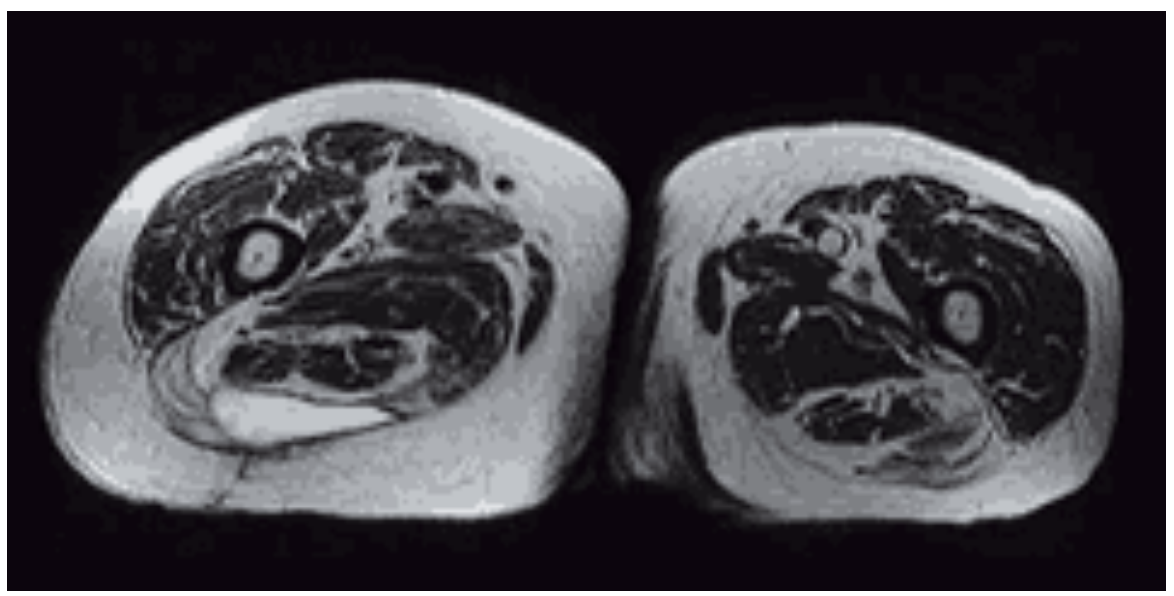

Abb. 2: Oberschenkelmuskulatur einer 79-jährigen Frau (mit freundlicher Genehmigung von Prof. Chris Boesch, Bern)

\subsubsection{Epidemiologie}

Betrachtet man unterschiedliche Quellen, erhält man verschiedene Informationen zur Prävalenz und Inzidenz der Sarkopenie. Dies ist unter anderem darauf zurückzuführen, dass die Sarkopeniediagnostik immer noch nicht standardisiert ist. Durchschnittlich leiden 5-13\% der Menschen über 60 Jahre an Sarkopenie. Bei den über 80-Jährigen sind es sogar bis zu 50 \% (Morley et al. 2014). Bei 25\% der Patienten auf einer geriatrischen Station kann eine Sarkopenie diagnostiziert werden (Smoliner et al. 2014). Anhand dieser Zahlen wird deutlich, dass dieses Krankheitsbild zunehmend an Bedeutung in der Bevölkerung gewinnt. Da das Durchschnittsalter der Menschen steigt, wird nicht nur die Osteo- 
porose, sondern auch die Sarkopenie immer wesentlicher für den klinischen Alltag. Es wird geschätzt, dass im Jahr 2050 20\% der amerikanischen Bevölkerung über 65 Jahre alt ist (Ali und Garcia 2014). Dieser Trend wird auch in anderen Ländern der Welt beobachtet.

Personen im Alter von über 80 Jahren mit Sarkopenie stürzen dreimal häufiger als Menschen in diesem Alter, die nicht von der Krankheit betroffen sind (Landi et al. 2012). Da die im Alter häufiger auftretenden Stürze als Hauptrisikofaktor für osteoporoseassoziierte Frakturen gelten, dadurch vermehrt Krankenhausaufenthalte und anschließend eine stationäre Unterbringung in einem Pflegeheim erforderlich werden, steigen die Kosten für das Gesundheitssystem enorm an.

\subsubsection{Pathogenese}

Die Pathogenese der Sarkopenie ist multifaktoriell. Auch wenn die grundlegenden Elemente bis heute noch nicht vollständig geklärt sind, spielen als mögliche Ursachen für die Krankheitsentstehung folgende Faktoren eine entscheidende Rolle:

1) Alter

2) vaskuläre Veränderungen

3) endokrinologische Veränderungen

4) neuronale Veränderungen

5) proinflammatorische Zytokine

Die körperliche Aktivität ist im Alter eingeschränkt, dadurch wird die Skelettmuskulatur nicht mehr so stark beansprucht und atrophiert. Der Mensch verliert während des natürlichen Alterungsprozesses Muskelfasern, hauptsächlich Fasern vom Typ 2 (Cederholm et al. 2013; Lexell 1995). Unausgewogene Ernährung sowie chronische Erkrankungen und ungenügende Sonnenexposition sind ebenfalls nicht unwichtige Punkte bei der Entstehung der Sarkopenie (Cederholm et al. 2013). Es gibt wenige Studien, die sich mit der Rolle der altersbedingten Apoptose beschäftigen, aber man geht davon aus, dass dieser Zellverlust in Zusammenhang mit dem Funktionsverlust des Muskels steht (Dirks und Leeuwenburgh 2002). Des Weiteren ist die oxidative Funktion der 
Mitochondrien im Alter eingeschränkt bzw. nimmt ab, sodass freie Radikale Zellschäden verursachen können.

Betrachtet man die vaskulären Veränderungen, die das Alter mit sich bringt, so ist ein Rückgang der Stickstoffmonoxidproduktion in den Gefäßen erkennbar, sodass insgesamt, aber vor allem in den Kapillaren der Skelettmuskulatur, eine Minderdurchblutung herrscht (Morley et al. 2014).

Ab etwa dem 50. Lebensjahr sinkt der Testosteronspiegel um $1 \%$ pro Jahr (Morales et al. 2000). Außerdem ist die Produktion von Wachstumshormonen herabgesetzt. Dies hat eine Abnahme sowohl der Muskelmasse als auch der Muskelkraft und eine Zunahme des Fettgewebes zur Folge (Bauer et al. 2008).

Auf neuronaler Ebene lässt sich eine Verminderung der a-Motoneurone und eine Denervation beobachten, welche sich in einem Rückgang der Muskelkraft zeigt (Lexell 1995).

Bei längerer Inaktivität, was infolge chronischer Erkrankungen oder auch akuten Gesundheitsproblemen mit Bettlägerigkeit häufig der Fall ist, kommt es zur Ausschüttung proinflammatorischer Zytokine wie zum Beispiel Interleukin-1, Interleukin-6 und Tumornekrosefaktor- $\alpha$. Dies führt zu Proteinkatabolismus und somit zum Muskelabbau (von Haehling et al. 2013).

Ein Verlust an Muskelmasse ist mit einem Verlust von Knochenmasse assoziiert, was das Risiko für Stürze und damit verbundene Frakturen im Alter massiv erhöht.

\subsubsection{Diagnostik}

Das Problem in der Diagnostik der Sarkopenie besteht darin, dass keine Einigkeit bezüglich diagnostischer Kriterien herrscht. In der Praxis werden meist folgende Parameter für die Diagnose herangezogen: Muskelmasse, Muskelkraft und Ausdauer.

Die Muskelmasse lässt sich unter anderem durch DoppelröntgenAbsorptiometrie (DXA) oder Bioelektrische Impedanzanalyse (BIA) bestimmen (Cruz-Jentoft et al. 2010). Die DXA ist eine Methode, bei der die Masse der Extremitätenmuskulatur im Verhältnis zur Körpergröße bestimmt wird und stellt die 
kostengünstigere und sensitivere Variante dar (Spira 2013). Sarkopenie ist dann zu diagnostizieren, wenn die ermittelten Messwerte einer Person um mehr als zwei Standardabweichungen unter den durchschnittlichen Werten einer gesunden Vergleichspopulation liegen (Cruz-Jentoft et al. 2010).

Die Muskelkraft wird anhand manueller Prüfung der Handkraftstärke und die Ausdauer bzw. die physische Leistungsfähigkeit durch Messung der Ganggeschwindigkeit (Timed-get-up-and-go-Test) und der Short Physical Performance Battery (SPPB) erhoben (Hohenstein et al. 2011). Der Timed-get-up-and-goTest wird im Abschnitt 1.2.4.4.1 beschrieben. Die SPPB, auch als „Performance Score" bezeichnet, besteht aus drei unterschiedlichen Übungen. Die erste Aufgabe besteht darin, das Gleichgewicht des Patienten zu prüfen. Die zweite Übung ist ein Ganggeschwindigkeitstest und im abschließenden Teil der SPPB wird die Stärke der unteren Extremität erfasst. Bei jeder Aufgabe wird die Zeit gestoppt. Es können bis zu vier Punkte erreicht werden. Der Patient hat bei 0-6 Punkten eine schwache Leistung, bei 7-9 Punkten eine mittlere Leistung und bei 10-12 Punkten eine normale bzw. gute Leistung erzielt.

\subsubsection{Therapie}

Aktuell existieren keine Leitlinien zur Therapie der Sarkopenie. Dies hat zur Folge, dass Verunsicherung und teilweise auch Unwissenheit über die Behandlung dieses geriatrischen Syndroms herrscht. Da kausale Ansätze nicht möglich sind, ist hier die Prävention von herausragender Bedeutung.

Die wichtigste Maßnahme gegen eine fortschreitende Abnahme der Skelettmuskulatur ist nach wie vor Krafttraining (Ali und Garcia 2014; Dodds und Sayer 2014). Aber auch Ausdauertraining hat einen positiven Effekt und sollte zusammen mit einem angepassten Krafttraining regelmäßig durchgeführt werden. Dieses körperliche Training verbessert sowohl die Muskelkraft als auch die Muskelmasse und das Gleichgewichtsvermögen (Dirks und Leeuwenburgh 2005).

Aktuell gibt es keine definitiven medikamentösen Ansätze für die Therapie der Sarkopenie (Meriggioli und Roubenoff 2015). Allerdings zeigt sich die Gabe von essentiellen Aminosäuren in einigen Studien positiv. Insbesondere die Amino- 
säure Leucin scheint sich positiv vor allem auf die Muskelmasse auszuwirken (Morley et al. 2010). Auch sollte auf eine generell ausreichende Zufuhr von Proteinen mit der Nahrung geachtet werden, da diese die erforderlichen Aminosäuren für die Muskelsynthese bereitstellen (Dodds et al. 2014). Zudem hat eine Vitamin D-Substitution bzw. ein suffizienter Vitamin D-Status nicht nur großen Einfluss auf den Knochenstoffwechsel, sondern verbessert zugleich die Muskelfunktion (Morley et al. 2014) und wirkt sich außerdem positiv auf Muskelstärke und Gleichgewicht der Patienten aus (Muir und Montero-Odasso 2011).

\subsubsection{Muskelgewebe}

Das Muskelgewebe, aus dem Mesoderm entstanden, lässt sich in drei Arten einteilen: Skelett- und Herzmuskulatur sowie glatte Muskulatur. Skelett- und Herzmuskulatur werden meist als quergestreifte Muskulatur zusammengefasst. Die Querstreifung ergibt sich aus den sehr regelmäßig angeordneten Myofibrillen, welche in glatten Muskelzellen weniger geordnet aufgebaut sind. Aktin und Myosin bilden neben weiteren Proteinen in allen Muskelzellen den kontraktilen Apparat, der für eine gleichmäßige Bewegung verantwortlich ist.

\subsubsection{Skelettmuskulatur}

Die Zellen der Skelettmuskulatur sind sehr groß und besitzen mehrere ovale Zellkerne, die randständig aufzufinden sind. Typisch ist die Querstreifung und das Netz aus Gefäßen und Nerven in den Bindegewebssepten. Mehrere Fasern des Muskels bilden zusammen ein Primärbündel, das vom Perimysium internum umhüllt wird. Mehrere Primärbündel werden vom Perimysium externum umgeben, und letztlich werden diese Bündel vom Epimysium und der Faszie umhüllt (Lüllmann-Rauch 2009).

Die Querstreifung ergibt sich aus einer strukturierten Anordnung der Myofibrillen. Das Muster entsteht durch die regelmäßige Folge von hellen und dunklen Streifen (A-Streifen und I-Streifen). Innerhalb des A-Streifens befindet sich der $\mathrm{H}$-Streifen, in dessen Mitte liegt der schmale M-Streifen und in der Mitte des IStreifens ist der Z-Streifen erkennbar. Der Bereich zwischen zwei Z-Streifen wird als Sarkomer bezeichnet. Viele Sarkomere zusammen und nacheinander 
ergeben dann eine Myofibrille. Ein Sarkomer besteht aus dünnen und dicken Filamenten. Die dünnen Filamente werden aus Aktin, Tropomyosin sowie Troponin gebildet, und die dicken Filamente bestehen aus Myosin II. Der Kopfteil des Myosinfilaments ist der Ort der ATPase-Aktivität und bildet eine Brücke zwischen Myosin und Aktin (Welsch 2006). Das Protein Titin verankert die Myosinfilamente am Z-Streifen. Nebulin ist für die Position der Aktinfilamente verantwortlich. Die Intermediärfilamente Dystrophin, Vinculin und Desmin dienen der mechanischen Stabilität der Muskelzelle.

Die Skelettmuskulatur ist für eine willkürliche Kontraktion verantwortlich. Der Kontraktionsvorgang beginnt mit einem Nervenimpuls, wodurch Kalzium aus dem sarkoplamatischen Retikulum strömt und für eine Konformationsänderung des Aktin-Myosin-Komplexes sorgt. Es kommt zu einem Überlappen der Filamente und somit zu einer Verkürzung des Sarkomers (sliding-filament-theory). Der molekulare Mechanismus der Kontraktion wird Querbrückenzyklus genannt. Innerviert werden Muskelfasern von einer motorischen Endplatte. Diese neuromuskulären Verbindungen entstehen durch Vereinigung von Nervenendigungen und Muskelfasern (Synapsen). Die Größe einer motorischen Einheit bestimmt die Feinheit der Bewegung, die von ihr ausgeführt werden kann (Junqueira und Carneiro 2005).

\subsection{Typ-I-Muskelfaser}

Muskelfasern, die ermüdungsresistent sind, langsam arbeiten und ihre Energie durch oxidative Phosphorylierung erhalten, nennt man Typ-I-Fasern. Sie erscheinen durch den hohen Myoglobingehalt rot. Myoglobin wird zur Bereitstellung von Sauerstoff benötigt. Man bezeichnet sie auch als Typ-S-Fasern ( $\mathrm{s}=$ slow) oder SO-Fasern (so = slow oxidative).

\subsection{Typ-lla-Muskelfaser (Intermediärtyp)}

Der Intermediärtyp weist einen geringeren Anteil an Myoglobin auf, als in den Typ-I-Fasern, dadurch erscheinen sie nur leicht rötlich. Die benötigte Energie wird hier entweder durch oxidative Phosphorylierung oder über anaerobe Glykolyse bereitgestellt. Sie werden auch FOG-Fasern (fog = fast oxidative glykolytic) genannt. 


\subsection{Typ-Ilb-Muskelfaser}

Typ-Ilb-Muskelfasern, auch Typ-F-Fasern ( $f=f a s t)$ oder FG-Fasern $(\mathrm{fg}=$ fast glykolytic) genannt, sind Zuckungsfasern, die für schnelle und kräftige Kontraktionen geeignet sind. Diese Fasern ermüden rasch. Sie enthalten kaum Myoglobin und werden daher auch als weiße Muskelfasern bezeichnet. Ihre Energie gewinnen sie durch Glykolyse von Glykogen.

\subsubsection{Herzmuskulatur}

Die Kardiomyozyten sind groß und besitzen einen zentral gelegenen Zellkern. Die Herzmuskelzellen sind über Nexus, auch Gap Junctions genannt, verbunden, sodass eine gleichmäßige Erregung des Myokards gewährleistet werden kann. Diese liegen im Glanzsteifen, der die Zellen miteinander verknüpft. Des Weiteren findet man im Glanzstreifen noch zwei Zellverbindungen: Desmosomen und Zonula adhaerentes.

Die myogene Erregung wird über spezielle Herzmuskelzellen gesteuert. Das System besteht aus folgenden Bestandteilen: Sinusknoten, atrioventrikulärer Knoten, His-Bündel, Tawara-Schenkel und Purkinje-Fasern.

\subsubsection{Glatte Muskulatur}

Die glatte Muskulatur kleidet viele Hohlorgane aus. Die spindelförmigen kleinen Zellen verfügen über einen zigarrenförmigen länglichen Zellkern, der mittig liegt. Außerdem findet man viele Gap Junctions, sodass die Zellen ein funktionelles Synzytium bilden. Glatte Muskelzellen weisen keine Querstreifung auf, sondern bilden ein netzförmiges Gitter. Die Kontraktion ist ausgeprägter und langsamer als bei der Skelettmuskulatur. Meist wird sie über ein Zusammenspiel von Innervation, myogenen und lokalen Mechanismen und Hormonen gesteuert.

\subsubsection{Urocortin}

Urocortin ist ein aus 40 Aminosäuren bestehendes Polypeptid, besitzt $45 \%$ Sequenzhomologie zum Corticotropin Releasing Factor (CRF) und gehört somit zur corticotropin-releasing factor-Peptidfamilie. Die Sequenzhomologie beschreibt die Ähnlichkeit aufgrund identischer Bausteinsequenzen (Latchman 
2002). Die molekulare Formel lautet folgendermaßen: $\mathrm{C}_{208} \mathrm{H}_{344} \mathrm{~N}_{60} \mathrm{O}_{63} \mathrm{~S}_{2}$. Es zählt zu den Neurohormonen und wird sowohl im zentralen Nervensystem, vor allem im Edinger Westphal Kern, als auch in peripheren Geweben vieler Säugetiere exprimiert. Im Jahr 1995 wurde es erstmals im Hypothalamus der Ratte nachgewiesen (Vaughan et al. 1995). Die menschlichen Urocortine sind Urocortin-1, Urocortin-2 und Urocortin-3. In der vorliegenden Arbeit geht es ausschließlich um Urocortin-1 (Abb. 3).

COOH-Asp-Asn-Pro-Ser-Leu-Ser-Ile-Asp-Leu-Thr-Phe-His-Leu-LeuArg-Thr-Leu-Leu-Glu-Leu-Ala-Arg-Thr-Gln-Ser-Gln-Arg-Glu-Arg-AlaGlu-Gln-Asn-Arg-Ile-Ile-Phe-Asp-Ser-Val-NH ${ }_{2}$

Abb. 3: Aminosäurenabfolge des humanen Urocortin (Ala = Alanin; Arg = Arginin; Asn = Asparagin; Asp = Asparaginsäure; $\mathrm{COOH}=$ Carboxy-Terminus des Peptids; Gln = Glutamin; Glu = Glutaminsäure; Gly = Glycin; His = Histidin; Ile = Isoleucin; Leu = Leucin; $\mathrm{NH}_{2}=$ Aminoterminus des Peptids; Phe = Phenylalanin; Pro = Prolin; Ser = Serin; Thr $=$ Threonin)

Es bindet an beide CRF-Rezeptoren, während Urocortin-2 und Urocortin-3 nur an den CRF-Rezeptor-2 andocken (Abb. 4). Urocortin besitzt eine höhere Affinität zu dem CRF-Rezeptor-2, welcher sowohl im zentralen Nervensystem als auch in der Peripherie vorkommt und von dem die zwei Untereinheiten CRF2a und CRF2b existieren (Vaughan et al. 1995). Zusätzlich bindet es an das CRFBindungsprotein (CRF-BP). Das lösliche Glykoprotein sorgt für ein schnelles Kontrollsystem der Liganden, indem bei Bindung an das CRF-Bindungsprotein die Bioverfügbarkeit der Neuropeptide reduziert wird und sie die CRFRezeptoren nicht mehr besetzen können (Behan et al. 1996). 


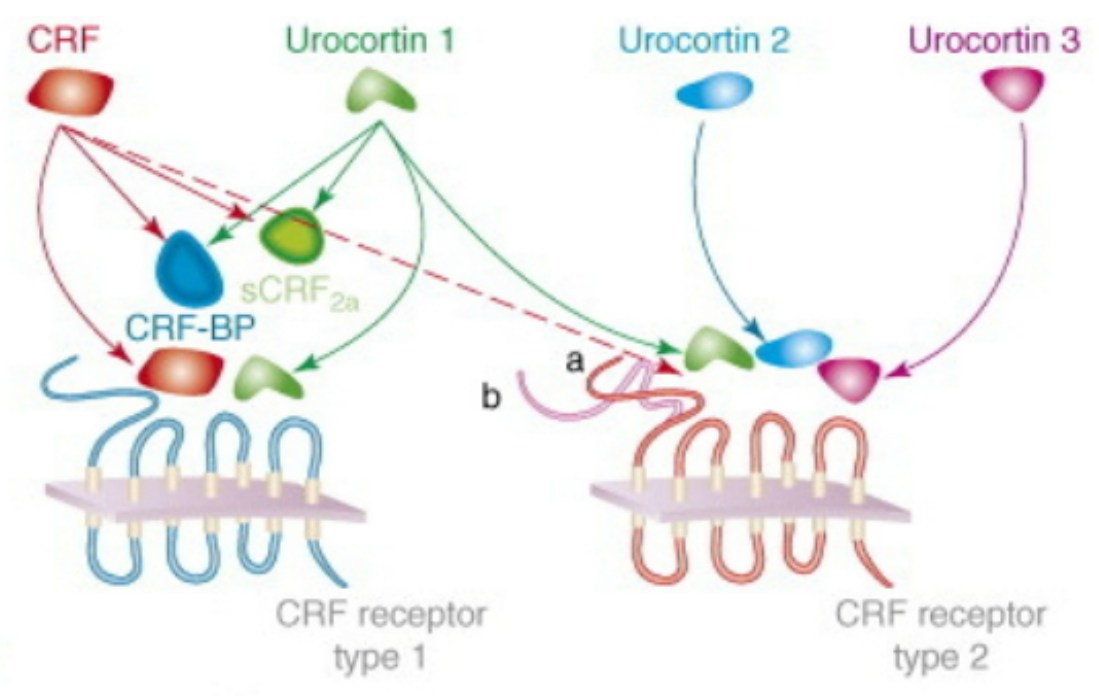

Abb. 4: CRF-Familie und ihre Rezeptoren (modifiziert nach Kuperman et al. 2008)

Durch die Affinität zu verschiedenen Rezeptoren entsteht ein vielfältiges und interessantes Wirkungsspektrum. Urocortin nimmt Einfluss auf neurobiologische und psychische Prozesse, spielt eine entscheidende Rolle sowohl im Fettstoffwechsel als auch im Knochenstoffwechsel, wirkt auf das kardiovaskuläre System und auf das Renalsystem, scheint in der Reproduktion eine Rolle zu spielen, beeinflusst immunologische Entwicklungen, agiert mit dem hormonellen System, wird in der Haut exprimiert und könnte für die Diagnose und Therapie maligner Erkrankungen von Bedeutung sein.

Urocortin moduliert Stress- und Angstreaktionen. Dabei kommt es zu einer gesteigerten Stressantwort und verstärktem Angstverhalten (Skelton et al. 2000). Die Regulation der Temperatur wird ebenfalls beeinflusst (Figueiredo et al. 2010). Kürzlich wurde auch eine neuroprotektive Wirkung des Moleküls bestätigt. Sowohl eine systemische als auch die intraventrikuläre Gabe von Urocortin bei Ratten brachte eine Reduktion des neurologischen Defizits mit sich (Liew et al. 2015). Außerdem ist es am Verhalten bezüglich der Nahrungs- und Wasseraufnahme beteiligt. Studien haben gezeigt, dass eine Interaktion zwischen Urocortin, Neuropeptid $Y$ und Leptin stattfindet. Dies führt dazu, dass der Appetit vermindert wird (Fekete und Zorrilla 2007; Oki und Sasano 2004). 
Es gibt Hinweise dafür, dass Urocortin direkt auf Adipozyten wirkt und der Metabolismus im Fettgewebe über das corticotropin-releasing hormone-System gesteuert wird (Seres et al. 2004; Lu et al. 2015). Über diese Mechanismen hat es erheblichen Einfluss auf die Energiebalance des Körpers.

Vor einigen Jahren konnte durch abteilungsinterne Untersuchungen gezeigt werden, dass Urocortin von humanen Osteoprogenitorzellen, Vorstufen der Osteoblasten, erzeugt wird (Tezval et al. 2009). Ebenfalls in Untersuchungen aus dem Forschungszentrum der Universitätsmedizin Göttingen beobachtete man osteoprotektive Effekte von Urocortin auf die Wirbelsäule von Ratten. Man erreichte durch die hochdosierte Therapie mit Urocortin über 35 Tage eine verbesserte Knochenmorphologie und zusätzlich eine gute Biomechanik (Sehmisch et al. 2015). Auch scheint sich die Behandlung positiv auf die Mikroarchitektur und die Knochenstärke des Femurs in ovariektomierten Ratten auszuwirken (Tezval et al. 2014). Combs et al. konnten 2012 in ihrer Studie die direkte Interaktion von Urocortin mit Osteoklasten und deren Vorläuferzellen belegen. Möglicherweise stellt die Regulation über das Urocortin-System eine Alternative zum RANK/RANKL/OPG-Signalweg dar, ein Regulationsweg, der Knochenabbau und -aufbau im Gleichgewicht hält, das eine Bedingung für eine gesunde Knochenstruktur ist.

Auch auf das kardiovaskuläre System nimmt Urocortin großen Einfluss. Es wirkt über verschiedene Mechanismen vasodilatatorisch. Zum einen wird über den Proteinkinase A-Signalweg eine Relaxation ausgelöst (Huang et al. 2003), zum anderen sind endothelabhängige und -unabhängige Mechanismen, die zu einer Vasorelaxation führen, bekannt (Huang et al. 2002; Lubomirov et al. 2001). Durch diese physiologischen Abläufe reguliert Urocortin indirekt Blutdruck und Blutfluss. Über die CRF-Rezeptor-Bindung wirkt es außerdem kardioprotektiv (Oki und Sasano 2004). Studien belegen den positiv inotropen und positiv lusitropen Effekt und die Begrenzung des Ischämie-Reperfusionsschadens durch Urocortin (Walczewska et al. 2014). In einer Untersuchung mit an Herzinsuffizienz erkrankten Schafen kam es nach intravenöser Gabe von Urocortin zu einer signifikanten Reduktion von Renin, Aldosteron, Vasopressin, atrialem Natriuretischen Peptid (ANP) und Endothelin-1, sodass die Erkenntnis gewonnen werden konnte, dass Urocortin Einfluss auf die kardiale Funktion bei Herzinsuf- 
fizienz hat und an der Regulation des Wasser- und Elektrolythaushalts beteiligt ist (Rademaker et al. 2002). Für die Therapie der arteriellen Hypertonie, der Herzinsuffizienz und des Myokardinfarkts könnte Urocortin eine neue Behandlungsmöglichkeit darstellen (Takahashi 2012).

Des Weiteren konnten interessante Beobachtungen bezüglich renaler Regulationsmechanismen getätigt werden. Es ist denkbar, dass Urocortin auch hier eine pathophysiologisch wichtige Rolle spielt (Devetzis et al. 2013).

Urocortin konnte im Ovar, in der Plazenta, in fetalem Gewebe, im Endometrium und Myometrium des Uterus und in der Prostata nachgewiesen werden. Es sorgt unter anderem für die funktionelle Aufrechterhaltung der Plazenta, reguliert dort den Gefäßwiderstand und führt zur Ausschüttung verschiedener Hormone, wirkt auf die Steroidsynthese im Ovar, stimuliert die Uteruskonraktion und scheint eine nicht unbedeutende Rolle bei der Präeklampsie und vorzeitigen Wehen zu spielen, da bei diesem Geschehen erhöhte Urocortinwerte gemessen werden konnten (Florio et al. 2004; Oki und Sasano 2004).

Zudem stimuliert es die Interleukin-6-Synthese in den glatten Muskelzellen der Aorta (Kageyama et al. 2006). Interleukin-6 ist ein proinflammatorisches Zytokin, welches in vielen verschiedenen Signalkaskaden durch komplexe Regulationsmechanismen eine bedeutende Rolle spielt. Möglicherweise hat Urocortin über diesen Weg großen Einfluss auf Entzündungsprozesse des Körpers.

Da Urocortin auch in der Nebenniere, vor allem im Nebennierenmark, exprimiert wird, geht man davon aus, dass eine hormonelle Wirkung besteht. 2013 wurde aus einer in vivo Studie gefolgert, dass ein intraadrenales Regulationssystem existiert, das die Struktur und Funktion der Nebenniere beeinflusst (Riester 2013).

Vor kurzem konnte gezeigt werden, dass Urocortin die Zellwanderung des hepatozellulären Karzinoms beeinflusst. So stimulierte es einerseits die Tumorzellwanderung durch die Expression von cPLA2 über den CRF-Rezeptor-1, wohingegen es über den CRF-Rezeptor-2 und eine Downregulation des Enzyms iPLA2 zur Unterdrückung der Zellmigration kam (Li et al. 2014).

Ferner besteht ein Zusammenhang zwischen Urocortin und dem duktalen Adenokarzinom des Pankreas. Es hat sich herausgestellt, dass die Höhe der Uro- 
cortinexpression mit dem Tumorgrad, dem AJCC-Stadium und der PanIn Klasse korreliert (Cheng et al. 2014).

Die Haut, das größte Organ des Menschen, exprimiert ebenfalls Urocortin (Slominski et al. 2000). Vermutlich besteht eine Interaktion mit Sebozyten (Krause 2010), doch hierzu ist noch wenig bekannt.

Hinkle et al. fanden im Jahr 2003 heraus, dass Urocortin die Entwicklung sowohl gesunder als auch atrophierter Skelettmuskulatur positiv beeinflussen kann. Es konnte gezeigt werden, dass der Verlust von Muskelmasse und Muskelfunktion in atrophiertem Gewebe durch Urocortin verhindert wird. Zusätzlich gewann man die Erkenntnis, dass Urocortin den Erhalt von Muskelmasse und Muskelfunktion in gesunder Skelettmuskulatur fördert. Diese Entdeckung ist wichtig für die Prävention und Behandlung von Muskelerkrankungen wie der Sarkopenie.

Die zuvor beschriebenen vielfältigen Effekte heben die klinische, diagnostische und therapeutische Relevanz dieses Peptids deutlich hervor.

\subsubsection{Osteoporose}

\subsubsection{Definition}

Die Osteoporose ist eine systemische Skeletterkrankung, die durch eine mangelhafte Knochenfestigkeit gekennzeichnet ist. Dies führt zu einer erhöhten Knochenbrüchigkeit. Knochendichte und Knochenqualität wirken gemeinsam auf die Knochenfestigkeit. Diese Definition stammt aus dem Jahr 2000 und wurde auf einer Konferenz durch das National Institute of Health $(\mathrm{NIH})$ festgelegt.

Laut der Weltgesundheitsorganisation (WHO) liegt eine Osteoporose dann vor, wenn die mittels einer "Dual-X-ray-Absorptiometrie“ (DXA) gemessene Knochendichte mehr als -2,5 Standardabweichungen vom Mittelwert eines gesunden Erwachsenen im Alter zwischen 20 und 40 Jahren abweicht. Die Standardabweichung wird als T-Wert bezeichnet.

Man unterscheidet zwei Formen der Osteoporose. Zum einen die primäre Osteoporose, zu der der postmenopausale Typ, der idiopathische Typ und der 
senile Typ zählt, und die sekundäre Osteoporose, die etliche Ursachen haben kann.

\subsubsection{Epidemiologie}

Bei älteren Menschen ist die Osteoporose die häufigste Knochenerkrankung (Herold 2012). Die Prävalenz für über 50-Jährige liegt zur Zeit in Deutschland bei ca. $14 \%$ und nimmt mit dem Alter zu. Die Inzidenz dieser Erkrankung beträgt 2,1\% (Hadji et al. 2013). Die jährlichen Kosten für die Behandlung der Osteoporose werden auf 5,4 Milliarden Euro geschätzt (Häussler et al. 2007). Daraus wird ersichtlich, dass die Osteoporose nach wie vor eine weit verbreitete Erkrankung mit sehr hohen Kosten und dringendem Behandlungsbedarf ist. Diese Erkrankung wird aufgrund der demografischen Entwicklung eine steigende medizinische, soziologische sowie wirtschaftliche Bedeutung bekommen.

\subsubsection{Pathogenese und Risikofaktoren}

Die häufigste Form der Osteoporose ist die primäre Osteoporose, die wiederum in die idiopathische, die postmenopausale und die senile Osteoporose unterteilt werden kann. Im Rahmen dieser Arbeit wird die postmenopausale Osteoporose betrachtet. Die am besten beeinflussbaren Risikofaktoren sind die Muskelkraft bzw. die Immobilität und der Mangel an Sexualhormonen. Weitere Risikofaktoren sind eine unausgewogene Ernährung, vor allem ein Mangel an Vitamin $D$ und Calcium, Untergewicht (Body Mass Index < 20), Nikotinkonsum, übermäßiger Alkoholkonsum, eine chronisch obstruktive Atemwegserkrankung (COPD), eine verminderte Handgriffsstärke, Stürze, genetische Faktoren, das Alter und das Geschlecht (Fini et al. 2012). Frauen sind häufiger betroffen, da sie eine niedrigere Knochenmasse als Männer aufweisen. Diese nimmt nach der Menopause nochmals ab.

\subsubsection{Diagnostik}

Die Diagnose sollte frühzeitig gestellt werden, damit eine optimale Therapie greifen kann und mögliche Risikofaktoren rechtzeitig ausgeschaltet werden können. Der Dachverband Osteologie (DVO) empfiehlt in den 2014 veröffent- 
lichten Leitlinien für Osteoporose eine Diagnostik für die Patienten, die ein erhöhtes Risikoprofil aufweisen und sich somit für sie ein erhöhtes Frakturrisiko ergibt.

\subsection{Anamnese und körperliche Untersuchung}

Ein ausführliches Gespräch, in dem man die Langzeiteinnahme von Medikamenten sowie Krankheiten, die das Osteoporoserisiko erhöhen, erfragt und eine Sturzanamnese durchführt, sollte bei jedem Patienten erfolgen. Außerdem sollte man die Körpergröße und das Gewicht dokumentieren. Eine Abnahme der Körpergröße von mehr als $4 \mathrm{~cm}$ ist hinweisend auf eine manifeste Osteoporose.

Bei der Inspektion ist vor allem auf einen Rundrücken und das sogenannte „Tannenbaumphänomen“ zu achten. Dieses entsteht durch schräg nach unten verlaufende Hautfalten am Rücken und ist ein wichtiges Kennzeichen einer Deformität der Wirbel.

Des Weiteren sollte die Koordination und Muskelkraft überprüft werden. Dies kann man anhand des Timed-up-and-go-Test beurteilen. Der Test wird folgendermaßen durchgeführt: Man bittet den Patienten, sich aufrecht auf einen Stuhl mit Armlehne zu setzen. Nach Aufforderung muss die Versuchsperson aufstehen, $3 \mathrm{~m}$ geradeaus gehen, sich umdrehen, $3 \mathrm{~m}$ zurück gehen und sich erneut hinsetzen. Dabei wird die Zeit gestoppt. Bei einer Dauer über oder gleich 30 Sekunden ist eine Sturzgefährdung und Mobilitätsstörung anzunehmen (Bartl 2010).

\subsection{Labor}

Ein Basislabor zur Diagnostik der Osteoporose sollte folgende Parameter enthalten: Kalzium, Phosphat, Alkalische Phosphatase, Gamma-GT, Kreatinin, CRP, BSG, TSH. Außerdem sollte eine Serum-Eiweißelektrophorese durchgeführt werden.

\subsection{DXA-Osteodensitometrie}

Das Standardverfahren zur Bestimmung der T-Werte ist die Osteodensitometrie, die eine Einteilung des Schweregrads einer Osteoporose erlaubt. Die Knochendichte wird an den Lendenwirbelkörpern L1 - L4 und am proximalen Femur gemessen. 


\subsection{Röntgen}

Eine Röntgenuntersuchung der Brustwirbel- und Lendenwirbelsäule in zwei Ebenen muss nicht zwingend ausgeführt werden, sollte jedoch der klinische Verdacht auf eine Fraktur vorliegen, ist sie fester Bestandteil der Diagnostik.

\subsubsection{Therapie}

Die Osteoporose ist eine chronische Erkrankung, welche nicht vollständig geheilt werden kann, jedoch gibt es einige wichtige Empfehlungen, die zur Fraktur- und Osteoporoseprophylaxe eingehalten werden sollten. Die Therapie umfasst Empfehlungen zur Ernährung, allgemeine Vorgehensweisen zur Verbesserung von Kraft und Koordination, außerdem Basismaßnahmen zur Reduktion funktioneller Einschränkungen und Schmerzen sowie eine medikamentöse Behandlung. Prinzipiell sollten individuelle Risikofaktoren erkannt und beseitigt werden. Diese sind in Abschnitt 1.2.1.3 aufgeführt.

Folgende Ausführungen richten sich nach den in den Leitlinien gegebenen Empfehlungen des DVO. Die aktuellen Leitlinien sind aus dem Jahr 2014.

Eine bewusste Ernährung bei Osteoporose bzw. um dieser vorzubeugen ist wichtig. Es ist ratsam, Lebensmittel zu sich nehmen, die den Knochen stärken und dies erfolgt vor allem durch Calcium, Mineralien, Spurenelemente und Vitamine. Hier sind vor allem Vitamin D und Calcium von herausragender Bedeutung. Eine tägliche Calciumzufuhr von 1000 mg kann zum Beispiel durch Milchprodukte und frisches Gemüse ausreichend aufrechterhalten werden, sodass eine Gabe von Calciumpräparaten oft nicht notwendig ist.

Auf Nikotin- und Alkoholkonsum sollte verzichtet bzw. Alkohol nur in Maßen getrunken werden. Medikamente, die eine Osteoporose begünstigen, zum Beispiel Kortikoide und Glitazone, oder solche, die das Sturzrisiko erhöhen, zum Beispiel Antidepressiva oder orthostatisch wirkende Medikamente, sollten kontrovers diskutiert werden.

Druck und Zug fordert den Knochen und bringt bei regelmäßigem körperlichen Training mehr Stabilität mit sich. Sport ist somit ebenfalls eine klare Empfehlung zur Prävention und Therapie der Osteoporose. Außerdem sollte zur Sturzprä- 
vention der Gleichgewichtssinn geschult werden und mögliche Stolperfallen aus dem Umfeld des Betroffenen entfernt werden.

Die medikamentöse Therapie beinhaltet folgende Präparate: Parathormon, Bisphosphonate, Strontiumranelat, selektive Estrogen-Rezeptormodulatoren (SERMs) und den monoklonalen RANKL-Antikörper Denosumab. Diese werden in den Leitlinien des DVO empfohlen und können in osteoanabole und antiresorptive Medikamente eingeteilt werden. $\mathrm{Zu}$ den osteoanabolen Präparaten zählen zum Beispiel Parathormon und Strontiumranelat. Bisphosphonate, SERMs, Estrogene, Calcium und Vitamin D gehören zu den antiresorptiven Therapeutika. Wie bereits erwähnt bringen diese Arzneien teilweise erhebliche Nebenwirkungen mit sich und erfordern gleichzeitig eine sehr regelmäßige und dauerhafte bzw. langfristige Einnahme, sodass die Compliance der Patienten eingeschränkt ist. Eine Indikation für eine medikamentöse antiosteoporotische Therapie besteht, wenn bei der Knochendichtemessung mittels DXA T-Werte von $<-2$ festgestellt wurden.

\subsubsection{Sarkopenie und Osteoporose}

Ein muskuläres Ungleichgewicht führt zu Instabilität der Knochen. Daraus resultieren Frakturen bei Patienten mit ohnehin schon vermindertem Aktivitätsniveau. Um das Sturzrisiko zu reduzieren und somit Frakturen zu vermeiden, ist es wichtig, den Zusammenhang zwischen den chronischen Skeletterkrankungen Sarkopenie und Osteoporose zu erkennen und genau zu betrachten. 


\section{Material und Methoden}

\subsection{Material}

\subsubsection{Versuchstiere}

Es wurden 60 weibliche Ratten vom Stamm Sprague Dawley (Firma HarlanWinkelmann, Borchen, Deutschland) in fünf Gruppen mit jeweils 12 Tieren eingeteilt.

Während des gesamten Zeitraumes hielt man die Ratten, die zu Beginn des Versuches drei Monate alt waren, tiergerecht in den Räumen der Zentralen Tierexperimentellen Einrichtung (ZTE) der Universitätsmedizin Göttingen (UMG). Die Operationen erfolgten eben dort. Futter (Typ ssniff SM R/M, sniff Spezialdiäten $\mathrm{GmbH}$, Soest, Deutschland) und Wasser waren zu jeder Zeit für die Tiere erreichbar. Ein Hell-Dunkel-Rhythmus, sowie eine Raumtemperatur von $22^{\circ} \mathrm{C}$ und eine relative Luftfeuchtigkeit von $55 \%$ wurden konstant eingehalten. Die Käfige wurden jede Woche gereinigt. Die Genehmigung für die Tierversuche (Tierschutzantrag 33.9-42502-04-10/0246) durch die Bezirksregierung Oldenburg liegt vor.

\subsubsection{Proben für die histologischen Untersuchungen}

Für die Untersuchung des Einflusses von Urocortin auf die Skelettmuskulatur der Ratte wurden den Tieren der gesamte M. soleus und ein Teil des M. Iongissimus und des M. gastrocnemius entnommen. Zuvor wurden die Versuchstiere 13 Wochen nach Beginn des Versuches durch Dekapitation in tiefer $\mathrm{CO}_{2}-\mathrm{Nar}-$ kose getötet. Zur Präparation der Muskelproben wurde für den M. soleus und den M. gastrocnemius ein Hautschnitt am dorsalen Unterschenkel und für den M. longissimus ein Hautschnitt paramedian der Wirbelsäule durchgeführt. Nach der Entnahme wurden die Muskelproben in flüssigem Stickstoff tiefgefroren und daraufhin bei $-80^{\circ} \mathrm{C}$ aufbewahrt. Außer den genannten Muskeln wurden Knochen, Hypothalamus, Serum und Fett der Tiere in weiteren Untersuchungen verwendet (Sehmisch et al. 2015; Tezval et al. 2014). 


\subsection{Methoden}

\subsubsection{Versuchsablauf}

Die insgesamt 60 Ratten wurden zu Beginn in fünf Gruppen mit jeweils 12 Tieren eingeteilt. Die erste Gruppe (SHAM) wurde nicht operiert, alle anderen Gruppen (OVX, OVX + UCN low, OVX + UCN high und OVX + Estradiol) wurden ovariektomiert. Daraufhin entwickelten die Tiere dieser Gruppen eine Osteoporose (Kalu 1991). Während der Narkose starben zwei Ratten der Gruppe OVX, daher standen für die weiteren Untersuchungen noch insgesamt 58 Versuchstiere zur Verfügung. Acht Wochen nach der Ovariektomie begann man mit der UCN-Behandlung. Dafür injizierte man den Ratten der Gruppen SHAM, OVX und OVX + Estradiol täglich subkutan 0,3 ml 0,9\% NaCl-Lösung, die Gruppe OVX + UCN low erhielt $3 \mu \mathrm{gg} / \mathrm{KG}$ Urocortin in 0,3 $\mathrm{ml} 0,9 \% \mathrm{NaCl}-$ Lösung und die Gruppe OVX + UCN high wurde mit $30 \mu \mathrm{g} \mathrm{kg} / \mathrm{KG}$ Urocortin in $0,3 \mathrm{ml} \mathrm{0,9 \%} \mathrm{NaCl-Lösung} \mathrm{behandelt.} \mathrm{Die} \mathrm{Tiere} \mathrm{der} \mathrm{Gruppe} \mathrm{OVX} \mathrm{+} \mathrm{Estradiol}$ erhielten 0,2 mg Estradiol pro kg/KG pro Tag über das Futter (Tab. 1).

Tab. 1: Zuordnung der Versuchsgruppen

\begin{tabular}{|l|l|l|l|}
\hline Käfig & Tiernummer & Behandlung & Beschreibung \\
\hline $1-3$ & $1-12$ & SHAM & Kontrollgruppe \\
\hline $4-6$ & $13-22$ & OVX & nur ovariektomiert \\
\hline $7-9$ & $23-34$ & OVX + UCN low & $\begin{array}{l}\text { Ovariektomie + subkutane } \\
\text { Behandlung mit niedrig } \\
\text { dosiertem Urocortin }\end{array}$ \\
\hline $10-12$ & $35-46$ & OVX + UCN high & $\begin{array}{l}\text { Ovariektomie + subkutane } \\
\text { Behandlung mit hoch do- } \\
\text { siertem Urocortin }\end{array}$ \\
\hline $13-15$ & $47-58$ & OVX + Estradiol & $\begin{array}{l}\text { Ovariektomie + Estradiol } \\
\text { über Nahrungsaufnahme }\end{array}$ \\
\hline
\end{tabular}


Um eine Identifikation der Versuchstiere sicherzustellen, implantierte man innen einen elektronischen Transponder in das subkutane Fettgewebe im Nacken. Das humane Urocortin stammt von der Firma Bachem aus Bubendorf in der Schweiz. Während dieser 35-tägigen Behandlung wurden alle Tiere mit den folgenden fluoreszierenden Stoffen ( $0,3 \mathrm{ml}$ subkutan) gespritzt, um den neugebildeten Knochen zu markieren (Tezval et al. 2010):

Tag 13: $\quad$ Xylenolorange (90 $\mathrm{mg}$ pro $\mathrm{kg} \mathrm{KG}$ )

Tag 18: $\quad$ Calceingrün (10 $\mathrm{mg}$ pro $\mathrm{kg} \mathrm{KG}$ )

Tag 24 und Tag 26: Alizarincomplexon (30 mg pro kg KG)

Tag 35: $\quad$ Tetrazyklin (25 $\mathrm{mg}$ pro $\mathrm{kg} \mathrm{KG}$ )

\subsubsection{Ovariektomie}

Die Operation erfolgte in Anästhesie mit Ketamin (90 mg pro kg KG, Hostaket $₫$, Firma Hoechst, Bad Soden, Deutschland) und Xylazin (7,5 mg pro kg KG, Rompun®, Firma Bayer, Leverkusen, Deutschland) im Verhältnis 5:3. Die Medikamente wurden den Tieren in einer Dosierung von 0,1 ml pro $100 \mathrm{~g} \mathrm{KG}$ intraperitoneal verabreicht. Zunächst wurde, auf beiden Seiten, der Bereich zwischen Rippenbogen und Hinterläufen rasiert und desinfiziert, daraufhin erfolgte die Inzision der Haut und nach stumpfer Präparation bis zum Peritoneum wurde das Abdomen eröffnet. Es folgte die Darstellung der Ovarien, die Ligatur der Tubae uterinae und das Absetzen der Ovarien mittels Skalpell. Der operative Zugang wurde durch Naht der Muskulatur mit Vicryl 4.0 (Ethicon, Johnson \& Johnson, Norderstedt, Deutschland) und durch Hautklammern (Michel wound brackets 7,5 x 1,75 mm, Gebrüder Martin GmbH \& Co. KG, Tuttlingen, Deutschland) verschlossen. Postoperativ wurden die Tiere auf Wärmeplatten gelegt, bis zur Beendigung der Narkose überwacht und erhielten $3 \mathrm{ml} \mathrm{NaCl-Lösung} \mathrm{0,9 \%}$ subkutan als Depot zur Stabilisierung des Flüssigkeit- und Elektrolythaushaltes. 


\subsubsection{Behandlung mit Urocortin}

Die ovariektomierten Tiere entwickelten innerhalb von acht Wochen eine Osteoporose und wurden nun täglich über einen Zeitraum von 35 Tagen mit niedrig- und hochdosiertem Urocortin, gelöst in $300 \mu \mathrm{l}$ 0,9\% NaCl-Lösung, behandelt. Man injizierte die Flüssigkeit, abwechselnd links oder rechts, in das Subkutangewebe. Die Behandlungen wurden jeden Tag zum gleichen Zeitpunkt durchgeführt.

\subsubsection{Enzymhistochemie}

Eine Gewebsprobe, im vorliegenden Fall eine Muskelprobe, durchläuft für die Herstellung eines histologischen Präparats folgende Schritte:

1) Schneiden

2) Fixieren

3) Färben

Die zuvor tiefgefrorenen Präparate der Muskeln wurden in ein Mikrotom (Frigocut, 2800E, Leica Jung, Leica Biosystems, Nussloch, Deutschland) gespannt. Hier herrschte eine Temperatur von $-22^{\circ} \mathrm{C}$. Es wurden $12 \mu \mathrm{m}$ dünne Schnitte angefertigt. Auf einen $-18^{\circ} \mathrm{C}$ kalten Objektträger (SuperFrost Ultra Plus, Menzel Gläser, Braunschweig, Deutschland) wurden mehrere Schnitte aufgetragen und bei Raumtemperatur getrocknet. Nach einer Stunde wurden die Schnitte erneut tiefgefroren. Es wurde von jedem Muskel jeweils ein Objektträger für die Amylase-PAS-Färbung und einer für die ATPase-/Diaphorase-Färbung erstellt.

Im Folgenden werden die einzelnen Schritte der Färbungen erläutert.

In der Regel stammen die Chemikalien der Lösungen von der Firma Merck (Darmstadt, Deutschland). 


\subsubsection{Amylase-PAS-Färbung}

Um das Verhältnis der einzelnen Muskelfasern und ihrer Kapillaren zu bestimmen, wurde die Färbemethode nach Anderson aus dem Jahr 1975 genutzt.

\subsection{Rezeptur}

1) Fixierlösung:

$\begin{array}{ll}128 \mathrm{ml} & \text { Ethanol }(95-100 \%) \\ 24 \mathrm{ml} & \text { Chloroform } \\ 8 \mathrm{ml} & \text { Essigsäure (99\%) }\end{array}$

2) alpha-Amylase-Lösung:

$500 \mathrm{mg}$ alpha-Amylase (Sigma-Aldrich Laborchemikalien $\mathrm{GmbH}$, Taufkirchen, Deutschland)

$160 \mathrm{ml} \quad$ Aqua dest.

3) Perjodsäure:

$1,5 \mathrm{~g}$ Perjodsäure (Carl Roth $\mathrm{GmbH}$ \& Co. KG, Karlsruhe, Deutschland)

$150 \mathrm{ml} \quad$ Aqua dest.

4) Schiff's Reagenz:

fertig angemischt (Carl Roth GmbH \& Co. KG, Karlsruhe, Deutschland)

5) $\mathrm{SO}_{2}$-Wasser:

$600 \mathrm{ml} \quad$ Aqua dest.

$30 \mathrm{ml} \quad$ Kaliumdisulfit-Lösung $\left(\mathrm{K}_{2} \mathrm{~S}_{2} \mathrm{O}_{5}\right.$-Lösung 10\%ig)

$30 \mathrm{ml} \quad \mathrm{HCl}(1 \mathrm{~N})$ 


\subsection{Protokoll}

1) Fixation in Fixierlösung $1 \mathrm{~h}$ bei $4^{\circ} \mathrm{C}$ im Kühlschrank $10 \min$ bei $20-25^{\circ} \mathrm{C}$

2) Spülung in Aqua dest. (10x)

3) $25 \mathrm{~min}$ Inkubation bei $37^{\circ} \mathrm{C}$ in alpha-Amylase-Lösung

4) Spülung in Aqua dest. (10x)

5) 30 min Inkubation in $1 \%$ iger Perjodsäure

6) Spülung in Aqua dest. (10x)

7) 35 min Inkubation in Schiffs Reagenz

8) 30 min Inkubation in $\mathrm{SO}_{2}$-Wasser

9) 10 min Spülung unter fließendem Leitungswasser

10) 3 min Spülung in Aqua dest. 


\subsubsection{ATPase-/Diaphorase-Färbung}

Die einzelnen Typen der Muskelfasern (fast glycolytic, fast oxidative glycolytic, slow oxidative) wurden durch die ATPase-/Diaphorase-Färbung nach Horak aus dem Jahr 1983 ausgewertet.

\subsection{Rezeptur}

1) Fixierlösung (pH-Wert 6,3 6,6 kurz vor Gebrauch einstellen):

$1,5 \mathrm{~g}$ Paraformaldehyd (Carl Roth $\mathrm{GmbH} \&$ Co. KG, Karlsruhe, Deutschland)

$3 \mathrm{~g} \quad \mathrm{CaCl}_{2}$ (-6Hydrat) (Sigma-Aldrich Laborchemikalien $\mathrm{GmbH}$, Taufkirchen, Deutschland)

$9 \mathrm{~g}$ Saccharose oder Dextran (AppliChem $\mathrm{GmbH}$, Darmstadt, Deutschland)

$150 \mathrm{ml} \quad$ Aqua dest.

2) Diaphorase-Inkubationslösung (Aufbewahrung im Kühlschrank):

$20 \mathrm{mg}$ NADH-Dinatriumsalz (AppliChem GmbH, Darmstadt, Deutschland)

$3,2 \mathrm{ml} \quad$ Phosphatpuffer $(0,1 \mathrm{M} ; \mathrm{pH} 7,4)$

$4 \mathrm{ml} \quad$ Nitro-BT (Carl Roth $\mathrm{GmbH} \&$ Co. KG, Karlsruhe, Deutschland)

$4,8 \mathrm{ml} \quad$ Aqua dest.

3) saure Vorinkubationslösung ( $\mathrm{pH}-$ Wert 4,2 kurz vor Gebrauch einstellen):

$15 \mathrm{ml} \quad \mathrm{CaCl}_{2}$-Stammlösung

$0,6 \mathrm{ml} \quad$ konzentrierte Essigsäure (Eisessig)

$135 \mathrm{ml}$ Aqua dest. 
4) Tris- $\mathrm{CaCl}_{2}-\mathrm{Lösung} \mathrm{(pH-Wert} \mathrm{7,8} \mathrm{kurz} \mathrm{vor} \mathrm{Gebrauch} \mathrm{einstellen):}$

$1,82 \mathrm{~g} \quad$ Tris (Tris-(hydroxymethyl)-aminomethan 99,9\%, $M=121,14 \mathrm{~g} / \mathrm{mol}$ ) (Carl Roth $\mathrm{GmbH} \&$ Co. KG, Karlsruhe, Deutschland)

$15 \mathrm{ml} \quad \mathrm{CaCl}_{2}$-Stammlösung

$135 \mathrm{ml} \quad$ Aqua dest.

5) ATPase-Inkubationslösung (Aufbewahrung im Trockenschrank bei $37^{\circ} \mathrm{C}$, pH-Wert 9,4 kurz vor Gebrauch einstellen):

$555 \mathrm{mg} \quad \mathrm{KCl}(\mathrm{M}=75 \mathrm{~g} / \mathrm{mol})$

$228 \mathrm{mg} \quad$ ATP $(\mathrm{M}=551,2 \mathrm{~g} / \mathrm{mol})$ (Carl Roth $\mathrm{GmbH}$ \& Co. KG, Karlsruhe, Deutschland)

$135 \mathrm{ml} \quad$ Glycinpuffer

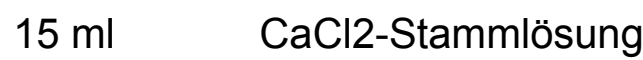

6) Kobaltchlorid-Lösung:

$3 \mathrm{~g}$ Kobaltchlorid $\left(\mathrm{CoCl}_{2} \times 6 \mathrm{H}_{2} \mathrm{O}\right)$ (AppliChem $\mathrm{GmbH}$, Darmstadt, Deutschland)

$150 \mathrm{ml} \quad$ Aqua dest.

7) Ammoniumsulfid-Lösung (Herstellung unter dem Abzug):

0,3 $\mathrm{ml} \quad$ Ammoniumsulfid

$150 \mathrm{ml} \quad$ Aqua dest.

8) Phosphatpuffer $(0,1 \mathrm{M}$; $\mathrm{pH} 7,4)(\mathrm{pH}$-Wert Einstellung mit Lösung 1 zum sauren Bereich, mit Lösung 2 zum alkalischen Bereich):

Lösung 1: $\quad 0,1 \mathrm{M} \quad$ prim. Natriumphosphat

$18,8 \mathrm{~g} \quad \mathrm{NaH}_{2} \mathrm{PO}_{4} \times \mathrm{H}_{2} \mathrm{O}$ oder

$15,6 \mathrm{~g} \quad \mathrm{NaH}_{2} \mathrm{PO}_{4} \times 2 \mathrm{H}_{2} \mathrm{O}$ mit

Aqua dest. auf 11 auffüllen. 


$\begin{array}{lll}\text { Lösung 2: } & \begin{array}{l}0,1 \mathrm{M} \\ 35,82 \mathrm{~g}\end{array} & \begin{array}{l}\text { sek. Natriumphosphat } \\ \mathrm{NaHPO}_{4} \times 12 \mathrm{H}_{2} \mathrm{O} \text { mit } \\ \text { Aqua dest. auf 1l auffüllen. }\end{array} \\ & & \begin{array}{l}\text { Lösung 1 } \\ \text { Ansatz: }\end{array} \\ & \begin{array}{l}15,9 \mathrm{ml} \\ 84,1 \mathrm{ml}\end{array} & \text { Lösung 2 }\end{array}$

9) Nitro-BT-Stammlösung:

$40 \mathrm{mg} \quad$ Nitro-BT (Nitro-blaues Tetrazoliumchlorid (Konz. $1 \mathrm{mg} / \mathrm{ml}$ )) $40 \mathrm{ml} \quad$ Aqua dest.

10) $\mathrm{CaCl}_{2}$-Stammlösung (Sigma-Aldrich Laborchemikalien $\mathrm{GmbH}$, Taufkirchen, Deutschland):

$4,99 \mathrm{~g} \quad \mathrm{CaCl}_{2}(\mathrm{M}=111 \mathrm{~g} / \mathrm{mol})$ mit Aqua dest. auf $250 \mathrm{ml}$ auffüllen.

11) $\mathrm{CaCl}_{2}$-Waschlösung (Sigma-Aldrich Laborchemikalien $\mathrm{GmbH}$, Taufkirchen, Deutschland):

$7,5 \mathrm{~g} \quad \mathrm{CaCl}_{2}(\mathrm{M}=111 \mathrm{~g} / \mathrm{mol})$ mit Aqua dest. auf $1 \mathrm{l}$ auffüllen.

12) Glycin-Stammlösung ( $\mathrm{pH}-$ Wert auf 9,4 einstellen) (AppliChem $\mathrm{GmbH}$, Darmstadt, Deutschland):

$7,51 \mathrm{~g} \quad$ Glycin $(98 \%, \mathrm{M}=75,07 \mathrm{~g} / \mathrm{mol})$ mit Aqua dest. auf $250 \mathrm{ml}$ auffüllen

13) Glycinpuffer ( $\mathrm{pH}$-Wert auf 9,4 einstellen) (AppliChem $\mathrm{GmbH}$, Darmstadt, Deutschland):

$125 \mathrm{ml} \quad$ Glycin-Stammlösung

$42 \mathrm{ml} 0,4 \mathrm{M} \mathrm{NaOH}(8 \mathrm{~g} / 500 \mathrm{ml}) \mathrm{mit}$ Aqua dest. auf $500 \mathrm{ml}$ auffüllen. 


\subsection{Protokoll}

1) Fixierung für $1 \mathrm{~min}(\mathrm{pH} 6,3-6,6)$

2) zweimalige Spülung in Aqua dest. für jeweils 5 min

3) Diaphorase-Inkubation bei $37^{\circ} \mathrm{C}$ für $60 \mathrm{~min}$

4) Spülung in Aqua dest. für 15 min

5) saure Vorinkubation für $15 \min \left(\mathrm{pH}_{4,2}\right)$

6) Inkubation in Tris- $\mathrm{CaCl}_{2}$-Lösung für $2 \min (\mathrm{pH} 7,8)$

7) ATPase Inkubationslösung bei $37^{\circ} \mathrm{C}$ für $30 \mathrm{~min}(\mathrm{pH} \mathrm{9,4)}$

8) dreimalige Reinigung in $\mathrm{CaCl}_{2}$-Waschlösung für jeweils 30 sek

9) Inkubation in Kobaltchlorid-Lösung für $1-2$ min

10) dreimalige Spülung in Aqua dest. für jeweils 45 sek

11) Inkubation in Ammoniumsulfid-Lösung unter dem Abzug für 1-2 min

12) Spülung unter fließendem Leitungswasser für 10 min

13) Spülung in Aqua dest. für 5 min 


\subsection{Versuchsauswertung}

\subsubsection{Mikroskopie}

Nachdem die einzelnen Präparate gefärbt worden waren, begutachtete man sie unter dem Mikroskop (Eclipse E 6000, Nikon) und beurteilte sie anhand von Bildern. Die Fotos wurden mit einer Digitalkamera (DVC 1301, DVC Company), die an den Computer gekoppelt ist, ausgewertet. Für diese Arbeit nutzte man die Bildanalyse-Software Lucia G (Version 4.82, Laboratory Imaging). Die einzelnen Schnitte der Präparate wurden mithilfe des Mikroskops richtig eingestellt und als Bilder auf dem Computer gespeichert, sodass sie im Nachhinein vom Untersucher ausgewertet werden konnten. Man wusste bei dieser Arbeit nicht, zu welcher Versuchsgruppe das jeweilige Bild bzw. das Präparat gehörte, sodass hier ein Blindversuch stattfand.

\subsubsection{Auswertung Amylase-PAS-Färbung}

Bei der Auswertung des Verhältnisses von Kapillaren zu Muskelfasern wurden zwei Rahmen auf die Präparateausschnitte gelegt (Abb. 5). Die Größe der Rahmen wurde mit 500 × $500 \mu \mathrm{m}$ festgelegt. Hier wurde erneut mit der Bildanalyse-Software Lucia G (Version 4.82, Laboratory Imaging) gearbeitet. Die Auswertung bestand darin, die Anzahl der Muskelfasern und ihrer Kapillaren innerhalb des Messrahmens zu erfassen. Diese Werte wurden dann in die folgende Formel eingefügt:

Verhältnis Kapillaren zu Muskelfasern = Anzahl Kapillaren / Anzahl Muskelfasern

Somit konnte das Verhältnis von Kapillaren zu Muskelfasern berechnet werden. 


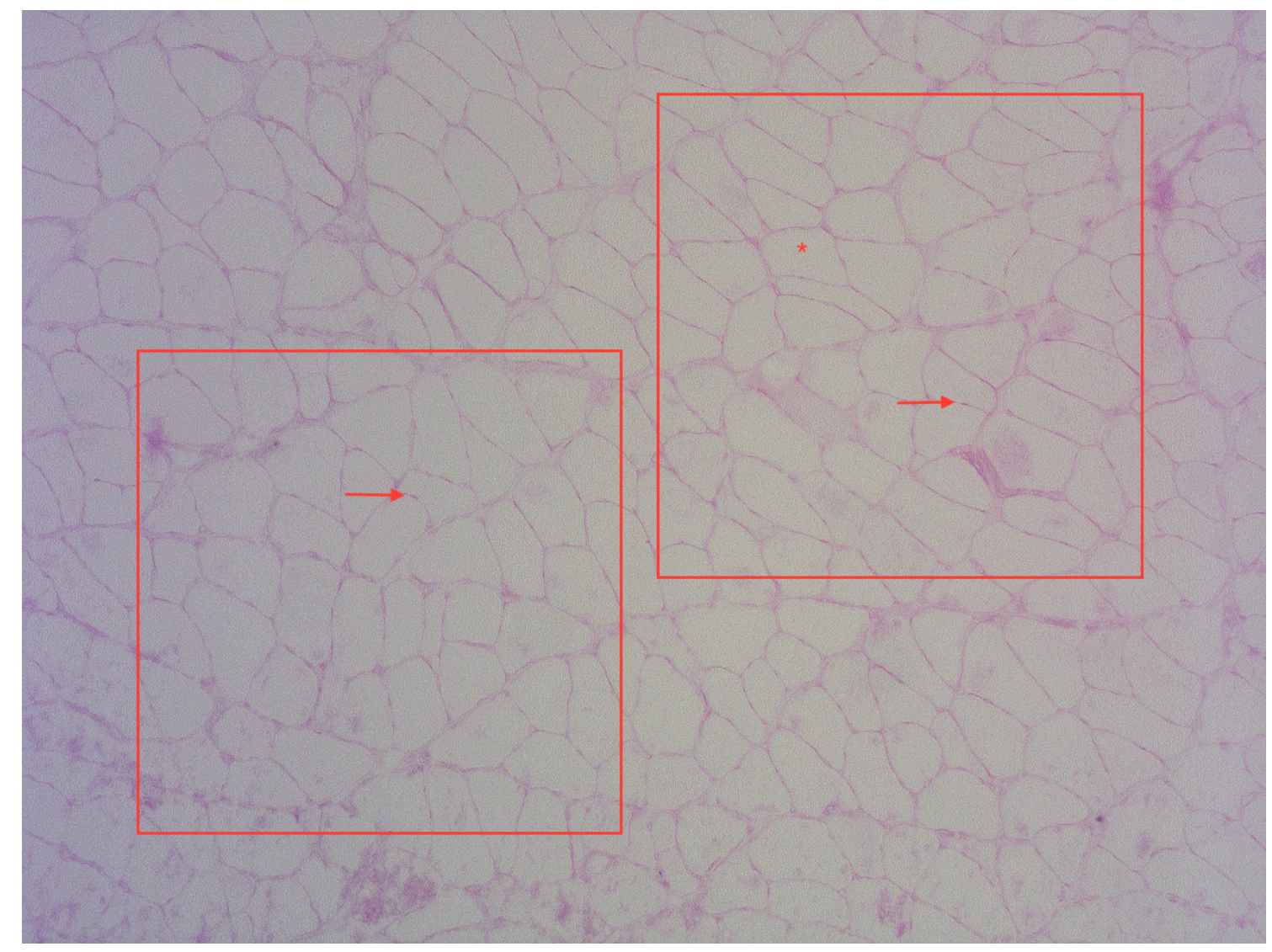

Abb. 5: Präparatausschnitt der Amylase-PAS-Färbung mit zwei aufgelegten Messrahmen zur Auswertung des Verhältnisses der Kapillaren zu den Muskelfasern (*: Anschnitt einer Muskelfaser des M. soleus; Pfeil: Anschnitt einer Kapillare)

\subsubsection{Auswertung ATPase-/Diaphorase-Färbung}

Hier wurde der Durchmesser und die Querschnittsfläche von Fasern des M. soleus, des M. gastrocnemius und des M. Iongissimus ausgewertet. Um diese Parameter zu bestimmen, wurden die einzelnen Zellen im Präparat am Computer vom Untersucher umrandet und durch die Bildanalyse-Software Lucia $G$ automatisch errechnet. Es sollten von jedem Präparat drei Ausschnitte ausgewertet werden. Im M. soleus kommen ausschließlich oxidative Fasern vor (Hoppeler 1986), sodass man in den Präparaten dieses Muskels jeweils 30 Fasern vom Typ slow oxidative (SO) und 30 Fasern vom Typ fast oxidative glykoIytic (FOG) untersuchte, also 60 Fasern pro Ausschnitt. Beim M. gastrocnemius und M. longissimus wurde der Durchmesser und die Querschnittsfläche von allen drei Fasertypen (SO-Fasern, FOG-Fasern und FG-Fasern) gemessen (Abb. 6), sodass man hier also 90 Fasern pro Ausschnitt untersuchte. Für spä- 
tere Analysen wurde der Mittelwert des Durchmessers sowie der Querschnittsflächen erstellt.

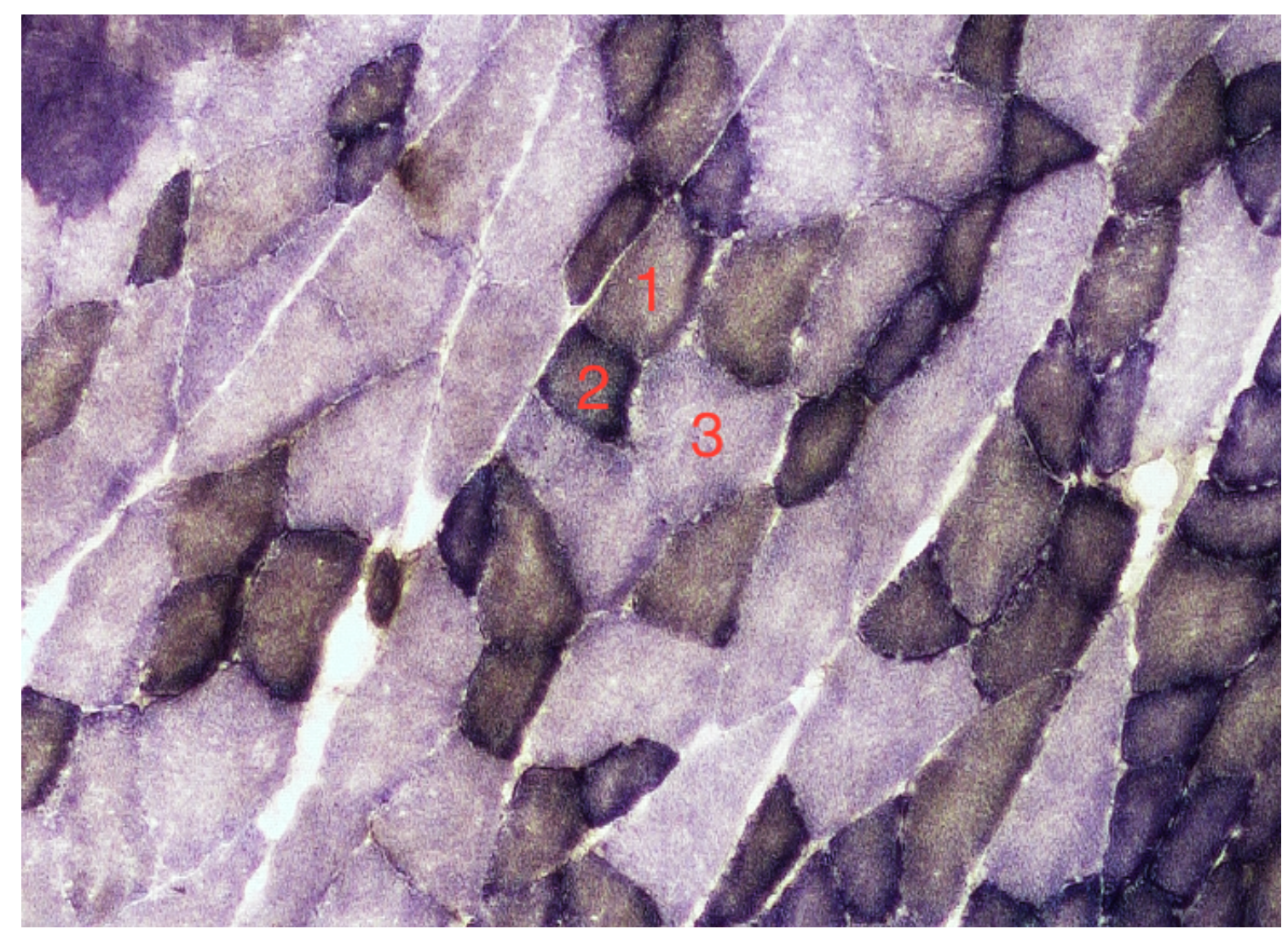

Abb. 6: Präparatausschnitt der ATPase-Diaphorase-Färbung zur Auswertung der Querschnittsflächen und der Durchmesser von FG-, FOG- und SO-Fasern (Anschnitt des M. gastrocnemius; 1: fast oxidative glycolytic (FOG)-Faser; 2: slow oxidative (SO)Faser; 3: fast glycolytic (FG)-Faser)

\subsection{Statistik}

Als Programm für die statistische Auswertung und die graphische Darstellung der Daten im Ergebnisteil diente GraphPad Prism (Version 6, GraphPad Software Inc., San Diego, USA). Die gewonnenen Daten wurden zunächst durch eine Varianzanalyse (one Way ANOVA) auf signifikante Unterschiede zwischen den Versuchsgruppen geprüft. Dabei wurde der Mittelwert jeder Gruppe mit dem Mittelwert jeder anderen Gruppe verglichen. Anschließend untersuchte man die Daten mittels eines Tukey-Kramer-post-hoc-Test. Darüber hinaus wurde für alle Ergebnisse der Mittelwert und die Standardabweichung berechnet. Als Signifikanzniveau galt ein $p$-Wert $\alpha<0,05$. 


\section{Ergebnisse}

Im folgenden Kapitel werden die Ergebnisse der experimentellen Versuche vorgestellt. Um Signifikanzen zwischen den Versuchsgruppen hervorzuheben, werden folgende Symbole verwendet:

* = signifikant zu SHAM

\# = signifikant zu OVX

${ }^{\circ}=$ signifikant zu OVX + UCN low

$\S=$ signifikant zu OVX + UCN high

$\wedge=$ signifikant zu OVX + Estradiol

$\&=$ signifikant zu allen anderen Gruppen

Die Darstellung der Ergebnisse erfolgt durch Säulendiagramme und Tabellen, in denen der jeweilige Mittelwert und die Standardabweichung der Versuchsgruppen abgebildet ist. Das Signifikanzniveau ist hier $p<0,05$.

\subsection{Futteraufnahme der Ratten im Verlauf}

Die Tiere der Gruppe SHAM fressen zu Beginn bzw. in den ersten Wochen des Versuches weniger als die ovariektomierten Tiere. Zwischen der 8. und der 9. Woche gibt es keine signifikanten Unterschiede bezüglich der Futteraufnahme der Tiere aller Gruppen. Die Futteraufnahme aller Tiere sinkt nach Beginn der Behandlung. Vor allem die Ratten der Gruppen OVX + Estradiol nehmen ab der 10. Woche signifikant weniger Nahrung zu sich. In der letzten Woche nimmt die Nahrungsaufnahme der Tiere dieser Gruppe wieder deutlich zu. In den letzten drei Wochen steigt die Futteraufnahme der Gruppe OVX + UCN high wieder an. Insbesondere diese Gruppe weist einen signifikant höheren Futterverbrauch 
gegenüber den restlichen Gruppen auf (Abb. 7, Tab. A-1). Das verbrauchte Futter wurde jeweils am Ende einer Versuchswoche berechnet.

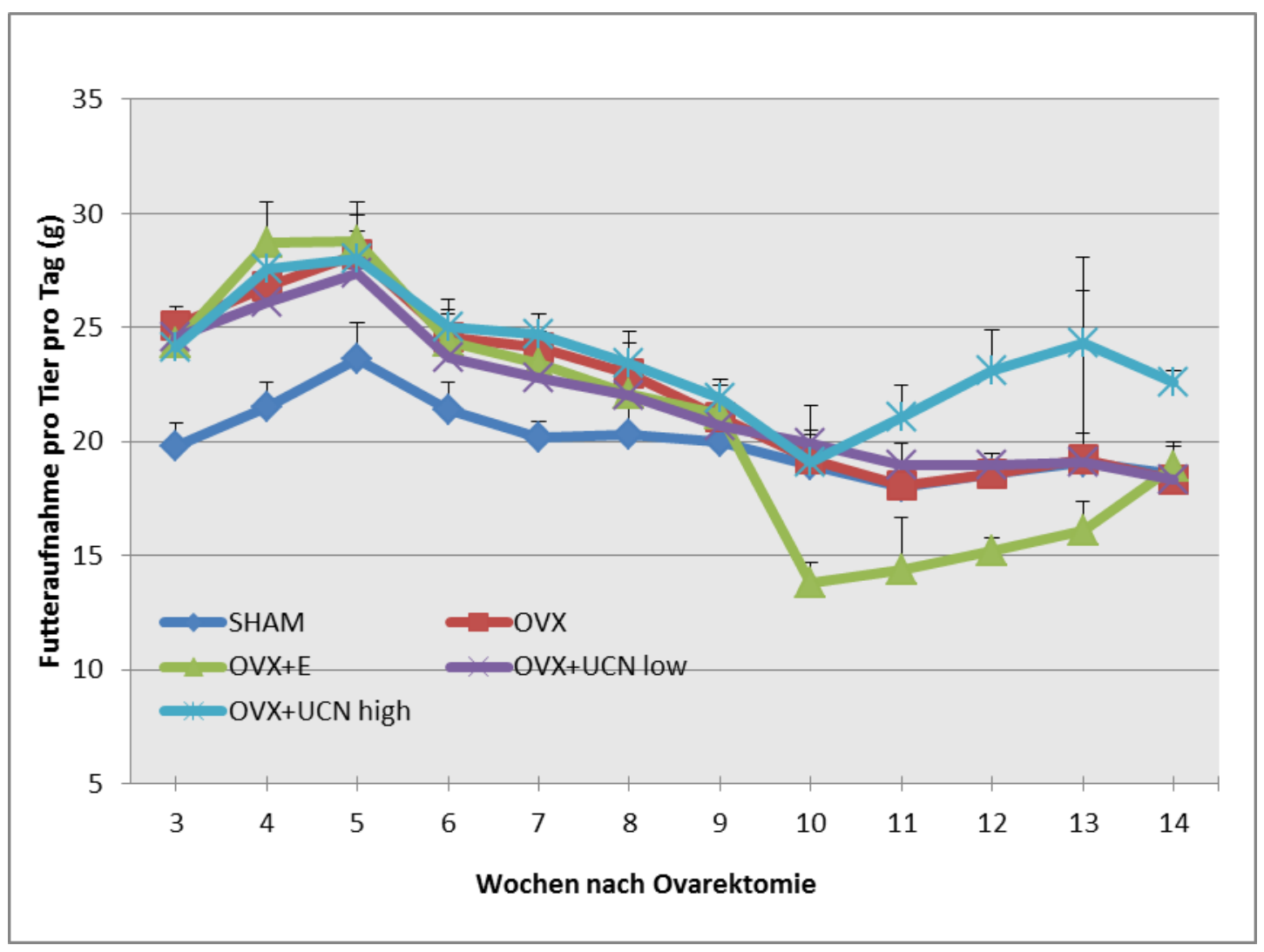

Abb. 7: Futteraufnahme der Tiere über den gesamten Versuchszeitraum in Gramm 


\subsection{Gewicht der Ratten im Verlauf}

Die Tiere wurden am Anfang einer Woche gewogen. Das Körpergewicht der Ratten war zu Beginn des Experiments nahezu gleich. Der Mittelwert betrug $266 \pm 12$ g. Zwei Wochen nach der Ovariektomie steigt das Gewicht der Tiere an. In der 9. Woche sinkt das Körpergewicht der mit Estradiol gefütterten Ratten und verändert sich danach nicht mehr. Die Gruppen SHAM und OVX + Estradiol weisen ab der 10. Woche ähnliche Körpergewichte auf. Die Tiere der Gruppe OVX, OVX + UCN low und OVX + UCN high haben in den letzten vier Wochen ein signifikant höheres Gewicht als die der Gruppe SHAM und der Gruppe OVX + Estradiol (Abb. 8, Tab. A-2).

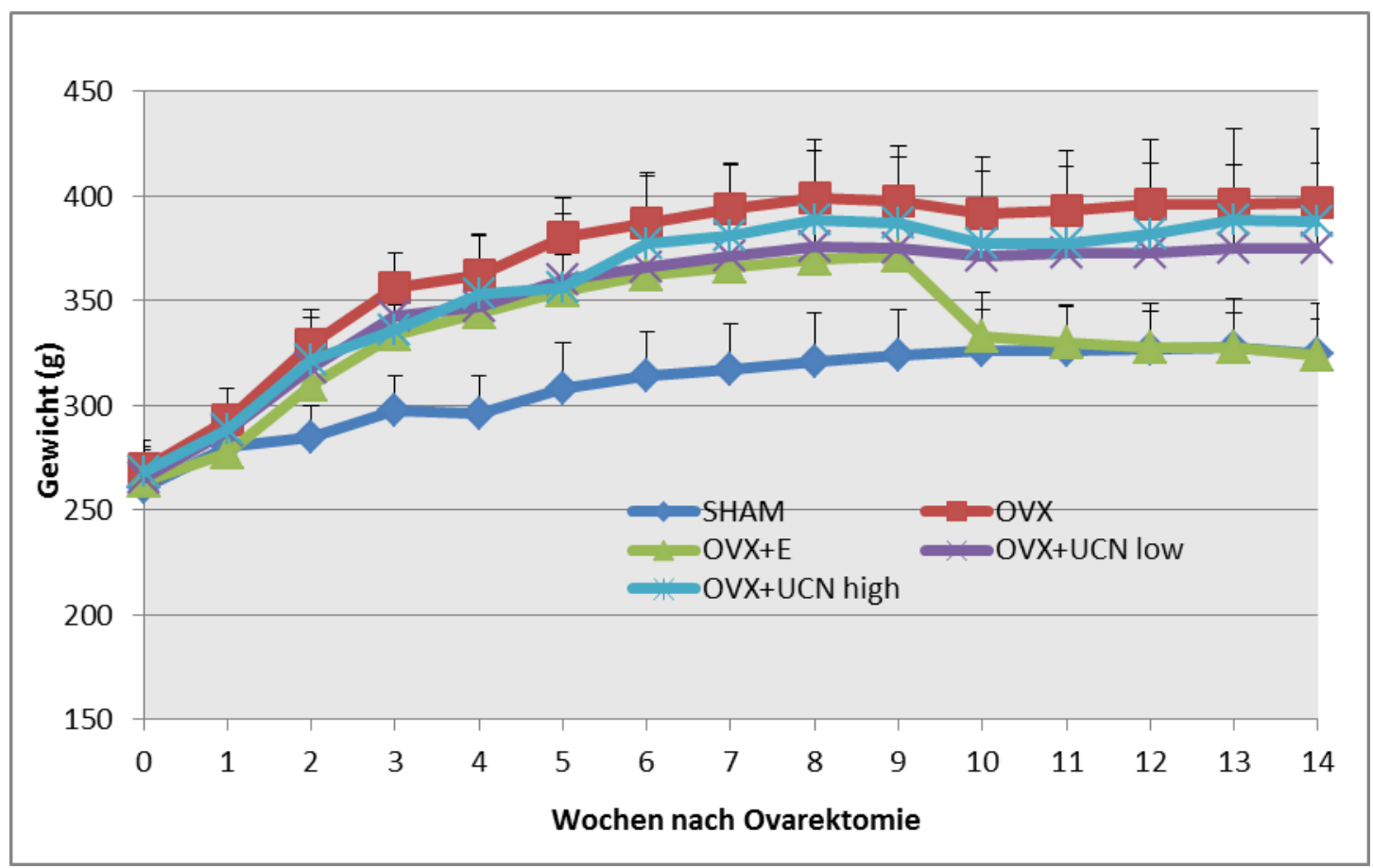

Abb. 8: Entwicklung des Körpergewichts der Tiere im Verlauf

\subsection{Uterusgewicht der Ratten im Verlauf}

Am Tag der Tötung wurde das Gewicht des Uterus von jedem Tier bestimmt. Das Uterusgewicht der Gruppen SHAM und OVX + Estradiol war signifikant höher als in den Gruppen OVX, OVX + UCN low und OVX + UCN high, wobei 
die Gruppe OVX + Estradiol niedrigere Werte aufweisen, als die Gruppe SHAM (Tab. A-3).

\subsection{Ergebnisse der histologischen Untersuchungen}

\subsubsection{Ergebnisse der Amylase-PAS-Färbung}

\subsubsection{M. soleus}

Zwischen den Gruppen konnten bezüglich des Verhältnisses von Kapillaren und Muskelfasern signifikante Unterschiede festgestellt werden (Abb. 9, Tab. A-4). Der höchste Wert findet sich in der Gruppe OVX + UCN high und ist gegenüber der Gruppe OVX + UCN low signifikant. Die niedrigsten Werte erhält man in den Gruppen OVX + UCN low und SHAM. Die Gruppen OVX und OVX + Estradiol weisen ähnliche Mittelwerte auf. Es lassen sich keine weiteren Signifikanzen beobachten.

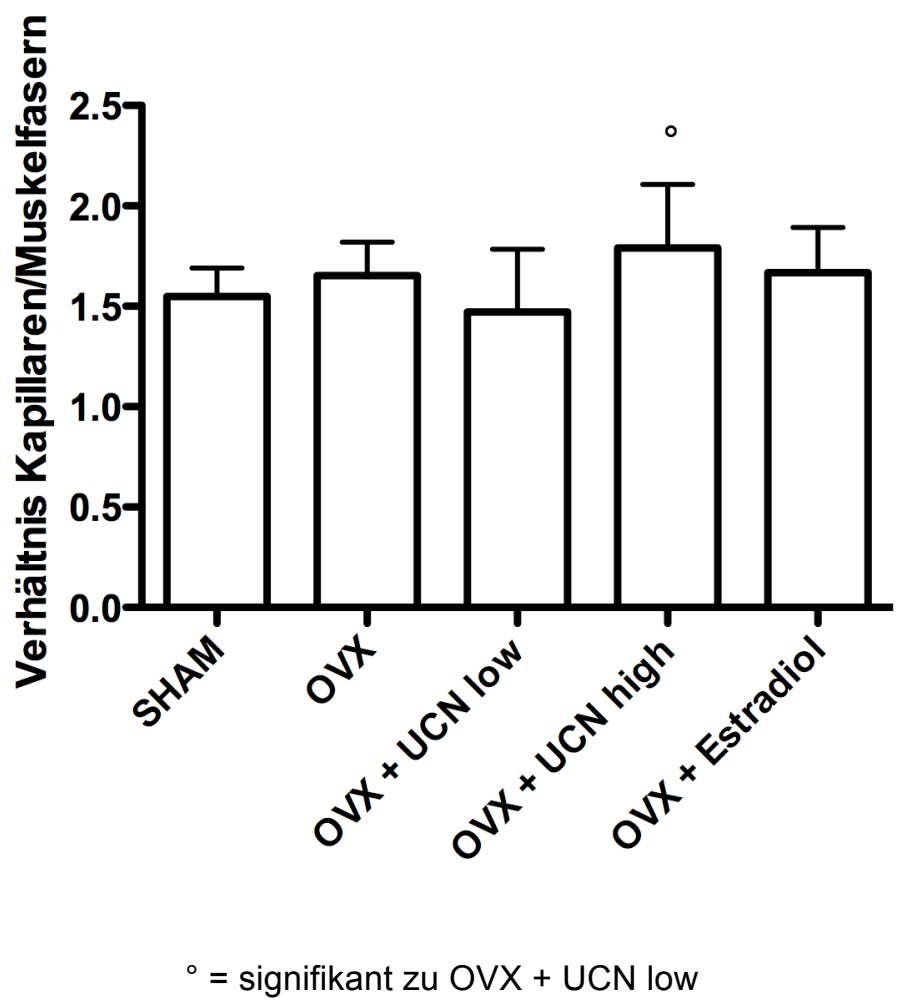

Abb. 9: Verhältnis der Kapillaren zu den Muskelfasern, M. soleus 


\subsubsection{M. gastrocnemius}

Die Auswertung der Kapillarfärbung des M. gastrocnemius zeigt, dass der höchste Wert in der Gruppe OVX + Estradiol besteht. Allerdings gibt es insgesamt keine signifikanten Unterschiede zwischen den Gruppen. Das Verhältnis zwischen Kapillaren und Muskelfasern liegt über alle Gruppen hinweg bei einem Mittelwert zwischen 1,147 und 1,539 (Abb. 10, Tab. A-5).

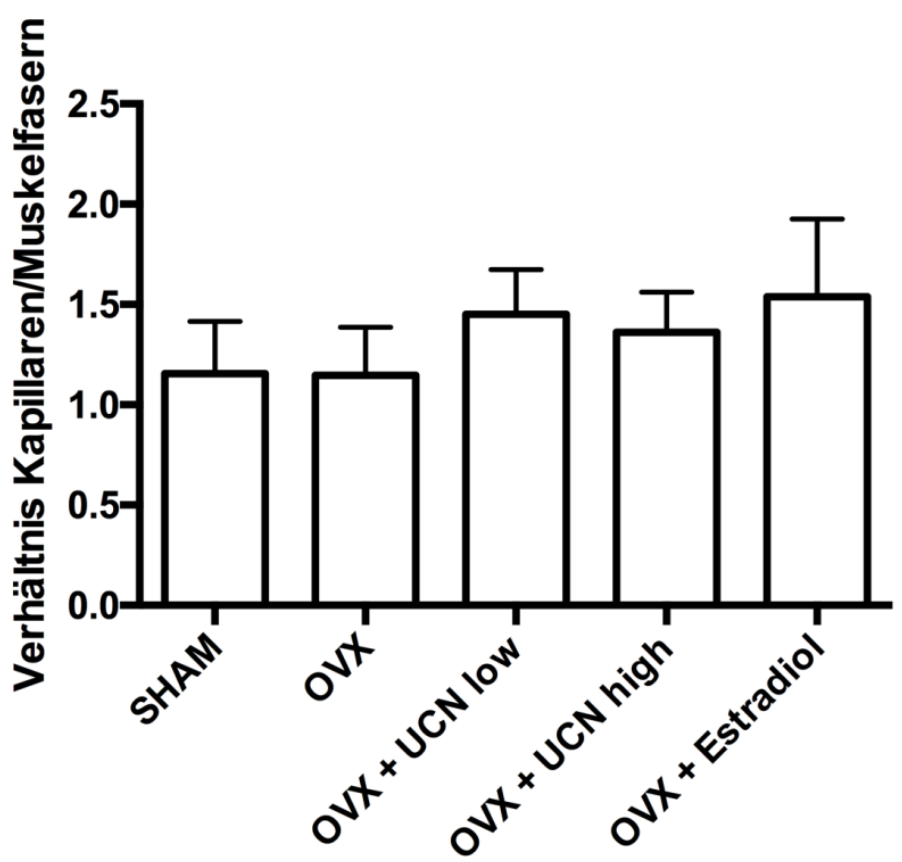

Abb. 10: Verhältnis Kapillaren zu Muskelfasern, M. gastrocnemius 


\subsubsection{M. longissimus}

Bei der Analyse des M. longissimus konnten keine signifikanten Unterschiede zwischen den fünf Gruppen festgestellt werden. Auffällig ist nur, dass die Gruppe OVX + UCN low einen niedrigeren Mittelwert als die restlichen Gruppen hat. (Abb. 11, Tab. A-6).

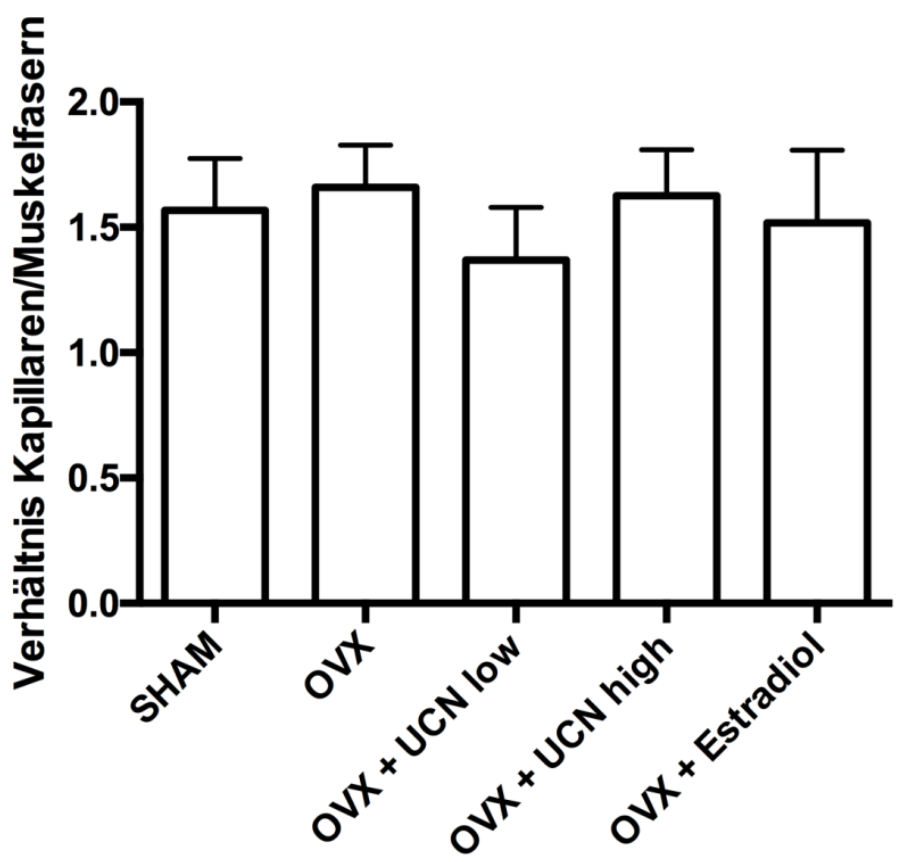

Abb. 11: Verhältnis Kapillaren zu Muskelfasern, M. longissimus 


\subsubsection{Ergebnisse der ATPase-/Diaphorase-Färbung}

\subsubsection{M. soleus}

\subsection{SO- und FOG-Fasertyp}

In der Auswertung des Faserdurchmessers des M. soleus zeigt sich ein deutlich erhöhter Wert in der Gruppe OVX + UCN high. Hier besteht eine Signifikanz gegenüber den restlichen Gruppen SHAM, OVX, OVX + UCN low und OVX + Estradiol. Die Gruppe OVX hat mit 59,9 $\mu \mathrm{m}$ zwar den niedrigsten Mittelwert, weist aber die größte Standardabweichung auf. (Abb. 12, Tab. A-7).

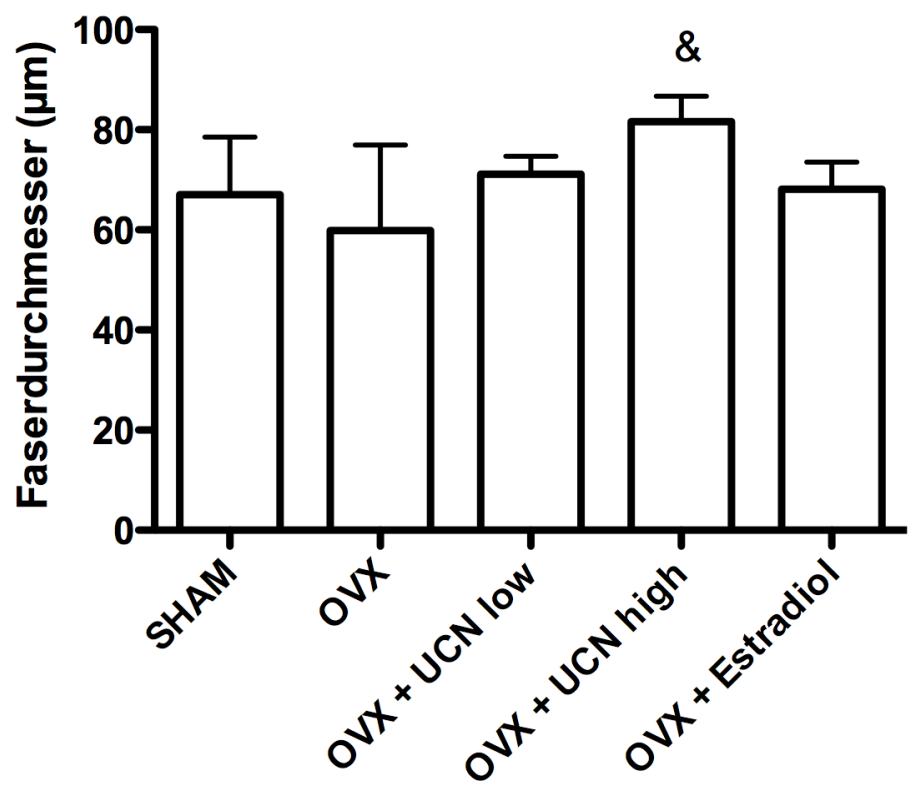

$\&=$ signifikant zu allen anderen Gruppen

Abb. 12: Faserdurchmesser der SO- und FOG-Fasern, M. soleus 
Der höchste Wert bezüglich der Faserquerschnittsfläche des $M$. soleus lässt sich hier ebenfalls der Gruppe OVX + UCN high zuordnen. Bei der Betrachtung der Graphen fällt auf, dass sich dieser Wert deutlich von den anderen Gruppen abhebt. Er ist signifikant erhöht gegenüber den Werten aller anderen Gruppen: SHAM, OVX, OVX + UCN low und OVX + Estradiol. Ansonsten konnten keinerlei Signifikanzen festgestellt werden. Auch hier zeigt die Gruppe OVX den niedrigsten Wert sowie die größte Standardabweichung. (Abb. 13, Tab. A-8).

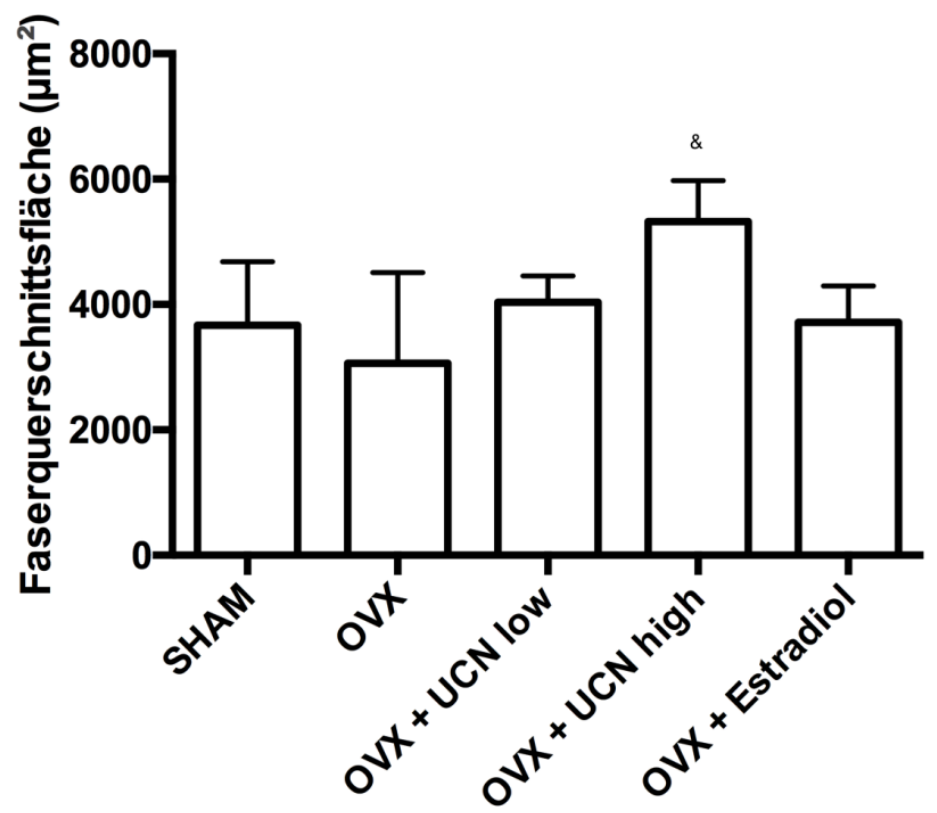

$\&=$ signifikant zu allen anderen Gruppen

Abb. 13: Faserquerschnittsfläche der SO- und FOG-Fasern, M. soleus 


\subsubsection{M. gastrocnemius}

\subsection{SO- und FOG-Fasertyp}

Zwischen den fünf Gruppen konnten keine signifikanten Unterschiede festgestellt werden (Abb. 14, Tab. A-9). Betrachtet man die Werte der einzelnen Gruppen, fällt jedoch auf, dass sich der größte Mittelwert in der Gruppe OVX + UCN high findet. Die Mittelwerte der restlichen Gruppen unterscheiden sich nur geringfügig voneinander.

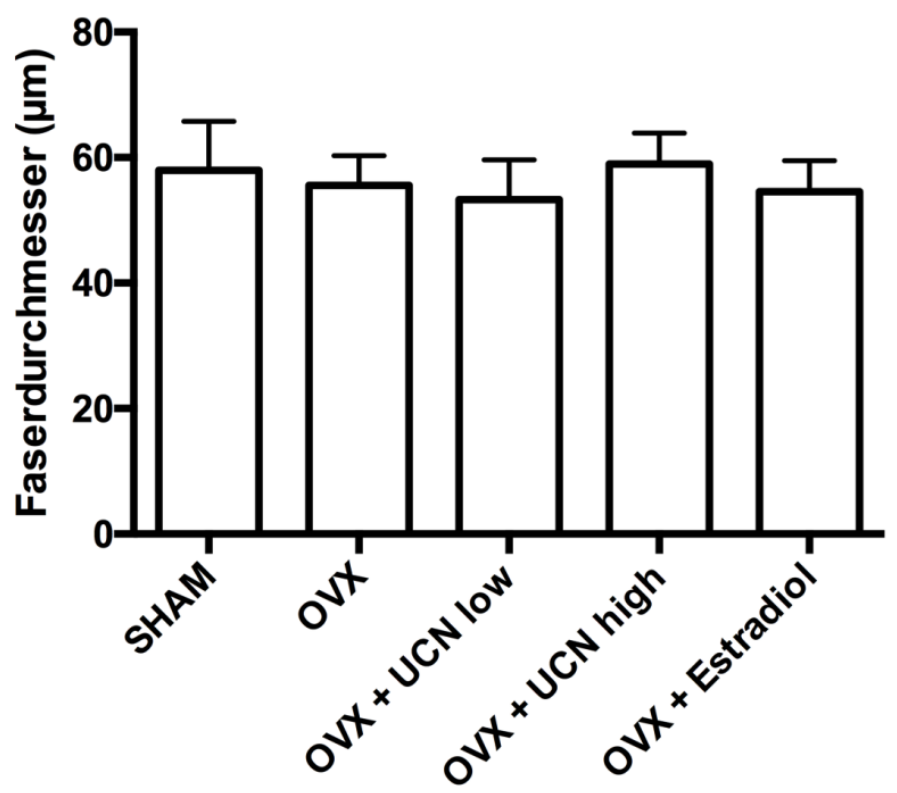

Abb. 14: Faserdurchmesser der SO- und FOG-Fasern, M. gastrocnemius 
Zwischen den Gruppen konnten keine signifikanten Unterschiede festgestellt werden (Abb. 15, Tab. A-10). Hier zeigt sich der höchste Wert wieder in der Gruppe OVX + UCN high, dicht gefolgt von der Gruppe SHAM. Die Mittelwerte der übrigen Gruppen weisen keine erhöhte Diskrepanz auf.

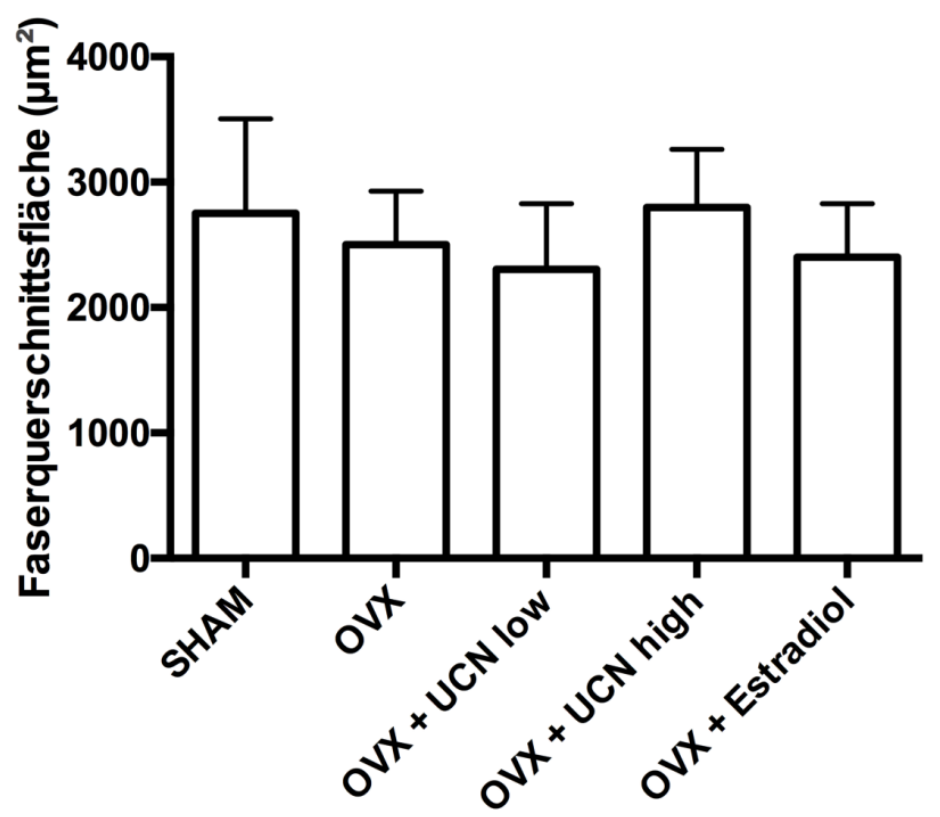

Abb. 15: Faserquerschnittsfläche der SO- und FOG-Fasern, M. gastrocnemius 


\subsection{FG-Fasertyp}

Zwischen den Gruppen konnten keine signifikanten Unterschiede festgestellt werden (Abb. 16, Tab. A-11). Die Mittelwerte der einzelnen Gruppen unterscheiden sich nur minimal.

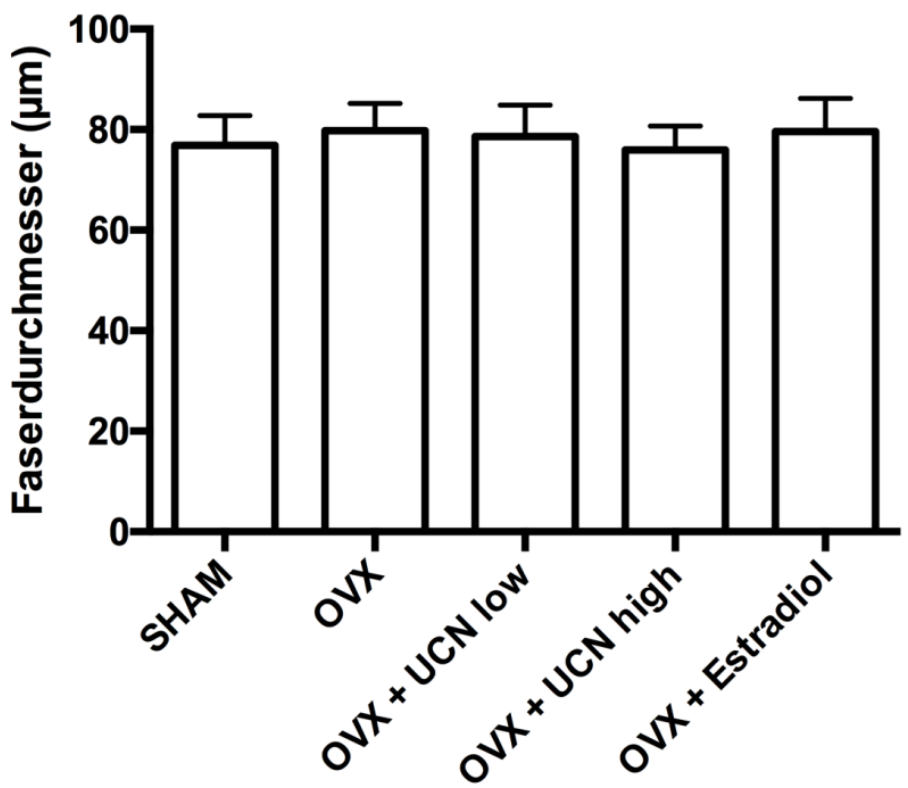

Abb. 16: Faserdurchmesser der FG-Fasern, M. gastrocnemius 
Auch bei der Faserquerschnittsfläche konnten zwischen den Gruppen keine signifikanten Unterschiede festgestellt werden (Abb. 17, Tab. A-12). Die Werte der einzelnen Gruppen unterscheiden sich erneut sehr wenig. Der kleinste Mittelwert ist in der Gruppe OVX + UCN high mit $4585 \mu m^{2}$ zu finden. Den größten Mittelwert weist die Gruppe OVX + Estradiol auf.

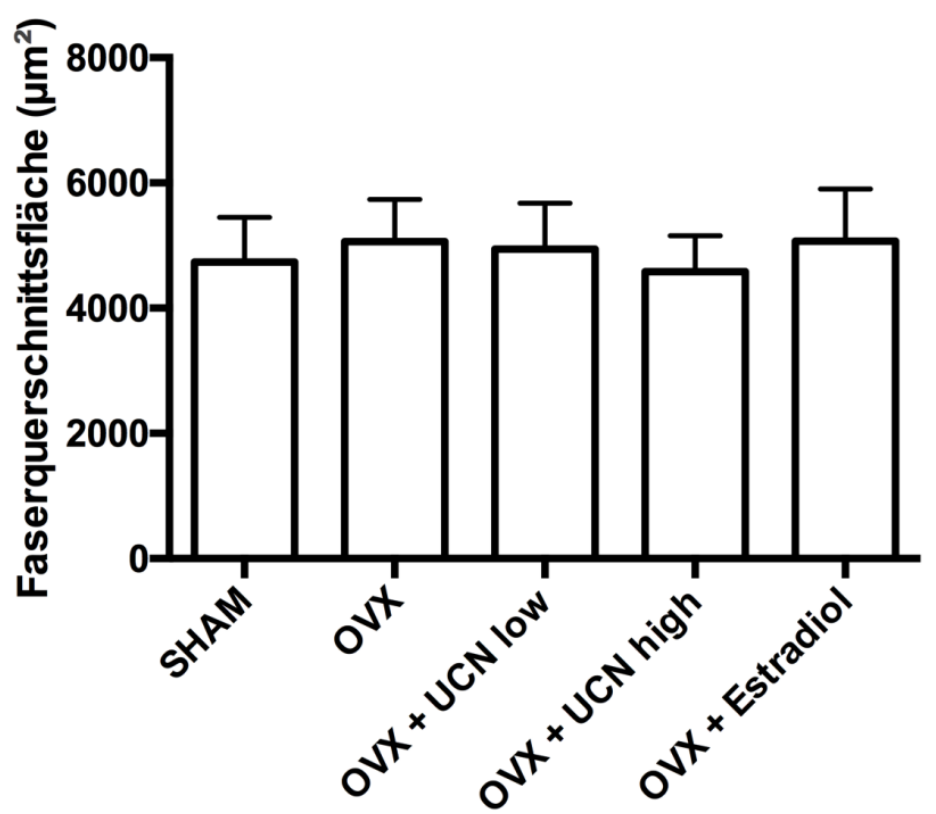

Abb. 17: Faserquerschnittsfläche der FG-Fasern, M. gastrocnemius 


\subsubsection{M. longissimus}

\subsection{SO- und FOG-Fasertyp}

Zwischen den Gruppen konnte ein signifikanter Unterschied festgestellt werden (Abb. 18, Tab. A-13). Die Gruppe OVX + UCN low tendiert zu einem höheren Wert als die restlichen Gruppen. Hier besteht eine Signifikanz gegenüber der Gruppe OVX + Estradiol. Zusätzlich ist zu erwähnen, dass die Standardabweichung der Gruppe OVX + UCN low im Vergleich zu den anderen Gruppen etwas höher liegt.

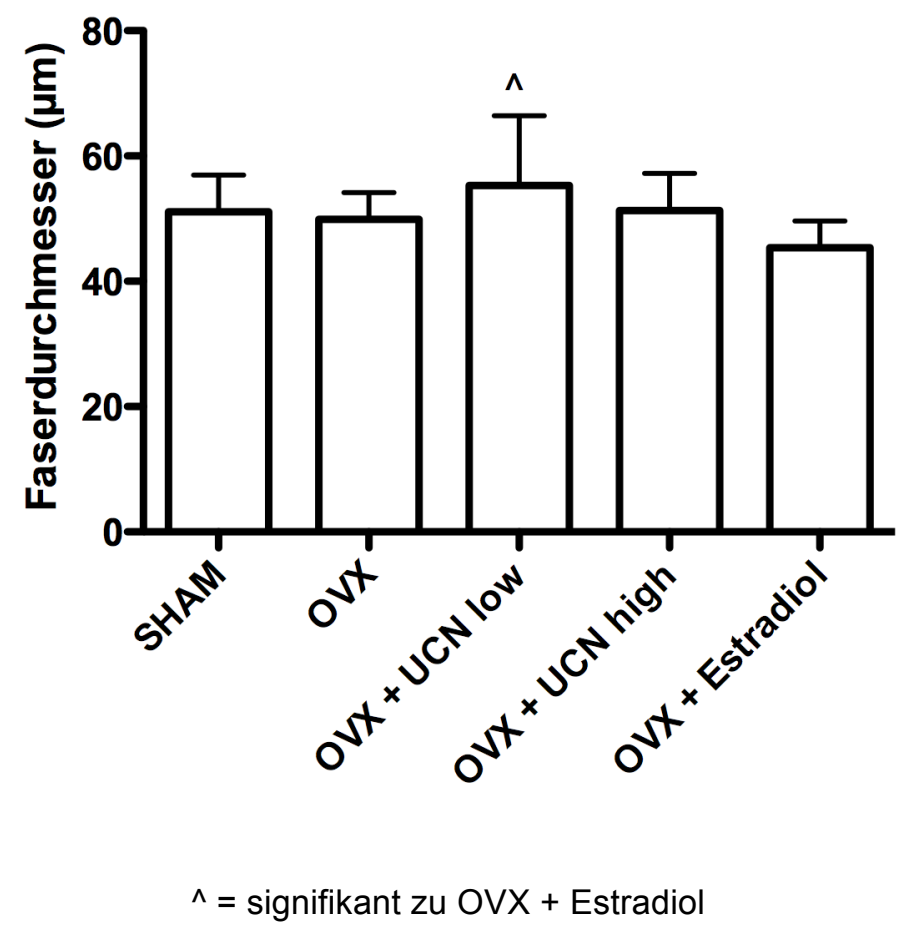

Abb. 18: Faserdurchmesser der SO- und FOG-Fasern, M. longissimus 
Die Gruppe OVX + UCN low weist einen höheren Wert als die anderen Gruppen auf (Abb. 19, Tab. A-14). Es besteht ein signifikanter Unterschied zu der Gruppe OVX + Estradiol, die den geringsten Mittelwert besitzt. Auch hier fällt auf, dass die Standardabweichung der Gruppe OVX + UCN low deutlich höher ausfällt. Die anderen Gruppen zeigen wenig Unterschiede bezügliche der Mittelwerte.

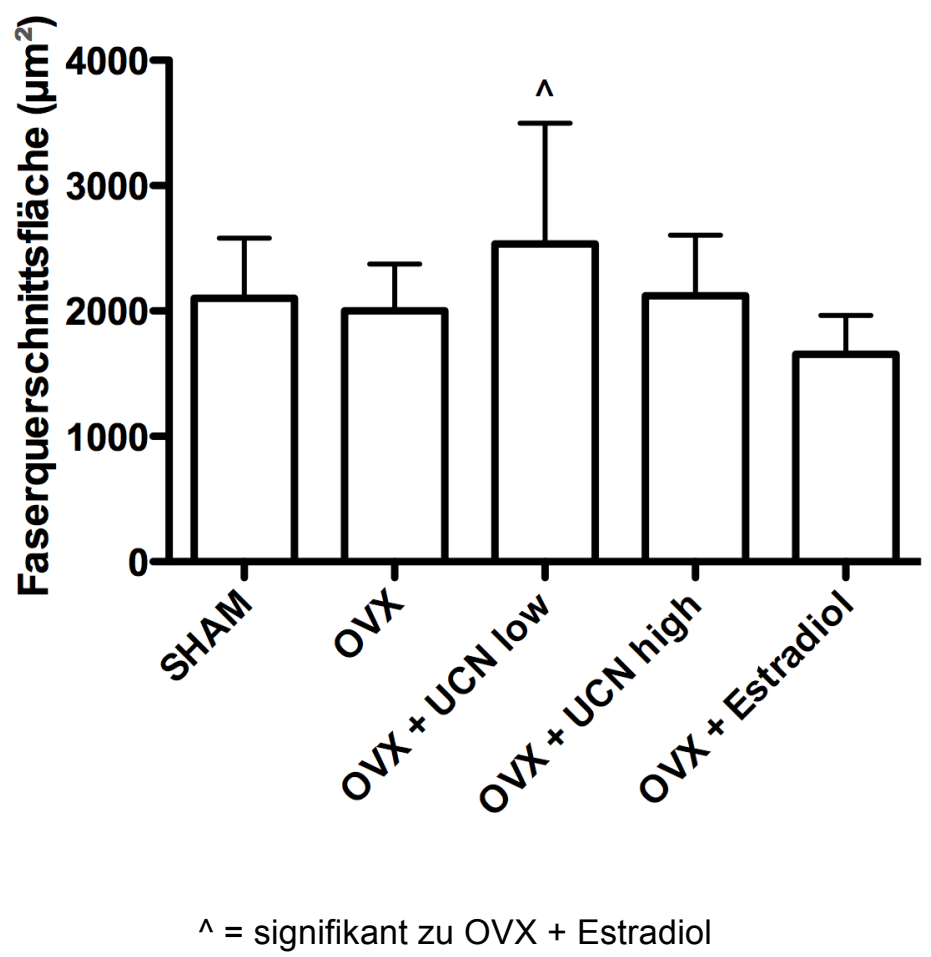

Abb. 19: Faserquerschnittsfläche der SO- und FOG-Fasern, M. Iongissimus 


\subsection{FG-Fasertyp}

Zwischen den Gruppen konnte ein signifikanter Unterschied festgestellt werden (Abb. 20, Tab. A-15). Hinsichtlich der Gruppen OVX + UCN high und OVX + UCN low fällt auf, dass der höchste Wert in der Gruppe OVX + UCN low und der niedrigste Wert in der Gruppe OVX + UCN high besteht. Die übrigen Gruppen unterscheiden sich nicht wesentlich voneinander.

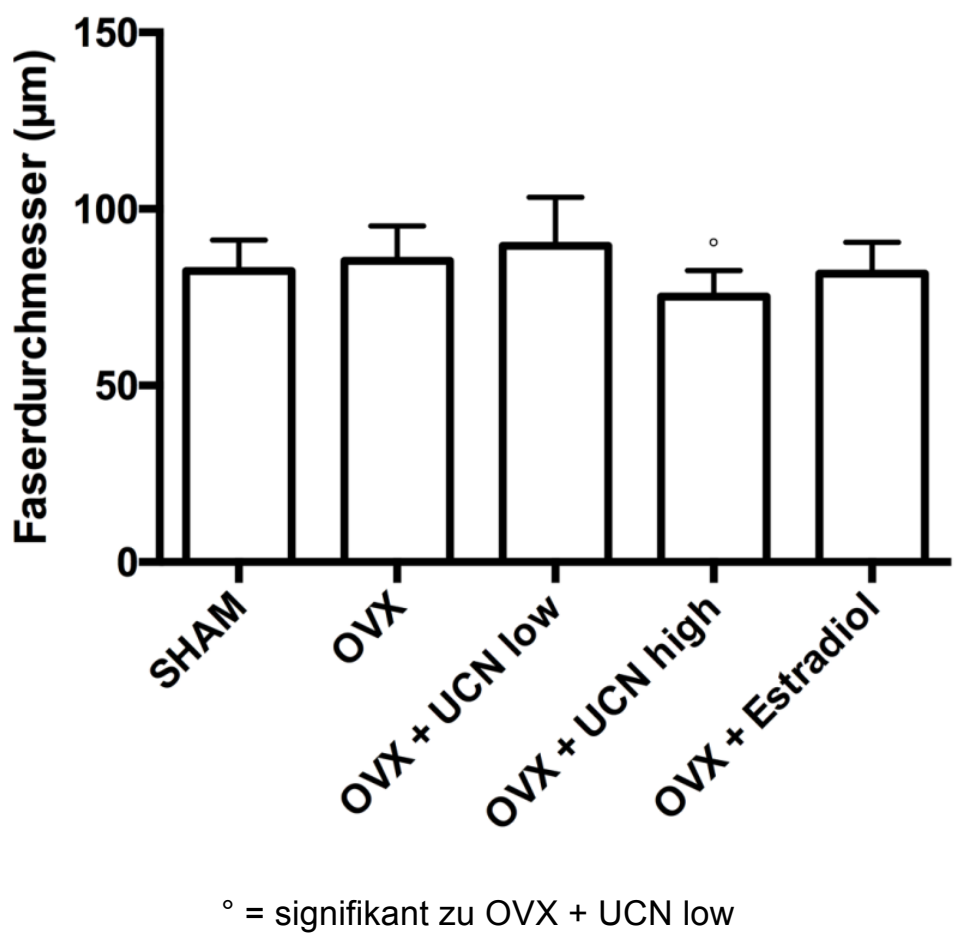

Abb. 20: Faserdurchmesser der FG-Fasern, M. Iongissimus 
Zwischen den Gruppen konnten keine signifikanten Unterschiede festgestellt werden (Abb. 21, Tab. A-16). Zu beachten ist allerdings wieder der hohe Mittelwert in der Gruppe OVX + UCN low und der vergleichsweise niedrige Wert in der Gruppe OVX + UCN high. Betrachtet man die restlichen Gruppen, lassen sich weniger große Unterschiede erkennen.

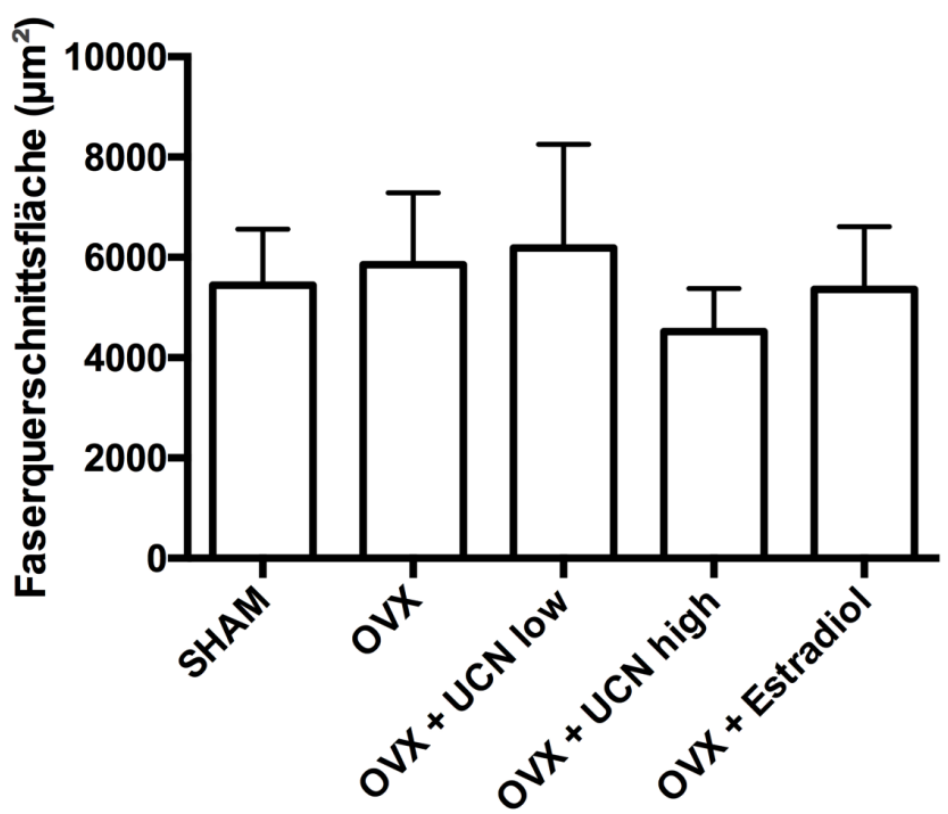

Abb. 21: Faserquerschnittsfläche der FG-Fasern, M. longissimus 


\section{Diskussion}

Ziel der Untersuchungen war es, die Auswirkungen von Urocortin, einem Neuropeptid, auf die Skelettmuskulatur der osteoporotischen Ratte zu ermitteln.

Urocortin ist ein Peptidhormon, das sowohl in peripheren Geweben als auch im zentralen Nervensystem vieler Säugetiere vorkommt und sehr weitreichende Funktionen mitbringt. Beschrieben sind Wirkungen auf psychische und neurobiologische Prozesse, auf den Knochen- und Fettstoffwechsel, auf das kardiovaskuläre und hormonelle System, das Renalsystem, das Immunsystem, auf dermatologische Vorgänge, auf die Entwicklung maligner Geschehen und auf die Reproduktion (Combs et al. 2012; Lu et al. 2015; Skelton et al. 2000; Takahashi 2012; Walczewska et al. 2014). Das Peptidhormon scheint an vielen verschiedenen Prozessen im Körper beteiligt zu sein.

Gegenstand des Versuches waren fünf Gruppen mit Ratten, die bis auf die Gruppe SHAM alle ovariektomiert wurden. Dadurch entstand ein Estrogenmangel, und die Versuchstiere entwickelten Osteoporose. Danach wurde jedem Tier aus jeder Gruppe über fünf Wochen täglich 0,3 $\mathrm{ml} \mathrm{NaCl-Lösung} \mathrm{in} \mathrm{das} \mathrm{Subku-}$ tangewebe injiziert. So konnte man den Effekt, der durch das alleinige Spritzen ausgelöst wird, vermeiden. Der Flüssigkeit für die Tiere der Gruppen OVX + UCN low und OVX + UCN high wurde zusätzlich eine niedrige (3 $\mu \mathrm{g} \mathrm{kg/KG)} \mathrm{und}$ eine hohe (30 $\mu \mathrm{g} \mathrm{kg/KG)} \mathrm{Konzentration} \mathrm{von} \mathrm{Urocortin} \mathrm{hinzugefügt.} \mathrm{Die} \mathrm{Dosie-}$ rung lehnt sich an frühere Studien mit Urocortin an Muskeln gesunder Mäuse (Hinkle et al. 2003) an. Anschließend entnahm man, randomisiert rechts oder links, Proben des M. soleus, des M. gastrocnemius und des M. longissimus von allen Tieren, die mittels histologischen Untersuchungen bearbeitet und ausgewertet wurden. Das Verhältnis von Kapillaren zu Muskelfasern, der Muskelfaserdurchmesser und der Muskelfaserquerschnitt wurden ermittelt. Bisher sind keine Forschungen zu der Fragestellung, welche Auswirkungen Urocortin auf die Skelettmuskulatur von ovariektomierten Ratten hat, durchgeführt oder veröffentlicht worden. Das Peptid hat positive Effekte auf den Knochen und die osteogene Differenzierung humaner Osteoprogenitorzellen. Außerdem wurde eine durch Urocortin induzierte Hemmung von Osteoklasten beobachtet 
(Sehmisch et al. 2015; Tezval et al. 2009; Tezval et al. 2014). Zusätzlich wurde der Effekt von Estrogen auf die Skelettmuskulatur untersucht. Diese Gruppe diente als positive Kontrollgruppe. Die Muskulatur umgibt die Knochen und schützt sie. Kommt es zu einer Verbesserung der Muskelkraft und Muskelstärke, führt dies zu einer Reduktion der Inzidenz von Frakturen. Es gibt bislang keine Untersuchungen über die Wirkung von Urocortin am Menschen. Mit dieser Arbeit soll ein erster Ansatz für die Effekte am Rattentiermodell geliefert werden.

\subsection{Die ovariektomierte Ratte als Osteoporosemodell}

Der vorliegende Versuch wurde mit Ratten der Rasse Sprague Dawley als Versuchstiere realisiert. Da hier leicht eine Osteoporose induzierbar ist, sie weniger aufwendig in der Haltung und eher verfügbar sind als andere Tiere, wie zum Beispiel Schafe oder Schweine, ist dieses Tiermodell ein lang erprobtes Modell zur Untersuchung der Osteoporose und ihrer Begleiterscheinungen (Kalu 1991). Nach einer erfolgreichen Resektion der Ovarien an der Ratte lässt sich nach acht bis zehn Wochen ein Rückgang der knöchernen Substanz beobachten. Vor allem kommt es hier zu einem Abfall der Knochendichte in den Lendenwirbelkörpern (Omi und Ezawa 1995). Dieser nach der Ovariektomie induzierte Verlust von Knochenmasse ähnelt der Osteoporose der postmenopausalen Frau in vielen Punkten: Anstieg des Knochenumbaus, wobei die Resorption die Neubildung übertrifft; schnelle Phase des Knochenverlusts zu Beginn, gefolgt von einer langsamen Phase; größerer Verlust des spongiösen Knochens als des kortikalen Knochens; geringere Calciumresorption im Intestinaltrakt. Zudem fand man heraus, dass Mensch und Ratte ähnlich gut auf antiosteoporotische Medikamente ansprechen und man dadurch optimale Versuchsbedingungen schaffen kann (Kalu 1991). Ein Unterschied zum Menschen ist, dass die Ratten trotz erheblichem Verlust von Knochenmasse keine spontanen Fragilitätsfrakturen aufweisen (Miller und Wronski 1993). Letztendlich kann man sagen, dass die erworbenen Erkenntnisse hinweisend dafür sind, dass das Rattentiermodell für Studien zur Therapie der Osteoporose empfohlen wird 
(Thompson et al. 1995). Auch in der Muskelforschung verwendet man meist Ratten als Versuchstiere (Müller 1975; Stein und Padykula 1962).

\subsection{Analyse der Ergebnisse der Futteraufnahme, der Tiergewichte und des Uterusgewichtes}

Der durch den Hormonmangel bedingte Anstieg der Futteraufnahme, die stetige Zunahme des Körpergewichts und das höchst signifikant niedrigere Uterusgewicht der ovariektomierten Tiere sind typisch und lassen auf einen erfolgreichen Beginn des Versuches schließen. Diese Ergebnisse decken sich mit früheren Untersuchungen an ovariektomierten Ratten (Komrakova et al. 2009). Das Körpergewicht der Ratten der Gruppe OVX + UCN low und auch der Gruppe OVX + UCN high war zum Ende des Versuches hin signifikant höher verglichen mit dem Gewicht der Gruppen SHAM und OVX + Estradiol. Im Vergleich zu der ovariektomierten Gruppe sind allerdings keine signifikanten Unterschiede bezüglich des Gewichts der Tiere erkennbar, sodass hier kein Effekt von Urocortin auf das Körpergewicht zu verzeichnen ist (Sehmisch et al. 2015). Manche Studien in der Literatur beschreiben durch die Behandlung mit Urocortin einen Rückgang der Futteraufnahme und ein niedrigeres Körpergewicht bei Mäusen, unabhängig davon, ob der Stoff zentral oder peripher verabreicht wurde (Stengel und Taché 2014). Dies ist durch die Aktivierung des CRF-Rezeptor-2 zu erklären (Wang et al. 2011). In den vorliegenden Untersuchungen beobachtete man jedoch einen Anstieg der Futteraufnahme auch bei den mit Urocortin behandelten Tieren. Offenbar greift Urocortin über die Modulation des Proteohormons Leptin in die Regulationsmechanismen des Energiehaushaltes ein (Thomas 2004). In dem hier vorgestellten Versuch sind die Leptinkonzentrationen im Serum nach der Behandlung mit Urocortin im Vergleich zu den nicht mit Urocortin gespritzten Tieren leicht erhöht, wenn auch nicht signifikant (Sehmisch et al. 2015). Dies steht im Widerspruch zu der bekannten appetitzügelnden Wirkung des Leptins (Kwon et al. 2016). Es gibt allerdings keine vergleichbaren Studien, in denen der Effekt von Urocortin bei ovariektomierten Ratten beschrieben ist. Jegliche Experimente in der Literatur wurden ausschließlich an gesunden Tieren vorgenommen. Des Weiteren sind möglicher- 
weise noch höhere Dosierungen des Peptids Urocortin nötig, um die Unterdrückung der Futteraufnahme beobachten zu können. Andere mögliche ausschlaggebende Faktoren wie zum Beispiel die Stoffwechselaktivität der Tiere wurden nicht berücksichtigt.

Die mit Estradiol gefütterten Tiere weisen das niedrigste Körpergewicht auf und passend dazu ist auch die Futteraufnahme dieser Tiere am geringsten. Dieses Resultat ist übereinstimmend mit früheren Studien (Komrakova et al. 2009; Piccone et al. 2005).

Das Uterusgewicht der Tiere der Gruppen SHAM und OVX + Estradiol ist signifikant höher verglichen mit den Gruppen OVX, OVX + UCN low und OVX + UCN high. Diese Beobachtung war zu erwarten und entspricht vergangenen Untersuchungen an ovariektomierten Ratten (Komrakova et al. 2009). Das Uterusgewicht der Ratten, die mit Estradiol gefüttert wurden, unterscheidet sich signifikant von allen anderen Gruppen. Die Behandlung mit Urocortin zeigt keine Auswirkungen auf das Uterusgewicht der Ratten (Sehmisch et al. 2015).

\subsection{Analyse der histologischen Untersuchungen}

Zunächst wurde mittels einer Amylase-PAS-Färbung die Kapillardichte untersucht. Hier gab es signifikante Unterschiede zwischen den Versuchsgruppen. Im M. soleus der Tiere der Gruppe OVX + UCN high war die Kapillardichte im Vergleich zu den anderen Gruppen am höchsten. Für die anderen beiden Muskelproben lassen sich weder Signifikanzen, noch bedeutende Tendenzen herausarbeiten.

Auch bei der darauf folgenden ATPase-Diaphorase-Färbung ergaben sich signifikante Abstufungen bezüglich Faserdurchmesser und Faserquerschnittsfläche der Muskeln. Der Faserdurchmesser der SO- und FOG-Fasern des M. soleus der Tiere in der Gruppe OVX + UCN high ist größer als der Mittelwert der restlichen Gruppen. Ein ähnliches Ergebnis wurde bezüglich der Faserquerschnittsfläche erreicht. Hier hebt sich der Mittelwert der Gruppe OVX + UCN high deutlich von den anderen Gruppen ab. Faserdurchmesser und Faserquerschnittsfläche des M. gastrocnemius weisen keine Unterschiede oder Besonderheiten 
auf. Betrachtet man die Ergebnisse des M. Iongissimus fällt auf, dass hier die höchsten Werte des Faserdurchmessers und der Faserquerschnittsfläche sowohl beim SO- und FOG-Fasertyp als auch beim FG-Fasertyp in der Gruppe OVX + UCN low erreicht werden. Hier sind Signifikanzen messbar.

In der Zusammenschau der vorliegenden Ergebnisse kann man sagen, dass ein positiver Effekt bezüglich der Urocortinbehandlung erkennbar ist. In einem der drei Muskeln ist eine signifikant höhere Kapillardichte messbar und auch im Hinblick auf Faserdurchmesser und Faserquerschnittsfläche kann man bei zwei der drei Muskeln signifikant höhere Werte feststellen.

Auch bezüglich der Wirkung von Urocortin auf den Knochen sind positive Effekte festgestellt worden (Sehmisch et al. 2015; Tezval et al. 2014). Speziell der Oberschenkelknochen und die Wirbelsäule wurden diesbezüglich untersucht. Es sind einige antiosteoporotisch wirksame Medikamente in Deutschland zugelassen, doch treten immer wieder Nebenwirkungen und limitierende Faktoren auf, daher ist es notwendig, neue Mittel zur Bekämpfung von chronischen Skeletterkrankungen, wie der Osteoporose und der Sarkopenie, zu entwickeln. Vor einigen Jahren entdeckte man bereits die Fähigkeit von Urocortin, die Bewegung der Osteoklasten zu behindern, indem es einen bestimmten Kationenkanal blockiert (Combs et al. 2012) und die Differenzierung von Osteoblasten im Hinblick auf die Therapie der Arthritis bei Mäusen positiv zu beeinflussen (Tezval et al. 2009; Zhu et al. 2011). In Einklang mit diesen Studien konnte kurz danach gezeigt werden, dass Urocortin die Mikroarchitektur und Stärke des Femurs, insbesondere des distalen Femurs, positiv beeinflusst (Tezval et al. 2014). Hier war es vor allem die höhere Dosierung des Urocortins, die diese Ergebnisse erzielte. Diese Erkenntnis deckt sich größtenteils mit den hier dargestellten Ergebnissen, da auch in dieser Studie die besten Effekte durch die hohe Dosierung mit Urocortin erreicht wurden. Die Kapillardichte im M. soleus sowie Faserdurchmesser und Faserquerschnittsfläche im M. soleus und M. Iongissimus der mit der hohen Dosis von Urocortin behandelten Tiere waren signifikant größer als in den restlichen Versuchsgruppen. Aufgrund unterschiedlicher Muskelstruktur und Funktion sind keine signifikanten Ergebnisse bezüglich der Kapillardichte im M. gastrocnemius und M. longissimus messbar. Deutlich osteoprotektive Auswirkungen auf die lumbale Wirbelsäule von Ratten erzielte 
man ebenfalls nach Therapie mit Urocortin in höherer Dosierung. Knochenmorphologie und Biomechanik konnten durch die subkutane Gabe von Urocortin verbessert werden (Sehmisch et al. 2015). Vergleicht man diese Resultate mit unseren Erhebungen, so sieht man auch hier, dass die Urocortinbehandlung in höherer Dosierung erfolgreicher ist.

Das Vorhandensein von Estrogenrezeptoren in der Skelettmuskulatur könnte darauf hindeuten, dass das Hormon hier eine relevante Rolle einnimmt (Piccone et al. 2005). Es konnte gezeigt werden, dass sich Estradiol positiv auf die Muskelkraft menopausaler Frauen und ovariektomierter Nager auswirkt (Lowe et al. 2010). Diese Ergebnisse konnten auf molekularer Ebene beobachtet werden. Estradiol soll die Bindung von Aktin an Myosin während der Kontraktion stärken und so eine qualitative Wirkung auf die Skelettmuskulatur aufweisen. In dem hier vorliegenden Versuch konnten keine signifikanten Ergebnisse bezüglich Kapillardichte oder Muskelfaser bei den mit Estradiol behandelten Tieren erhoben werden. Dies entspricht vorangegangenen Beobachtungen, in denen unter anderem der Effekt von Estradiol auf den M. gastrocnemius in der Phase der Knochenheilung untersucht wurde (Komrakova et al. 2009). Interessant ist in diesem Zusammenhang die Interaktion von Urocortin und Estradiol. Es ist denkbar, dass man durch das Zusammenspiel und die Wirkung beider Substanzen maßgebliche Effekte auf die Muskulatur erreichen kann. Hier sollten weitere Untersuchen unternommen werden.

Urocortin scheint nicht nur auf die Skelettmuskulatur Einfluss zu nehmen. Auch sind Effeke auf die Herzmuskulatur beschrieben. Neben einer positiv inotropen Wirkung soll es ebenso bei Herzinsuffizienz und Hypertrophie des Herzens eine Rolle spielen (Nishikimi et al. 2000).

Einige Studien befassen sich mit den Auswirkungen der Ganzkörpervibration auf die Knochen und Skelettmuskulatur osteoporotischer Ratten. Man geht davon aus, dass sich die vertikale Ganzkörpervibration mit den Frequenzen 35 und $50 \mathrm{~Hz}$ vorteilhaft sowohl auf die Knochenstruktur und die Knochenheilung als auch auf die Muskulatur auswirkt (Komrakova et al. 2013). Möglicherweise könnten durch die kombinierte Behandlung mit Urocortin und der Ganzkörpervibration noch bessere Effekte auf die Knochenstruktur und die Muskulatur erzielt 
werden. Diesem Ansatz sollte man in der Forschung um Prävention und Therapie bei Osteoporose zukünftig nachgehen.

\subsection{Schlussfolgerung}

Die im Rahmen dieser Forschungsarbeit gesetzte Fragestellung, ob das Neuropeptid Urocortin messbare Auswirkungen auf die Skelettmuskulatur der osteoporotischen Ratte hat, kann anhand der vorliegenden positiven Ergebnisse bestätigt werden. Diese Ergebnisse schreiben Urocortin eine wichtige Rolle im Bereich der Skeletterkrankungen zu. Welche Mechanismen hier zugrunde liegen, ist unklar und sollte in weiterführenden Studien geklärt werden.

Zusammenfassend lässt sich sagen, dass es trotz der überwiegend positiven Tendenz weiterer Untersuchungen bedarf, um diese Fragestellung eindeutig beantworten zu können. Es existiert keine Literatur über die Effekte von Urocortin auf die Skelettmuskulatur nach einer Ovariektomie, daher sind weitere Vergleiche mit anderen Studien nicht möglich. 


\section{Zusammenfassung}

Die Osteoporose ist eine chronisch progressive Skeletterkrankung und führt, durch Frakturen verursacht, zu erheblichen Komplikationen im Krankheitsverlauf. Ziel dieser Arbeit war es, die Auswirkungen von Urocortin auf die Skelettmuskulatur osteoporotischer Ratten zu untersuchen.

Urocortin ist ein aus etwa 40 Aminosäuren bestehendes Neuropeptid aus der Gruppe der corticotropin-releasing factor-Peptidfamilie. Es ist sowohl in peripheren Geweben als auch im zentralen Nervensystem nachweisbar und bindet an das CRF-Bindungsprotein und insbesondere an den CRF-Rezeptor-2. Dadurch besitzt es ein breites Wirkspektrum. Unter anderem konnten positive Auswirkungen auf den Knochen im Rahmen der Osteoproseforschung beobachtet werden.

Um den Effekt von Urocortin auf die Skelettmuskulatur von osteoporotischen Ratten zu untersuchen, wurden 48 Sprague Dawley-Ratten ovariektomiert und 12 Tiere scheinoperiert. Neun Wochen nach der Operation teilte man die Versuchstiere in fünf Gruppen [SHAM, OVX, OVX + UCN low (3 $\mu \mathrm{g} / \mathrm{kg} \mathrm{KG),} \mathrm{OVX} \mathrm{+}$ UCN high (30 $\mu \mathrm{g} / \mathrm{kg} \mathrm{KG),} \mathrm{OVX} \mathrm{+} \mathrm{Estradiol} \mathrm{(0,2} \mathrm{mg/kg} \mathrm{KG)]} \mathrm{ein.} \mathrm{Über} 35$ Tage applizierte man den Tieren der Gruppen UCN low und UCN high subkutan Urocortin, dem Futter der Ratten der Gruppe OVX + Estradiol wurde Estradiol zugesetzt und die Tiere der Gruppe SHAM erhielten subkutan NaCl-Lösung. Im darauf folgenden Schritt des Versuches wurden die Versuchstiere obduziert. Es wurden Muskelproben des M. soleus, des M. gastrocnemius und des M. longissimus entnommen und histologisch untersucht. Um die Kapillardichte zu bestimmen, nutzte man die Amylase-PAS-Färbung und um den Muskelfaserdurchmesser und den Muskelfaserquerschnitt zu erhalten, verwendete man die ATPase-/Diaphorase-Färbung.

Die Ergebnisse der vorliegenden Studie zeigen einen positiven Effekt von Urocortin auf die Skelettmuskulatur der osteoporotischen Ratte. Sowohl die Kapillardichte als auch Faserdurchmesser und Faserquerschnittsfläche des M. soleus sind signifikant erhöht. Im M. longissimus konnte ebenfalls eine signifikante Zunahme des Faserdurchmessers und der Faserquerschnittsfläche festgestellt 
werden. Für die Muskulatur der osteopenischen Ratte bedeutet dies, dass die Struktur nachweislich verbessert wurde.

Urocortin scheint ein vielversprechendes Peptid zu sein und könnte eine neue Behandlungsoption für die Muskulatur osteoporotischer Patienten darstellen. Die Verbesserung der Muskelstruktur könnte dazu führen, dass die Inzidenz pathologischer Frakturen bei Osteoporosepatienten sinkt, da die Knochen durch die Skelettmuskulatur geschützt werden. Außerdem ist eine gesunde und kräftige Muskulatur wichtig, um sich entsprechend sportlich betätigen zu können. Auch dies verhindert Frakturen, und gerade im Alter sind diese Faktoren von großer Bedeutung.

Die Zusammenschau der dargestellten Ergebnisse und Überlegungen rechtfertigt die Aussage, dass weitere Studien bezüglich der Wirkmechanismen von Urocortin unternommen werden sollten, um möglichst optimale therapeutische Ziele zu erreichen. 


\section{Literaturverzeichnis}

Ali S, Garcia JM (2014): Sarcopenia, Cachexia and Aging: Diagnosis, Mechanisms and Therapeutic Options. Gerontology 60(4), 294-305

Andersen P (1975): Capillary density in skeletal muscle of man. Acta Physiol Scand $\underline{\text { 95 }}(2)$, 203-205

Bartl R: Osteoporose: Prävention - Diagnostik - Therapie. 4. Auflage; Georg Thieme Verlag, Stuttgart 2010

Bauer JM, Wirth R, Volkert D, Werner H, Sieber, CC (2008): Malnutrition, Sarkopenie und Kachexie im Alter - Von der Pathophysiologie zur Therapie. Dtsch Med Wochenschr 133, 305-310

Behan DP, Khongsaly O, Ling N, De Souza EB (1996): Urocortin interaction with corticotropin-releasing factor (CRF) binding protein (CRF-BP): a novel mechanism for elevating "free' CRF levels in human brain. Brain Res $\underline{725}(2), 263-267$

Bianchi L, Ferrucci L, Cherubini A, Maggio M, Bandinelli S, Savino E, Volpato S (2016): The Predictive Value of the EWGSOP Definition of Sarcopenia: Results From the InCHIANTI Study. Gerontol A Biol Sci Med Sci 71(2), 259-264

Cederholm T, Cruz-Jentoft AJ, Maggi S (2013): Sarcopenia and fragility fractures. Eur J Phys Rehabil Med 49(1), 111-117

Cederholm T, Morley JE (2015): Sarcopenia: the new definitions. Curr Opin Clin Nutr Metab Care 18(1), 1-4

Cheng MF, Tsai WC, Hsia KT, Yang YS, Jin JS (2014). Expression of urocortin in pancreatic ductal adenocarcinoma and pancreatic intraepithelial neoplasia. APMIS 122(2), 147-154

Combs CE, Fuller K, Kumar H, Albert AP, Pirianov G, McCormick J, Lawrence KM (2012): Urocortin is a novel regulator of osteoclast differentiation and function through inhibition of a canonical transient receptor potential 1like cation channel. Endocrinology 212(2), 187-197

Cruz-Jentoft AJ, Baeyens JP, Bauer JM, Boirie Y, Cederholm T, Landi F, Martin FC, Michel J-P, Rolland Y et al. (2010): Sarcopenia: European consensus on definition and diagnosis Report of the European Working Group on Sarcopenia in Older People. Age Ageing 39(4), 412-423

Devetzis V, Zarogoulidis P, Kakolyris S, Vargemezis V, Chatzaki E (2013): The corticotropin releasing factor system in the kidney: perspectives for novel therapeutic intervention in nephrology. Med Res Rev $\underline{33}(4), 847-872$ 
Dirks A, Leeuwenburgh C (2002): Apoptosis in skeletal muscle with aging. Am J Physiol Regul Integr Comp Physiol 282(2), R519-527

Dirks A, Leeuwenburgh C (2005): Der Einfluss von Alter und Training auf die Apoptose im Skelettmuskel, Dtsch Z Sportmed 56(3), 62-67

Dodds R, Sayer A, Dodds R, Sayer A (2014): Sarcopenia. Arq Bras de Endocrinol Metab $\underline{58}(5), 464-469$

DVO-Leitlinie 2009 zur Prophylaxe, Diagnostik und Therapie der Osteoporose bei Erwachsenen. Langfassung. Osteoporose 18, 304-328

Fekete ÉM, Zorrilla EP (2007): Physiology, pharmacology, and therapeutic relevance of urocortins in mammals: Ancient CRF paralogs. Front Neuroendocrinol $\underline{28}(1), 1-27$

Figueiredo MJ, Fabricio ASC, Machado RR, Melo MCC, Soares DM, Souza GEP (2010): Increase of core temperature induced by corticotropinreleasing factor and urocortin: a comparative study. Reg Pept $\underline{165}(2-3)$, 191-199

Fini M, Salamanna F, Veronesi F, Torricelli P, Nicolini A, Benedicenti S, Giavaresi $G$ (2012): Role of obesity, alcohol and smoking on bone health. Front Biosci (Elite Ed) 4, 2686-2706

Florio P, Vale W, Petraglia F (2004): Urocortins in human reproduction. Peptides $\underline{25}(10), 1751-1757$

Hadji P, Klein S, Gothe, H (2013): Epidemiologie der Osteoporose-Bone Evaluation Study: Eine Analyse von Krankenkassen-Routinedaten. Dtsch Ärztebl Int 110, 52-57

Häussler B, Gothe H, Göl D, Glaeske G, Pientka L, Felsenberg D (2007): Epidemiology, treatment and costs of osteoporosis in Germany--the BoneEVA Study. Osteoporos Int 18(1), 77-84

Herold G: Innere Medizin 2012. Gerd Herold (Verlag), Köln 2011

Hinkle RT, Donnelly E, Cody DB, Bauer MB, Isfort RJ (2003): Urocortin II Treatment Reduces Skeletal Muscle Mass and Function Loss During Atrophy and Increases Nonatrophying Skeletal Muscle Mass and Function. Endocrinology 144(11), 4939-4946

Hohenstein K, Lechleitner M, Roth E, Sieber C, Thalhammer E (2011), Expert/innen-Statement Altersassoziierter Muskelverlust: Diagnose und Therapie bei Sarkopenie

Hoppeler H (1986): Exercise-induced ultrastructural changes in skeletal muscle. Int J Sports Med $\underline{7}(4), 187-204$ 
Horak V (1983): A successive histochemical staining for succinate dehydrogenase and "reversed"-ATPase in a single section for the skeletal muscle fibre typing. Histochemistry $\underline{78}(4), 545-553$

Huang Y, Chan FL, Lau CW, Tsang SY, He GW, Chen ZY, Yao X (2002): Urocortin-induced endothelium-dependent relaxation of rat coronary artery: role of nitric oxide and K+ channels. Br J Pharmacol 135(6), 1467-1476

Huang Y, Chan FL, Lau CW, Tsang SY, Chen ZY, He GW, Yao X (2003): Roles of cyclic AMP and Ca2+-activated $\mathrm{K}+$ channels in endotheliumindependent relaxation by urocortin in the rat coronary artery. Cardiovasc Res $\underline{57}(3), 824-833$.

Junqueira LCU, Carneiro J: Histologie. 6. Auflage; Springer Medizin Verlag, Heidelberg 2005

Kageyama K, Hanada K, Nigawara T, Moriyama T, Terui K, Sakihara S, Suda T (2006): Urocortin induces interleukin-6 gene expression via cyclooxygenase-2 activity in aortic smooth muscle cells. Endocrinology 147(9), 4454-4462

Kalu DN (1991): The ovariectomized rat model of postmenopausal bone loss. Bone Miner 15(3), 175-191

Komrakova M, Werner C, Wicke M, Nguyen BT, Sehmisch S, Tezval M, Stuermer EK (2009): Effect of daidzein, 4-methylbenzylidene camphor or estrogen on gastrocnemius muscle of osteoporotic rats undergoing tibia healing period. Endocrinology 201(2), 253-262

Komrakova M, Sehmisch S, Tezval M, Ammon J, Lieberwirth P, Sauerhoff C, Stuermer EK (2013): Identification of a Vibration Regime Favorable for Bone Healing and Muscle in Estrogen-Deficient Rats. Calcif Tissue Int 92(6), 509-520

Krause K: Neuropeptide und Lipide der Haut. Med. Diss. Berlin 2010

Kuperman Y, Chen A (2008): Urocortins: emerging metabolic and energy homeostasis perspectives. Trends Endocrinol Metab 19(4), 122-129

Kwon O, Kim KW, Kim MS (2016): Leptin signalling pathways in hypothalamic neurons. Cell Mol Life Sci $\underline{73}(7), 1457-1477$

Landi F, Liperoti R, Russo A, Giovannini S, Tosato M, Capoluongo E, Onder G (2012): Sarcopenia as a risk factor for falls in elderly individuals: results from the iISIRENTE study. Clin Nutr 31(5), 652-658

Latchman DS (2002): Urocortin. Int J Biochem Cell Biol 34(8), 907-910

Leitlinie Osteoporose s. DVO-Leitlinie 2009

Lexell J (1995): Human aging, muscle mass, and fiber type composition. Gerontol A Biol Sci Med Sci $\underline{50}, 11-16$ 
Li S, Sun Z, Wan R, Li C, Zhu C, Jin L, Guo R (2014): Urocortin affects migration of hepatic cancer cell lines via differential regulation of CPLA2 and iPLA2. Cell Signal 26(5), 1125-1134

Liew HK, Huang LC, Yang HI, Peng HF, Li KW, Tsai APY, Pang CY (2015): Therapeutic effects of human urocortin-1, -2 and -3 in intracerebral hemorrhage of rats. Neuropeptides $\underline{52}, 89-96$

Lowe DA, Baltgalvis KA, Greising SM (2010): Mechanisms behind Estrogens' Beneficial Effect on Muscle Strength in Females. Exerc Sport Sci Rev $\underline{38}(2), 61-67$

Lu B, Diz-Chaves Y, Markovic D, Contarino A, Penicaud L, Fanelli F, Tabarin A (2015): The corticotrophin-releasing factor/urocortin system regulates white fat browning in mice through paracrine mechanisms. Int $\mathrm{J}$ Obes $\underline{39}(3), 408-417$

Lubomirov L, Gagov H, Petkova-Kirova P, Duridanova D, Kalentchuk VU, Schubert R (2001): Urocortin relaxes rat tail arteries by a PKA-mediated reduction of the sensitivity of the contractile apparatus for calcium. $\mathrm{Br} \mathrm{J}$ Pharmacol 134(7), 1564-1570

Lüllmann-Rauch R: Taschenlehrbuch - Histologie. 3. Auflage; Georg Thieme Verlag, Stuttgart 2009

Meriggioli MN, Roubenoff R (2015): Prospect for pharmacological therapies to treat skeletal muscle dysfunction. Calcif Tissue Int 96(3), 234-242

Miller SC, Wronski TJ (1993): Long-term osteopenic changes in cancellous bone structure in ovariectomized rats. Anat $\operatorname{Rec} \underline{236}(3), 433-441$

Morales A, Heaton JP, Carson CC 3rd (2000): Andropause: A misnomer for a true clinical entity. J Urol $\underline{163(3), 705-712}$

Morley JE, Argiles JM, Evans WJ, Bhasin S, Cella D, Deutz NEP, Society for Sarcopenia, Cachexia, and Wasting Disease. (2010). Nutritional recommendations for the management of sarcopenia. J Am Med Dir Assoc 11(6), 391-396

Morley JE, Anker SD, von Haehling S (2014): Prevalence, incidence, and clinical impact of sarcopenia: facts, numbers, and epidemiology - update 2014. J Cachexia Sarcopenia Muscle $\underline{5}(4), 253-259$

Muir SW, Montero-Odasso M (2011): Effect of vitamin D supplementation on muscle strength, gait and balance in older adults: a systematic review and meta-analysis. J Am Geriatr Soc $\underline{59}$ (12), 2291-2300

Müller W (1975): A method for the comparison of morphometrical data on skeletal muscles in young rats of different ages and body weights. Histochemistry $\underline{43}(3), 241-248$ 
NIH Consensus Development Conference (2000): Osteoporosis prevention, diagnosis and therapy. NIH Consens Statement 17(1), 1-36

Nishikimi T, Miyata A, Horio T, Yoshihara F, Nagaya N, Takishita S, Kangawa K (2000): Urocortin, a member of the corticotropin-releasing factor family, in normal and diseased heart. Am J Physiol Heart Circ Physiol 279(6), H3031-3039

Oki Y, Sasano H (2004): Localization and physiological roles of urocortin. Peptides $\underline{25}(10), 1745-1749$

Omi N, Ezawa I (1995): The effect of ovariectomy on bone metabolism in rats. Bone 17(4), 163S-168S

Piccone CM, Brazeau GA, McCormick KM (2005): Effect of oestrogen on myofibre size and myosin expression in growing rats. Exp Physiol 90(1), 8793

Rademaker MT, Charles CJ, Espiner EA, Fisher S, Frampton CM, Kirkpatrick CMJ, Vale WW (2002): Beneficial hemodynamic, endocrine, and renal effects of urocortin in experimental heart failure: comparison with normal sheep. J Am Coll Cardiol 40(8), 1495-1505

Riester A: Urocortin-abhängige Effekte auf die Struktur und Funktion der Nebenniere in vivo. Med. Diss. München 2013

Sehmisch S, Komrakova M, Kottwitz L, Dullin C, Schmelz U, Stuermer KM, Tezval M (2015): Effekte von Urocortin auf die Wirbelsäule. Osteologie $\underline{24}(2), 99-106$

Seres J, Bornstein SR, Seres P, Willenberg HS, Schulte KM, Scherbaum WA, Ehrhart-Bornstein M (2004): Corticotropin-releasing hormone system in human adipose tissue. J Clin Endocrinol Metabol 89(2), 965-970

Skelton KH, Owens MJ, Nemeroff CB (2000): The neurobiology of urocortin. Regul Pept 93(1-3), 85-92

Slominski A, Roloff B, Curry J, Dahiya M, Szczesniewski A, Wortsman J (2000): The skin produces urocortin. J Clin Endocrinol Metabol 85(2), 815-823

Smoliner C, Sieber CC, Wirth R (2014): Prevalence of sarcopenia in geriatric hospitalized patients. J Am Med Dir Assoc 15(4), 267-272

Sobotta Lehrbuch Histologie. Mit Student Consult-Zugang. Hrsg. v. Welsch U. 2. Auflage; Urban \& Fischer in Elsevier, München 2006

Spira D: Untersuchungen zum Zusammenhang zwischen Vitamin D-Mangel, Sarkopenie und Frailty-Syndrom am Beispiel einer Stichprobe in BASE-II (Berliner Altersstudie 2). Med. Diss. Berlin 2013

Stein JM, Padykula HA (1962) Histochemical classification of individual skeletal muscle fibers of the rat. Am J Anat 110(2), 103-123 
Stengel A, Taché Y (2014): CRF and urocortin peptides as modulators of energy balance and feeding behavior during stress. Front Neurosci $\underline{8}, 52$

Takahashi K (2012): Distribution of Urocortins and Corticotropin-Releasing Factor Receptors in the Cardiovascular System. Int J Endocrinol 2012

Tezval M, Tezval H, Dresing K, Stuermer EK, Blaschke M, Stuermer KM, Siggelkow H (2009): Differentiation dependent expression of urocortin's mRNA and peptide in human osteoprogenitor cells: influence of BMP-2, TGF-beta-1 and dexamethasone. J Mol Histol 40(5-6), 331-341

Tezval M, Stuermer EK, Sehmisch S, Rack T, Stary A, Stebener M, Stuermer KM (2010): Improvement of trochanteric bone quality in an osteoporosis model after short-term treatment with parathyroid hormone: a new mechanical test for trochanteric region of rat femur. Osteoporos Int $\underline{21}(2)$, 251-261

Tezval M, Hansen S, Schmelz U, Komrakova M, Stuermer KM, Sehmisch S (2014): Effect of Urocortin on strength and microarchitecture of osteopenic rat femur. J Bone Miner Metabol 33(2), 154-160

Thomas T (2004): The complex effects of leptin on bone metabolism through multiple pathways. Curr Opin Pharmacol 4(3), 295-300

Thompson DD, Simmons HA, Pirie CM, Ke HZ (1995): FDA Guidelines and animal models for osteoporosis. Bone 17(4), 125S-133S

Vaughan J, Donaldson C, Bittencourt J, Perrin MH, Lewis K, Sutton S, Rivier C (1995): Urocortin, a mammalian neuropeptide related to fish urotensin I and to corticotropin-releasing factor. Nature $\underline{378}(6554), 287-292$

von Haehling S, Steinbeck L, Doehner W, Springer J, Anker SD (2013): Muscle wasting in heart failure: An overview. Int J Biochem Cell Biol $\underline{45}(10)$, 2257-2265

Walczewska J, Dzieza-Grudnik A, Siga O, Grodzicki T (2014): The role of urocortins in the cardiovascular system. J Physiol Pharmacol 65(6), 753766

Walston JD (2012): Sarcopenia in older adults. Curr Opin Rheumatol 24(6), 623-627

Wang L, Stengel A, Goebel M, Martinez V, Gourcerol G, Rivier J, Taché Y (2011): Peripheral activation of corticotropin-releasing factor receptor 2 inhibits food intake and alters meal structures in mice. Peptides 32(1), 51-59

Zhu H, Wang J, Li J, Li S (2011): Corticotropin-releasing factor family and its receptors: pro-inflammatory or anti-inflammatory targets in the periphery? Inflamm Res $\underline{60}(8), 715-721$ 


\section{Anhang}

\section{Abbildungsverzeichnis}

$\underline{\text { Seite }}$

Abb. 1: Oberschenkelmuskulatur einer 26-jährigen Frau ............................. 3

Abb. 2: Oberschenkelmuskulatur einer 79-jährigen Frau …......................... 3

Abb. 3: Aminosäurenabfolge des humanen Urocortin ............................ 10

Abb. 4: CRF-Familie und ihre Rezeptoren ......................................... 11

Abb. 5: Präparatausschnitt der Amylase-PAS-Färbung mit zwei aufgelegten Messrahmen zur Auswertung des Verhältnisses der Kapillaren zu den Muskelfasern

Abb. 6: Präparatausschnitt der ATPase-Diaphorase-Färbung zur Auswertung der Querschnittsflächen und der Durchmesser von FG, FOG- und SO-Fasern

Abb. 7: Futteraufnahme der Tiere über den gesamten Versuchszeitraum in Gramm.

Abb. 8: Entwicklung des Körpergewichts der Tiere im Verlauf 34

Abb. 9: Verhältnis der Kapillaren zu den Muskelfasern, M. soleus 35

Abb. 10: Verhältnis Kapillaren zu Muskelfasern, M. gastrocnemius . 36

Abb. 11: Verhältnis Kapillaren zu Muskelfasern, M. longissimus 37

Abb. 12: Faserdurchmesser der SO- und FOG-Fasern, M. soleus 38

Abb. 13: Faserquerschnittsfläche der SO- und FOG-Fasern, M. soleus 39

Abb. 14: Faserdurchmesser der SO- und FOG-Fasern, M. gastrocnemius .40

Abb. 15: Faserquerschnittsfläche der SO- und FOG-Fasern, M. gastrocnemius

Abb. 16: Faserdurchmesser der FG-Fasern, M. gastrocnemius .42

Abb. 17: Faserquerschnittsfläche der FG-Fasern, M. gastrocnemius 43

Abb. 18: Faserdurchmesser der SO- und FOG-Fasern, M. longissimus 44

Abb. 19: Faserquerschnittsfläche der SO- und FOG-Fasern, M. longissimus . 45 
Abb. 20: Faserdurchmesser der FG-Fasern, M. longissimus ..................... 46

Abb. 21: Faserquerschnittsfläche der FG-Fasern, M. longissimus . 


\section{Tabellenverzeichnis}

$\underline{\text { Seite }}$

Tab. 1: Zuordnung der Versuchsgruppen......................................... 20

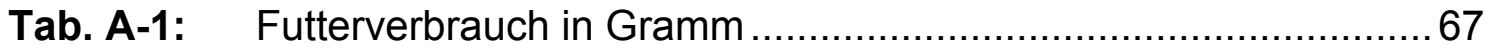

Tab. A-2: $\quad$ Entwicklung des Körpergewichts der Tiere in Gramm über den Versuchszeitraum.............................................................. 68

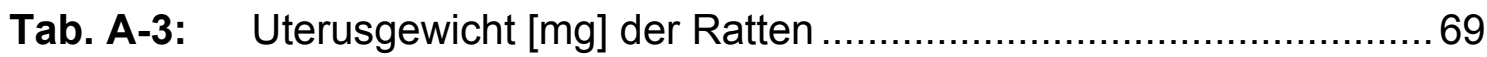

Tab. A-4: $\quad$ Auswertung der Amylase-PAS-Färbung, M. soleus ....................69 69

Tab. A-5: $\quad$ Auswertung der Amylase-PAS-Färbung, M. gastrocnemius ........69 69

Tab. A-6: $\quad$ Auswertung der Amylase-PAS-Färbung, M. longissimus ..............69

Tab. A-7: Auswertung des Faserdurchmessers der SO- und FOG-Fasern, M. soleus ..................................................................... 70

Tab. A-8: $\quad$ Auswertung der Faserquerschnittsfläche der SO- und FOGFasern des M. soleus .................................................... 70

Tab. A-9: Auswertung des Faserdurchmessers der SO- und FOG-Fasern, M. gastrocnemius ..................................................... 70

Tab. A-10: Auswertung der Faserquerschnittsfläche der SO- und FOGFasern, M. gastrocnemius ........................................... 70

Tab. A-11: Auswertung des Faserdurchmessers der FG-Fasern, M. gastrocnemius.

Tab. A-12: Auswertung der Faserquerschnittsfläche der FG-Fasern, M. gastrocnemius.

Tab. A-13: Auswertung des Faserdurchmessers der SO- und FOG-Fasern, M. longissimus.

Tab. A-14: Auswertung der Faserquerschnittsfläche der SO- und FOGFasern, M. longissimus

Tab. A-15: Auswertung des Faserdurchmessers der FG-Fasern, M. longissimus. 
Tab. A-16: Auswertung der Faserquerschnittsfläche der FG-Fasern, M.

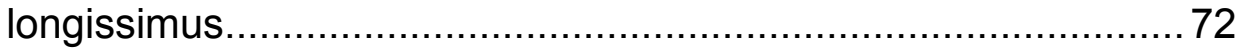




\section{Ergebnistabellen}

Tab. A-1: Futterverbrauch in Gramm, angegeben durch den Mittelwert für die einzelnen Versuchsgruppen \pm Standardabweichung

\begin{tabular}{|l|l|l|l|l|l|}
\hline Woche & SHAM & OVX & $\begin{array}{l}\text { OVX } \\
\text { + UCN low }\end{array}$ & $\begin{array}{l}\text { OVX } \\
\text { + UCN high }\end{array}$ & $\begin{array}{l}\text { OVX } \\
\text { + Estradiol }\end{array}$ \\
\hline 3 & $19,83(\&)$ & 25,09 & 24,58 & 24,05 & 24,25 \\
& $\pm 1,01$ & $\pm 0,81$ & $\pm 0,29$ & $\pm 0,97$ & $\pm 0,89$ \\
\hline 4 & $21,47(\&)$ & 26,81 & 26,07 & 27,61 & 28,67 \\
& $\pm 1,11$ & $\pm 1,96$ & $\pm 0,48$ & $\pm 0,98$ & $\pm 1,84$ \\
\hline 5 & $23,62(\&)$ & 28,22 & 27,38 & 27,93 & 28,76 \\
& $\pm 1,58$ & $\pm 0,99$ & $\pm 0,45$ & $\pm 2,45$ & $\pm 1,07$ \\
\hline 6 & $21,42(\&)$ & 24,64 & 23,67 & 24,98 & 24,44 \\
& $\pm 1,24$ & $\pm 1,57$ & $\pm 1,32$ & $\pm 0,80$ & $\pm 1,22$ \\
\hline 7 & $20,17(\&)$ & 24,09 & 22,76 & 24,73 & 23,36 \\
& $\pm 0,66$ & $\pm 0,67$ & $\pm 1,25$ & $\pm 0,88$ & $\pm 0,89$ \\
\hline 8 & 20,25 & 22,99 & 21,98 & 23,35 & 22,14 \\
& $\pm 1,34$ & $\pm 1,79$ & $\pm 1,21$ & $\pm 0,86$ & $\pm 0,41$ \\
\hline 9 & 20,00 & 21,08 & 20,66 & 21,87 & 21,17 \\
& $\pm 0,53$ & $\pm 0,60$ & $\pm 0,95$ & $\pm 0,82$ & $\pm 1,27$ \\
\hline 10 & 19,04 & 19,16 & 19,86 & 19,06 & $13,75(\&)$ \\
& $\pm 0,89$ & $\pm 1,13$ & $\pm 0,62$ & $\pm 2,54$ & $\pm 0,92$ \\
\hline 11 & 18,32 & 18,07 & 19,04 & 21,10 & $14,44(\&)$ \\
& $\pm 0,98$ & $\pm 0,95$ & $\pm 0,91$ & $\pm 1,37$ & $\pm 2,33$ \\
\hline 12 & 18,55 & 18,60 & 18,98 & $23,05(\&)$ & $15,18(\&)$ \\
& $\pm 0,36$ & $\pm 0,88$ & $\pm 0,55$ & $\pm 1,79$ & $\pm 0,60$ \\
\hline 13 & 19,06 & 19,20 & 19,11 & $24,29(\&)$ & $16,08(\&)$ \\
& $\pm 1,25$ & $\pm 0,47$ & $\pm 0,93$ & $\pm 2,29$ & $\pm 1,34$ \\
\hline 14 & 21,11 & 20,89 & 20,91 & $25,87(\&)$ & 21,45 \\
& $\pm 1,49$ & $\pm 2,98$ & $\pm 2,10$ & $\pm 3,65$ & $\pm 1,41$ \\
\hline$\& 5$ & & & & \\
\hline
\end{tabular}

$\&$ = signifikant zu allen anderen Gruppen 
Tab. A-2: Entwicklung des Körpergewichts der Tiere in Gramm über den Versuchszeitraum, angegeben durch den Mittelwert für die einzelnen Versuchsgruppen \pm Standardabweichung

\begin{tabular}{|c|c|c|c|c|c|}
\hline Woche & SHAM & OVX & $\begin{array}{l}\text { OVX } \\
+ \text { UCN low }\end{array}$ & $\begin{array}{l}\text { OVX } \\
+ \text { UCN high }\end{array}$ & $\begin{array}{l}\text { OVX } \\
+ \text { Estradiol }\end{array}$ \\
\hline 0 & $\begin{array}{l}261 \\
\pm 13\end{array}$ & $\begin{array}{l}270 \\
\pm 13\end{array}$ & $\begin{array}{l}265 \\
\pm 15\end{array}$ & $\begin{array}{l}268 \\
\pm 11\end{array}$ & $\begin{array}{l}264 \\
\pm 9\end{array}$ \\
\hline 1 & $\begin{array}{l}280 \\
\pm 15 \\
\end{array}$ & $\begin{array}{l}293 \\
\pm 15 \\
\end{array}$ & $\begin{array}{l}288 \\
\pm 12 \\
\end{array}$ & $\begin{array}{l}289 \\
\pm 12 \\
\end{array}$ & $\begin{array}{l}277 \\
\pm 5\end{array}$ \\
\hline 2 & $\begin{array}{l}285(\&) \\
\pm 15\end{array}$ & $\begin{array}{l}329 \\
\pm 17\end{array}$ & $\begin{array}{l}318 \\
\pm 13 \\
\end{array}$ & $\begin{array}{l}322 \\
\pm 20 \\
\end{array}$ & $\begin{array}{l}310 \\
\pm 9\end{array}$ \\
\hline 3 & $\begin{array}{l}298(\&) \\
\pm 16\end{array}$ & $\begin{array}{l}356 \\
\pm 17 \\
\end{array}$ & $\begin{array}{l}343 \\
\pm 13 \\
\end{array}$ & $\begin{array}{l}336 \\
\pm 27\end{array}$ & $\begin{array}{l}334 \\
\pm 14 \\
\end{array}$ \\
\hline 4 & $\begin{array}{l}296(\&) \\
\pm 18\end{array}$ & $\begin{array}{l}362 \\
\pm 20 \\
\end{array}$ & $\begin{array}{l}347 \\
\pm 13 \\
\end{array}$ & $\begin{array}{l}353 \\
\pm 28\end{array}$ & $\begin{array}{l}344 \\
\pm 14\end{array}$ \\
\hline 5 & $\begin{array}{l}307(\&) \\
\pm 22\end{array}$ & $\begin{array}{l}380 \\
\pm 19 \\
\end{array}$ & $\begin{array}{l}360 \\
\pm 13 \\
\end{array}$ & $\begin{array}{l}356 \\
\pm 36 \\
\end{array}$ & $\begin{array}{l}355 \\
\pm 17 \\
\end{array}$ \\
\hline 6 & $\begin{array}{l}314(\&) \\
\pm 21\end{array}$ & $\begin{array}{l}387 \\
\pm 24\end{array}$ & $\begin{array}{l}366 \\
\pm 15\end{array}$ & $\begin{array}{l}377 \\
\pm 33\end{array}$ & $\begin{array}{l}362 \\
\pm 19\end{array}$ \\
\hline 7 & $\begin{array}{l}317(\&) \\
\pm 22\end{array}$ & $\begin{array}{l}394 \\
\pm 21\end{array}$ & $\begin{array}{l}371 \\
\pm 15 \\
\end{array}$ & $\begin{array}{l}381 \\
\pm 35 \\
\end{array}$ & $\begin{array}{l}366 \\
\pm 20 \\
\end{array}$ \\
\hline 8 & $\begin{array}{l}321(\&) \\
\pm 23\end{array}$ & $\begin{array}{l}399 \\
\pm 23 \\
\end{array}$ & $\begin{array}{l}376 \\
\pm 16\end{array}$ & $\begin{array}{l}389 \\
\pm 38 \\
\end{array}$ & $\begin{array}{l}370 \\
\pm 23 \\
\end{array}$ \\
\hline 9 & $\begin{array}{l}324(\&) \\
\pm 22\end{array}$ & $\begin{array}{l}398 \\
\pm 21 \\
\end{array}$ & $\begin{array}{l}375 \\
\pm 17 \\
\end{array}$ & $\begin{array}{l}387 \\
\pm 37 \\
\end{array}$ & $\begin{array}{l}370 \\
\pm 24 \\
\end{array}$ \\
\hline 10 & $\begin{array}{l}326\left(\#^{\circ} \S\right) \\
\pm 20\end{array}$ & $\begin{array}{l}392 \\
\pm 20\end{array}$ & $\begin{array}{l}371 \\
\pm 15\end{array}$ & $\begin{array}{l}377 \\
\pm 42\end{array}$ & $\begin{array}{l}333\left(\#^{\circ} \S\right) \\
\pm 21\end{array}$ \\
\hline 11 & $\begin{array}{l}326\left(\#^{\circ} \S\right) \\
\pm 22\end{array}$ & $\begin{array}{l}393 \\
\pm 21\end{array}$ & $\begin{array}{l}373 \\
\pm 16\end{array}$ & $\begin{array}{l}377 \\
\pm 45\end{array}$ & $\begin{array}{l}330\left(\#^{\circ} \S\right) \\
\pm 17\end{array}$ \\
\hline 12 & $\begin{array}{l}327\left(\#^{\circ} \S\right) \\
\pm 22\end{array}$ & $\begin{array}{l}396 \\
\pm 20\end{array}$ & $\begin{array}{l}373 \\
\pm 16\end{array}$ & $\begin{array}{l}382 \\
\pm 45\end{array}$ & $\begin{array}{l}328\left(\#^{\circ} \S\right) \\
\pm 17\end{array}$ \\
\hline 13 & $\begin{array}{l}328\left(\#^{\circ} \S\right) \\
\pm 23\end{array}$ & $\begin{array}{l}396 \\
\pm 19\end{array}$ & $\begin{array}{l}375 \\
\pm 18\end{array}$ & $\begin{array}{l}389 \\
\pm 43\end{array}$ & $\begin{array}{l}328\left(\#^{\circ} \S\right) \\
\pm 16\end{array}$ \\
\hline 14 & $\begin{array}{l}325\left({ }^{\circ} \S\right) \\
\pm 24\end{array}$ & $\begin{array}{l}397\left(^{*}\right) \\
\pm 19\end{array}$ & $\begin{array}{l}375\left(^{*}\right) \\
\pm 17\end{array}$ & $\begin{array}{l}388\left(^{*}\right) \\
\pm 44\end{array}$ & $\begin{array}{l}324\left(\#^{\circ} \S\right) \\
\pm 16\end{array}$ \\
\hline
\end{tabular}

* = signifikant zu SHAM; \# = signifikant zu OVX; ${ }^{\circ}=$ signifikant zu OVX + UCN low; $\S$ = signifikant zu UCN high; \& = signifikant zu allen anderen Gruppen 
Tab. A-3: Uterusgewicht [mg] der Ratten

\begin{tabular}{|l|l|l|l|l|l|}
\hline & SHAM & OVX & $\begin{array}{l}\text { OVX } \\
+ \text { UCN low }\end{array}$ & $\begin{array}{l}\text { OVX } \\
+ \text { UCN high }\end{array}$ & $\begin{array}{l}\text { OVX } \\
+ \text { Estradiol }\end{array}$ \\
\hline $\begin{array}{l}\text { Uterusge- } \\
\text { wicht [mg] }\end{array}$ & $\begin{array}{l}627 \\
\pm 103\end{array}$ & $\begin{array}{l}105\left(^{*}\right) \\
\pm 21\end{array}$ & $\begin{array}{l}124\left(^{*}\right) \\
\pm 29\end{array}$ & $\begin{array}{l}101\left(^{*}\right) \\
\pm 19\end{array}$ & $\begin{array}{l}263(\&) \\
\pm 36\end{array}$ \\
\hline
\end{tabular}

* = signifikant zu SHAM; \& = signifikant zu allen anderen Gruppen

Tab. A-4: Auswertung der Amylase-PAS-Färbung, M. soleus

\begin{tabular}{|c|c|c|c|c|c|}
\hline $\begin{array}{l}\text { Verhältnis Kapillaren/ } \\
\text { Muskelfasern }\end{array}$ & SHAM & OVX & $\begin{array}{l}\text { OVX } \\
+ \text { UCN low }\end{array}$ & $\begin{array}{l}\text { OVX } \\
+ \text { UCN high }\end{array}$ & $\begin{array}{l}\text { OVX } \\
+ \text { Estradiol }\end{array}$ \\
\hline Mittelwert & 1,550 & 1,635 & 1,472 & $1,791\left(^{\circ}\right)$ & 1,667 \\
\hline \pm Standardabweichung & 0,140 & 0,167 & 0,313 & 0,316 & 0,225 \\
\hline
\end{tabular}

${ }^{\circ}=$ signifikant zu OVX + UCN low

Tab. A-5: Auswertung der Amylase-PAS-Färbung, M. gastrocnemius

\begin{tabular}{|l|l|l|l|l|l|}
\hline $\begin{array}{l}\text { Verhältnis Kapillaren/ } \\
\text { Muskelfasern }\end{array}$ & SHAM & OVX & $\begin{array}{l}\text { OVX } \\
\text { + UCN low }\end{array}$ & $\begin{array}{l}\text { OVX } \\
\text { + UCN high }\end{array}$ & $\begin{array}{l}\text { OVX } \\
\text { + Estradiol }\end{array}$ \\
Mittelwert & 1,156 & 1,147 & 1,451 & 1,361 & 1,539 \\
\hline Standardabweichung & 0,260 & 0,240 & 0,224 & 0,120 & 0,386 \\
\hline
\end{tabular}

Tab. A-6: Auswertung der Amylase-PAS-Färbung, M. longissimus

\begin{tabular}{|c|c|c|c|c|c|}
\hline $\begin{array}{l}\text { Verhältnis Kapillaren/ } \\
\text { Muskelfasern }\end{array}$ & SHAM & ovX & $\begin{array}{l}\text { OVX } \\
+ \text { UCN low }\end{array}$ & $\begin{array}{l}\text { OVX } \\
+ \text { UCN high }\end{array}$ & $\begin{array}{l}\text { OVX } \\
\text { + Estradiol }\end{array}$ \\
\hline Mittelwert & 1,568 & 1,659 & 1,368 & 1,626 & 1,517 \\
\hline \pm Standardabweichung & 0,207 & 0,168 & 0,211 & 0,182 & 0,290 \\
\hline
\end{tabular}


Tab. A-7: Auswertung des Faserdurchmessers der SO- und FOG-Fasern, M. soleus

\begin{tabular}{|l|l|l|l|l|l|}
\hline Faserdurchmesser $(\boldsymbol{\mu m})$ & SHAM & OVX & $\begin{array}{l}\text { OVX } \\
\text { + UCN low }\end{array}$ & $\begin{array}{l}\text { OVX } \\
\text { + UCN high }\end{array}$ & $\begin{array}{l}\text { OVX } \\
\text { + Estradiol }\end{array}$ \\
\hline Mittelwert & 67,0 & 59,9 & 71,1 & $81,6(\&)$ & 68,2 \\
\hline Standardabweichung & 11,5 & 17,1 & 3,6 & 5,1 & 5,4 \\
\hline
\end{tabular}

\& = signifikant zu allen anderen Gruppen

Tab. A-8: Auswertung der Faserquerschnittsfläche der SO- und FOG-Fasern des M. soleus

\begin{tabular}{|l|l|l|l|l|l|}
\hline $\begin{array}{l}\text { Faserquerschnittsfläche } \\
\left(\boldsymbol{\mu m}^{2}\right)\end{array}$ & SHAM & OVX & $\begin{array}{l}\text { OVX } \\
+ \text { UCN low }\end{array}$ & $\begin{array}{l}\text { OVX } \\
+ \text { UCN high }\end{array}$ & $\begin{array}{l}\text { OVX } \\
+ \text { Estradiol }\end{array}$ \\
Mittelwert & 3672 & 3063 & 4036 & $5321(\&)$ & 3719 \\
\pm Standardabweichung & 1008 & 1446 & 419 & 657 & 579 \\
\hline
\end{tabular}

Tab. A-9: Auswertung des Faserdurchmessers der SO- und FOG-Fasern, M. gastrocnemius

\begin{tabular}{|c|c|c|c|c|c|}
\hline Faserdurchmesser $(\mu \mathrm{m})$ & SHAM & OVX & $\begin{array}{l}\text { OVX } \\
+ \text { UCN low }\end{array}$ & $\begin{array}{l}\text { OVX } \\
+ \text { UCN high }\end{array}$ & $\begin{array}{l}\text { OVX } \\
+ \text { Estradiol }\end{array}$ \\
\hline Mittelwert & 58,0 & 55,5 & 53,3 & 59,0 & 54,6 \\
\hline \pm Standardabweichung & 7,8 & 4,7 & 6,3 & 4,9 & 4,9 \\
\hline
\end{tabular}

Tab. A-10: Auswertung der Faserquerschnittsfläche der SO- und FOG-Fasern, M. gastrocnemius

\begin{tabular}{|l|l|l|l|l|l|}
\hline $\begin{array}{l}\text { Faserquerschnittsfläche } \\
\left(\mu \mathrm{m}^{2}\right)\end{array}$ & SHAM & OVX & $\begin{array}{l}\text { OVX } \\
+ \text { UCN low }\end{array}$ & $\begin{array}{l}\text { OVX } \\
+ \text { UCN high }\end{array}$ & $\begin{array}{l}\text { OVX } \\
+ \text { Estradiol } \\
\text { Mittelwert }\end{array}$ \\
\hline Standardabweichung & 755 & 427 & 522 & 464 & 2400 \\
\hline
\end{tabular}


Tab. A-11: Auswertung des Faserdurchmessers der FG-Fasern, M. gastrocnemius

\begin{tabular}{|l|l|l|l|l|l|}
\hline Faserdurchmesser $(\boldsymbol{\mu m})$ & SHAM & OVX & $\begin{array}{l}\text { OVX } \\
\text { + UCN low }\end{array}$ & $\begin{array}{l}\text { OVX } \\
\text { + UCN high }\end{array}$ & $\begin{array}{l}\text { OVX } \\
\text { + Estradiol }\end{array}$ \\
\hline Mittelwert & 76,9 & 79,8 & 78,6 & 75,9 & 79,6 \\
\hline I Standardabweichung & 5,9 & 5,4 & 6,2 & 4,8 & 6,6 \\
\hline
\end{tabular}

Tab. A-12: Auswertung der Faserquerschnittsfläche der FG-Fasern, M. gastrocnemius

\begin{tabular}{|l|l|l|l|l|l|}
\hline $\begin{array}{l}\text { Faserquerschnittsfläche } \\
\left(\boldsymbol{\mu m}^{2}\right)\end{array}$ & SHAM & OVX & $\begin{array}{l}\text { OVX } \\
+ \text { UCN low }\end{array}$ & $\begin{array}{l}\text { OVX } \\
+ \text { UCN high }\end{array}$ & $\begin{array}{l}\text { OVX } \\
\text { + Estradiol }\end{array}$ \\
\hline Mittelwert & 4738 & 5060 & 4944 & 4585 & 5070 \\
\pm Standardabweichung & 714 & 677 & 733 & 573 & 832 \\
\hline
\end{tabular}

Tab. A-13: Auswertung des Faserdurchmessers der SO- und FOG-Fasern, M. longissimus

\begin{tabular}{l|l|l|l|l|l|}
\hline Faserdurchmesser $(\boldsymbol{\mu m})$ & SHAM & OVX & $\begin{array}{l}\text { OVX } \\
+ \text { UCN low }\end{array}$ & $\begin{array}{l}\text { OVX } \\
+ \text { UCN high }\end{array}$ & $\begin{array}{l}\text { OVX } \\
+ \text { Estradiol }\end{array}$ \\
Mittelwert & 51,1 & 49,9 & $55,3\left(^{\wedge}\right)$ & 51,3 & 45,3 \\
\pm Standardabweichung & 5,8 & 4,3 & 11,2 & 5,9 & 4,3 \\
\hline
\end{tabular}

Tab. A-14: Auswertung der Faserquerschnittsfläche der SO- und FOG-Fasern, M. longissimus

\begin{tabular}{|c|c|c|c|c|c|}
\hline $\begin{array}{l}\text { Faserquerschnittsfläche } \\
\left(\mu \mathrm{m}^{2}\right)\end{array}$ & SHAM & OVX & $\begin{array}{l}\text { OVX } \\
+ \text { UCN low }\end{array}$ & $\begin{array}{l}\text { OVX } \\
+ \text { UCN high }\end{array}$ & $\begin{array}{l}\text { OVX } \\
+ \text { Estradiol }\end{array}$ \\
\hline Mittelwert & 2102 & 2003 & $2535\left(^{\wedge}\right)$ & 2122 & 1655 \\
\hline \pm Standardabweichung & 479 & 372 & 963 & 482 & 312 \\
\hline
\end{tabular}


Tab. A-15: Auswertung des Faserdurchmessers der FG-Fasern, M. longissimus

\begin{tabular}{|c|c|c|c|c|c|}
\hline Faserdurchmesser $(\mu \mathrm{m})$ & SHAM & ovX & $\begin{array}{l}\text { OVX } \\
+ \text { UCN low }\end{array}$ & $\begin{array}{l}\text { OVX } \\
+ \text { UCN high }\end{array}$ & $\begin{array}{l}\text { OVX } \\
+ \text { Estradiol }\end{array}$ \\
\hline Mittelwert & 82,5 & 85,3 & 89,6 & $75,2\left({ }^{\circ}\right)$ & 81,7 \\
\hline \pm Standardabweichung & 8,7 & 9,8 & 13,8 & 7,4 & 8,8 \\
\hline
\end{tabular}

Tab. A-16: Auswertung der Faserquerschnittsfläche der FG-Fasern, M. longissimus

\begin{tabular}{|l|l|l|l|l|l|}
\hline $\begin{array}{l}\text { Faserquerschnittsfläche } \\
\left(\boldsymbol{\mu m}^{2}\right)\end{array}$ & SHAM & OVX & $\begin{array}{l}\text { OVX } \\
+ \text { UCN low }\end{array}$ & $\begin{array}{l}\text { OVX } \\
+ \text { UCN high }\end{array}$ & $\begin{array}{l}\text { OVX } \\
\text { + Estradiol }\end{array}$ \\
\hline Mittelwert & 5444 & 5857 & 6187 & 4521 & 5360 \\
\pm Standardabweichung & 1121 & 1430 & 2065 & 855 & 1253 \\
\hline
\end{tabular}




\section{Danksagung}

Ich danke Prof. Dr. med. W. Lehmann, dass er mir ermöglichte, meine Dissertation in seiner Abteilung für Unfallchirurgie, Plastische- und Wiederherstellungschirurgie an der Universitätsmedizin Göttingen durchzuführen.

Außerdem danke ich Prof. Dr. med. Stephan Sehmisch für die Aufnahme in seine Arbeitsgruppe und die kompetente Betreuung meiner Arbeit.

Des Weiteren gilt mein besonderer Dank Dr. rer. nat. Marina Komrakova, Ramona Castro-Machguth und Annette Witt. Die fachliche Unterstützung, die ständige Erreichbarkeit bei Fragen und Problemen und ihre aufrichtige Kritik haben mir bei der Erstellung dieser Dissertation sehr geholfen und mich immer wieder motiviert.

Für die Unterstützung bezüglich der Probenaufarbeitung für die histologischen Untersuchungen und die gute Zusammenarbeit danke ich Prof. Dr. Michael Wicke und Ruth Wigger. 


\section{Lebenslauf}

Mein Name ist Laura Katharina Geisberg, ich wurde am 22. August 1987 als zweites Kind von Ursula Geisberg, geb. Becker, und Wilhelm Alexander Geisberg in Leverkusen geboren.

Meine Schwester Verena Isabell Kohnert, geb. Geisberg, kam am 30. März 1976, ebenfalls in Leverkusen, zur Welt.

Bis zum Ende meiner Schulzeit wohnte ich in Leverkusen.

Von 1994 bis 1998 besuchte ich die Gemeinschaftsgrundschule Heinrich Lübke - Straße und wechselte anschließend auf das Freiherr - vom - Stein Gymnasium. Ich durchlief erfolgreich die Klassen fünf bis dreizehn, sodass ich im Jahr 2007 die allgemeine Hochschulreife erlangte.

Nach dem Abitur begann ich ein Freiwilliges Soziales Jahr im Klinikum Leverkusen und beendete dies, als ich im Herbst 2007 das Studium der Humanmedizin an der Georg - August - Universität Göttingen aufnahm.

Im Frühjahr 2015 erhielt ich meine Approbation als Ärztin.

Von Juli 2015 bis April 2016 habe ich als Bereitschaftsärztin in der Kinder- und Jugendpsychiatrie in der SOMNIA Privatklinik in Hürth gearbeitet. Im Mai 2016 nahm ich meine Facharztausbildung in der Abteilung für Anästhesie und operative Intensivmedizin im Klinikum Leverkusen auf. 